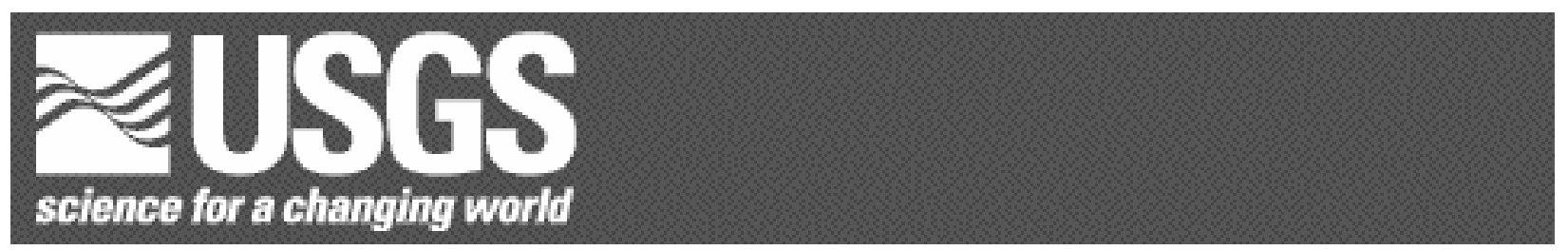

\title{
Abstracts of the Annual Meeting of Planetary Geologic Mappers, Flagstaff, AZ, 2004
}

Edited By Tracy K.P. Gregg, ${ }^{1}$ Kenneth L. Tanaka, ${ }^{2}$ and R. Stephen Saunders 3 Open-File Report 2004-1289

2004

Any use of trade, firm, or product names is for descriptive purposes only and does not imply endorsement by the U.S. Government.

\section{U.S. DEPARTMENT OF THE INTERIOR}

U.S. GEOLOGICAL SURVEY

${ }^{1}$ The State University of New York at Buffalo, Department of Geology, 710 Natural Sciences Complex, Buffalo, NY 14260-3050.

${ }^{2}$ U.S. Geological Survey, 2255 N. Gemini Drive, Flagstaff, AZ 86001.

${ }^{3}$ NASA Headquarters, Office of Space Science, 300 E. Street SW, Washington, DC 20546. 
Mappers Meeting

USGS Flagstaff, Arizona

June 17-19, 2004

The annual Planetary Geologic Mappers Meeting was held this year in Flagstaff, Arizona at the USGS. Mappers presented their work on June 17 and 18, 2004; on Saturday, June 19, Noel Gorelick of Arizona State University led a Mars Odyssey Thermal Emission Imaging System (THEMIS) data-use workshop. Approximately 40 attendees were at the meeting, and about 15 people (both NASA-funded mappers and interested USGS staff) attended the THEMIS workshop on Saturday. Several others, who were unable to attend, sent their maps to the USGS and these maps were posted for viewing and discussion.

Presentations made on June 17 demonstrated the richness and breadth the mapping program is achieving through mapping of the outer planets' satellites. P. Figueredo presented an interesting technique developed in GIS by T. Hare to create a stratigraphy for Europa using lineaments (which are ubiquitous) rather than impact craters (which are remarkably few). W. Patterson showed preliminary maps of portions of Ganymede. Mapping Ganymede poses challenges caused by gross variations in available image resolution across the planet. Even though tectonic terrains are easily identified, geologic units are much more difficult to discern. The Geologic Mapping Subcommittee (GEMS) panel noted that as these mapping efforts mature, guidelines may need to be issued for uniform generation of unit names, descriptions, and correlation charts for the outer-planet satellites. L. Keszthelyi presented the unique challenges involved with mapping volcanically active Io. Although this mapping is still in the early states, Keszthelyi indicated that generating a map of Io can really only be done using multiple GIS layers so that the user will be able to specify a time, as well as a place, for an Ionian geologic map. L. Gaddis presented the progress being made on a pilot lunar quadrangle map at 1:2,500,000 scale of the Copernicus region based on Lunar Orbiter, Clementine, and Lunar Prospector data sets. This project was funded as a test case, to determine the feasibility and functionality of a revised Lunar Mapping Program. To date, Gaddis and colleagues have identified a scheme for dividing the planet into mappable quads, based on the original lunar mapping program, and have determined that Clementine data will provide the best base maps.

The GEMS panel met on Thursday during lunch, and decided to raise the issue of incorporating THEMIS data into the Mars mapping program during the group discussion period that afternoon. Specifically, the question to be addressed was: how to deal with Mars maps that were made using Viking Orbiter (VO) images now that THEMIS data are available? The following hypothetical situations were discussed: 1) a VO-based map is completely through the review process, but not yet printed; 2) a VO-based map is not yet submitted; 3) a VO-based map has already been published. We reached consensus to deal with the maps in the following ways.

1) If a VO-based map is complete except for publication, it is the author's discretion to decide whether the map should be published as-is, or if the map publication should be delayed so that THEMIS data can be incorporated and the map re-reviewed as necessary. It will be at the discretion of the USGS Map Coordinator (currently Ken Tanaka) to determine the extent of the rereview. It may be, for example, that only a few contacts or interpretations 
need to be re-reviewed; alternatively, the whole map may be significantly changed, which would require beginning a new review process. In the case of a completely new review, the mapping community still believes it is valuable for the VO-based map to be available to the public. The USGS Open-File Report series would be a suitable venue for making such a map available without forcing it through the formal USGS map review process.

2) If a VO-based map is not yet submitted, every effort should be made by the mapper to incorporate THEMIS data. If additional time is then needed to complete the map (outside of what was originally requested from NASA PG\&G), the mapper needs to request funds by submitting a new mapping proposal to $\mathrm{PG} \& \mathrm{G}$.

3) If a VO-based map is already published, but THEMIS data reveal that the interpretations and conclusions based on the VO images may be sufficiently vague and/or erroneous that a new map may be justified, investigators could choose to submit a new mapping proposal to the PG\&G program at NASA.

Friday was filled with presentations about Mars mapping. Also, K. Tanaka showed how his team's photogeologic mapping of a Mars-like terrestrial site, part of the San Francisco Volcanic Field in northern Arizona, could help refine photogeologic mapping techniques including unit outcrop identification, unit lumping vs. splitting, and relative age dating of units and features. D. Ryan indicated how Adobe Illustrator could be used more effectively in mapping. K. Tanaka and J. Zigler (USGS Map Editor) discussed how USGS terrestrial geologic maps are now in digital, GIS format. S. Saunders emphasized once again the need for good scholarship in planetary geologic maps by fully addressing and debating scientific issues and advancing new hypotheses therein.

The value of the THEMIS data was readily apparent to our understanding of Martian geology and therefore to the Mars mapping program. It was therefore quite useful to have the THEMIS data workshop on Saturday. Noel Gorelick, of the THEMIS team at ASU, gave a demonstration on how to access and use THEMIS data, providing information on the software JMARS and ISIS. We thank Noel for taking time out of his busy schedule to educate us!

Finally, K. Williams at the Center for Earth and Planetary Studies at the National Air and Space Museum, Smithsonian Institution, offered to host next year's mappers meeting. Precise dates have yet to be determined, but we're looking forward to meeting in Washington, DC, in 2005. 


\section{CONTENTS}

\section{Venus}

Geologic Mapping of V-17 Beta Regio Quadrangle: A Progress Report

A.T. Basilevsky

Results From Ongoing Mapping of V-14, the Ganiki Planitia (Formerly Called Nemesis

Tesserae) Quadrangle, Venus

E.B. Grosfils and S.M. Long

Preliminary Geology of the Niobe Quadrangle (V-23), Venus

V.L. Hansen

Geological Mapping of Quadrangles V-3, V-7, and V-57, Venus: Preliminary Results M.A. Ivanov and J.W. Head

Geological Mapping of Four Quadrangles on Venus: Implications for "Directional" and

"Non-directional" Models of Geologic History

M.A. Ivanov and J.W. Head

Continued Geologic Mapping of the Greenaway Quadrangle (V-24), Venus

N.P. Lang and V.L. Hansen

Geologic Mapping of the Helen Planitia Quadrangle (V-52), Venus

I. López and V.L. Hansen

Geologic Mapping of the Bellona Fossae (V-5) Quadrangle, Venus J.R. Zimbelman

\section{Galilean Satellites}

Geological Mapping of Europa: Update and Lineament Sequencing P.H. Figueredo, T. Hare, K. Tanaka, R. Greeley, D. Senske

Geological Mapping of Ganymede: A Progress Report

G.W. Patterson, J.W. Head, G.C. Collins, R.T. Pappalardo, L.M. Prockter, B.K. Lucchitta and J. Savage

Geologic Mapping of Io: Update D.A. Williams and R. Greeley

\section{Moon}

The Lunar Geologic Mapping Program: 2004 Status

L. Gaddis, K. Tanaka, T. Hare, J. Skinner, B.R. Hawke, M. Staid, P. Spudis, B. Bussey, C. Pieters, and D. Lawrence 


\section{Mars}

Martian Impact Crater Resources for Planetary Mappers

N.G. Barlow and the Mars Crater Consortium

Geologic Mapping in the Hellas Region of Mars

D.A. Crown and S.C. Mest

MTM Quadrangles -15257 and -20257: Western Hesperia Planum, Mars

M.A. Farley and T.K.P. Gregg

1:500,000 Geomorphic Mapping of Southeastern Margaritifer Sinus, Mars II: Geologic Evolution in MTMs -20012 And -25012 C.M. Fortezzo and J.A. Grant

Geologic Map of the MTM 85200 Quadrangle, Planum Boreum Region of Mars K.E. Herkenhoff

New Mapping Efforts in the Enigmatic Arabia Terra, Mars

B.M. Hynek, B.M. Jakosky, and R.J. Phillips

Initial 1:1,500,000-Scale Geologic Mapping Results of Planum Australe, Mars E.J. Kolb and K.L. Tanaka

Geologic Mapping of the Medusae Fossae Formation on Mars K.M. Shockey, J.R. Zimbelman, S.J. Friedmann, and R.P. Irwin

Testing Planetary Photogeologic Mapping Methods Using Terrestrial Mars-Like Data Sets and Geologic Settings

K.L. Tanaka, J.A. Skinner, Jr., J.M. Dohm, L.S. Crumpler, and T.M. Hare

Aspects of Claritas Fossae Region, Mars, Identified During 1:1,000,000 Geologic

Mapping

J.R. Underwood

1:500,000 Geomorphic Mapping of Southeastern Margaritifer Sinus, Mars I: Geologic Evolution in MTMs -10022 and -15022

K.K. Williams and J.A. Grant 
GEOLOGIC MAPPING OF V17 BETA REGIO QUDRANGLE: A PROGRESS REPORT. A. T. Basilevsky, Vernadsky Institute of Geochemistry and Analytical Chemistry, Russian Academy of Sciences, Moscow, 119991, Russia atbas@geokhi.ru and Department of Geological Sciences, Brown University, Providence, RI 02912, USA.

Introduction: First results of the mapping of the V17 quadrangle $\left(25-50^{\circ} \mathrm{N}, 270-300^{\circ} \mathrm{E}\right)$ were published in [1]. This paper presents results of a new stage of the mapping. It is based on the photogeological analysis of C1-MIDRPs, F-MAPs, and the USGS-produced Magellan-based map of the quadrangle. The advantage of the latter is a combination of reasonably high resolution with the same degree of brightness/contrast stretch within the whole quadrangle. This study takes into consideration both the post-1996 results of our research group in the area of stratigraphy and the geological history of this planet [e.g., 2-13] as well as other approaches [e.g., 14-16].

Material and tectonic units: These are described in [1]. New work shows that previously mapped tessera terrain material can now be subdivided into: material of "true" tessera terrain $(t t)$ and so-called tessera transitional terrain $(t t t)$, the latter earlier identified by [8]. Also material of smooth plains (ps) is now mapped within V17. The material units (from older to younger) are as follows:

Tessera terrain material (tt) forms islands of different sizes embayed by practically all younger units. Its surface morphology is generally similar to that of tesserae in other areas of Venus and is characterized by two or more intersecting systems of ridges and grooves of obviously tectonic origin [e.g., 2, 17-19]. On the images, unit $t t$ appears radar bright with no or almost no areas free of tectonic structures (Figure 1).

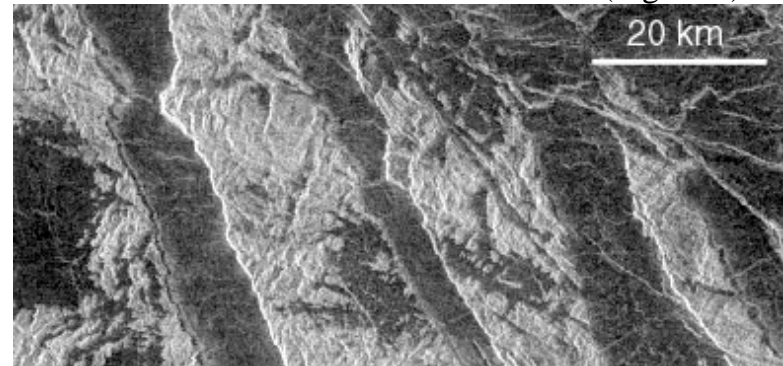

Figure 1. Tessera terrain (bright) north of crater Sanger embayed by the material of pwr plains (dark).

Material of densely fractured plains (pdf) is observed as islands mostly embayed by the $p w r / p s h$ regional plains. Its surface morphology is dominated by densely packed grooves.

Material of fractured and ridged plains (pfr) is observed either as elongated areas with clusters of broad gently-sloping ridges thus forming what is usually called ridge-belts [20] or as broad plains only locally deformed into a few ridges (Figure 2).

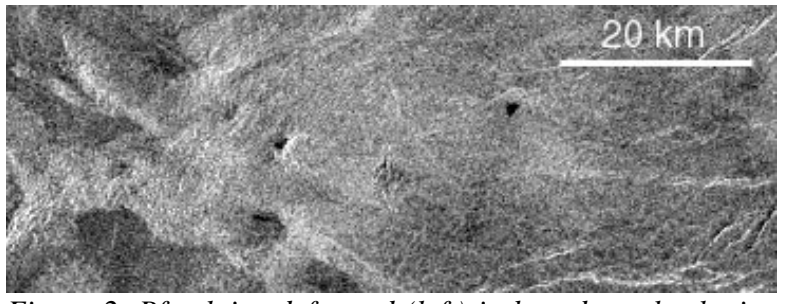

Figure 2. Pfr plains deformed (left) in broad gently-sloping ridges seen mostly due to embayment by the darker pwr plains.

Shield plains material (psh) forms areas consisting of abundant to coalescing small shield-shaped features. In most mapped areas the psh unit is deformed with wrinkle ridges which often are smaller than those observed on unit $p w r$ and form a dense network. Unit $p s h$ embays $t t, p d f$, pfr, and $t t t$ units and is embayed by the younger plains.

Material of plains with wrinkle ridges (pwr) forms generally smooth intermediate-dark to intermediatebright plains complicated with wrinkle ridges. Pwr is the unit most abundant in the V17 area. There is evidence that on a global scale the mean age of $p w r$ plains is close to the mean surface age of Venus T [e.g., 4, 7, $10]$ and that their emplacement comparing to time duration $\mathrm{T}$ was short $[6,11]$. The global-wide crater counts suggest that $\mathrm{T} 750$ m.y. [21].

Material of smooth plains (ps) forms small fields of radar-dark smooth-appearing terrain. It is not deformed by wrinkle ridges and typically is superposed on Pwr.

Material of lobate plains (pl) forms radar-bright flow-like features often coalescing into a radial or fanlike pattern, and not deformed by wrinkle ridges. The largest field of $p l$ within V17 is associated with the Theia Mons volcano sitting on the Devana rift about $100 \mathrm{~km}$ south of the southern boundary of the V17 quadrangle. There is evidence that on the global scale the rate of $p l$ emplacement was rather constant so their age in different areas may vary from the present time to $\sim \mathrm{T}[9]$.

Crater materials (c) include those composing rims, slopes, floors and ejecta including hummocky facies and outflows. Within V17 there are identified 25 impact craters from 1.3 to $83 \mathrm{~km}$ in diameter [22]. As shown by a number of researchers [e.g., 10, 12, 23] the degree of preservation of a crater-associated radar-dark halo is indicative of crater age: craters with dark parabolas (DP) have age $<0.1-0.15 \mathrm{~T}$, craters with a clear dark halo (CH) - from 0.1-0.15T to 0.5T, and craters with a faint halo $(\mathrm{FH})$ or with no halo $(\mathrm{NH})>0.5 \mathrm{~T}$. 
From the analysis of age relations of craters with surrounding units and structures it is possible to estimate ages of those units and structures (Figure 3 ).

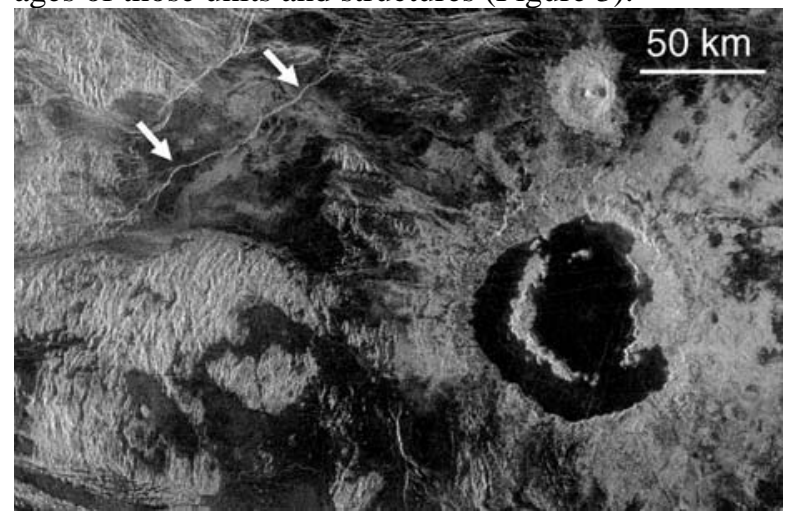

Figure 3. $\mathrm{CH}$ crater Sanger whose ejecta outflows are cut by the rift fault suggesting that at a time more recent than $0.5 T$ rifting was still active.

In addition to the material units within the V17 quadrangle three tectonic units have been mapped:

Material of tessera transitional terrain (ttt) forms areas of different sizes. Typically these are elongated, very gently-sloping highs composed of $p$ fr plains material and criss-crossed by transverse grooves (Figure 4). In some cases, $p d f$ material is involved in formation of $t t t$ unit.

Material of fracture belts (fb) forms elongated zones, mostly at the northern foot of the Beta uplift saturated with subparallel grooves (fractures). The latter are mostly embayed by $p w r$ and younger units but some of $f b$ fractures extend into $p w r$ plains deforming them. Fracture belts are considered to be ancient rift zones [e.g., 7]. Arcuate fracture belts form parts of some coronae.

Material of rifted terrain (rt) composes areas with dominating clusters of faults and graben mostly concentrated in Devana Chasma. The $r t$ structures are typically anastomosing with variable width. They cut all units and are locally buried by $\mathrm{pl}$ flows.

Structures: Eight major types of structures are identified (from older to younger): 1) Tessera-forming deformation morphologically represented by crisscrossing ridges and grooves; 2) Swarms of closely spaced grooves deforming the $p d f$ material; 3) Ridges deforming the $p f r$ unit; 4) Grooves (graben) deforming the $p f r$ material thus making it the ttt unit; 5) Grooves (graben) typical of the $f b$ unit, close or similar in age to the previous structures (type 4) but are typically longer; 6) Wrinkle ridges forming regional networks on $p w r$ and psh units; 7) Swarms of anastomosing graben associated with the Devana rift; 8) Long linear graben mostly cutting $p w r$ plains.

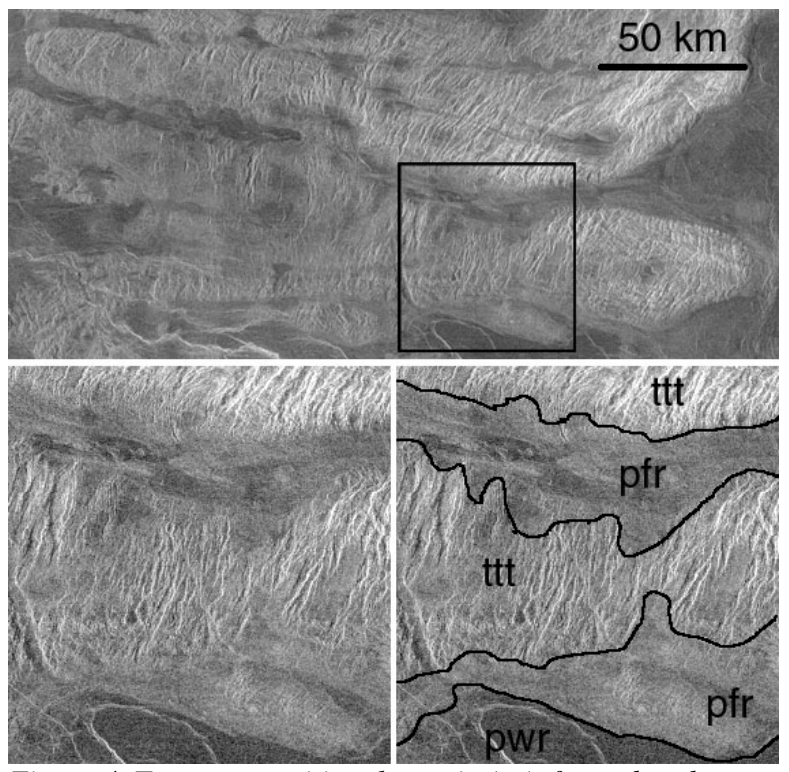

Figure 4. Tessera transitional terrain (ttt), formed at the expense of prr plains (see with broad ridges in the upper left of the inset).

A scenario of geologic history: Until the Beta uplift occurred, the geologic history of V17 area seems to be similar to that of many other areas of Venus: emplacement of materials of $t t, p d f$ and $p f r$ units and their deformation by the corresponding structures. Within the uplift area there is some deficit of $p w r$ plains implying that at the time of their emplacement (close to T) this area was topographically higher and volcanically less active than the neighboring regions. However, the ridge belts and wrinkle ridges are not aligned with these highs implying that significant tectonic uplift occurred later. The degree of preservation of craters affected by the Devana rifting and Theia volcanism [10] suggests at the time close to $0.5 \mathrm{~T}$ these processes were still active.

References: [1] Basilevsky (1996) LPSC 27 Abs., 65-66. [2] Ivanov \& Head (1996) JGR, 101, 14,861-14,908. [3] Gilmore et al. (1997) JGR, 102, 13,357-13,368. [4] Basilevsky et al. (1997) Venus II, 1047-1086. [5] Head \& Basilevsky (1998) Geology, 26, 35-38. [6] Collins et al. (1999) JGR, 104, 24,12124,139. [7] Basilevsky \& Head (2000) PSS, 48, 75-111. [8] Ivanov \& Head (2001) JGR, 106, 17,515-17,566. [9] Basilevsky \& Head (2002) JGR, 107, 10.1029/2000JE001471. [10] Basilevsky \& Head (2002) JGR, 107, 10.1029/2000JE00584. [11] Basilevsky \& Head (2003) Geology, 30, 1015-1018. [12] Basilevsky et al. (2003) GRL, 10.1029/2003GL 017504. [13] Ivanov \& Head (2004) JGR, 109 (in press). [14] Guest \& Stofan (1999) Icarus, 139, 55-66. [15] Hansen (2000) EPSL, 176, 527542. [16] Addington (2001) Icarus, 149, 16-36. [17] Barsukov et al. (1986) JGR, 91, D378-D398. [18] Solomon et al. (1992) JGR, 97, 13,199-13,256. [19] Hansen et al. (1997) Venus II, 797-844. [20] Tanaka et al. (1997) Venus II, 667-694. [21] McKinnon et al. (1997) Venus II, 969-1014. [22] Schaber et al. (1998) USGS Open File Report. [23] Arvidson et al. (1992) JGR, 97, 13,199-13,256. 
RESULTS FROM ONGOING MAPPING OF V14, THE GANIKI PLANITIA (FORMERLY CALLED NEMESIS TESSERAE) QUADRANGLE, VENUS. Eric B. Grosfils \& Sylvan M. Long, Geology Department, Pomona College, Claremont, CA 91711 (egrosfils@pomona.edu).

Introduction: The Ganiki Planitia quadrangle ${ }^{1}(25-$ $50^{\circ} \mathrm{N}, 180-210^{\circ} \mathrm{E}$ ) is located north of Atla Regio, south of Vinmara Planitia, and southeast of Atalanta Planitia. The region contains a diverse array of volcanic-, tectonic- and impact-derived features, and the objectives for the ongoing mapping effort are fivefold: 1) explore the formation and evolution of radiating dike swarms within the region, 2) use the diverse array of volcanic deposits to further test the neutral buoyancy hypothesis proposed to explain the origin of reservoir-derived features, 3\&4) unravel the volcanic and tectonic evolution in this area, and 5) explore the implications of 1-4 for resurfacing mechanisms. Previous reports focused on progress with objectives 1 and 2; the current report focuses on efforts to decipher the quadrangle's complex material unit stratigraphy.

Approach: Ongoing mapping and analysis of the geology within the Ganiki Planitia quadrangle builds upon integrated interpretation of multiple datasets. The primary mapping base is a single, $250 \mathrm{~m} / \mathrm{pixel}^{2}$, georeferenced, Lambert Conformal Conic-projected Magellan radar image, co-registered in ArcGIS 8.3 with topography and remote sensing (e.g., emissivity, etc.) datasets. Complementing this mapping configuration, similar resolution synthetic stereo images (at 10x vertical exaggeration) viewed on an adjacent screen provide powerful topographic insight into material unit boundary locations and stratigraphy. Finally, georeferenced FMAP resolution (75 m/pixel) radar data, sinusoidally projected to a central meridian of $195 \mathrm{E}$ and then digitally mosaicked within ArcGIS, are also employed; all units defined during mapping on the lower resolution Lambert base can be reprojected "on the fly" through a simple cut-and-paste operation in ArcGIS so that they co-register with the sinusoidally projected FMAP images, yielding a quick and efficient way to use high resolution data to refine problematic unit boundaries and stratigraphic relationships.

Undergraduate Involvement in '03-'04. Extensive work by six undergraduates ${ }^{3}$ during the 2003-2004 academic year yielded new insight into the stratigraphy of the quadrangle. Five of the students were assigned different material and structural units and each was asked to create notes within ArcGIS regarding the

1 The quadrangle name was changed this year by the USGS; hence, previous reports describe work in Nemesis Tessera (V14).

2 This translates, when viewed at full resolution, to an effective mapping scale of approximately 1:1M.

3 Thanks to (listed alphabetically): Dorothy Drury; Debra Hurwitz; Brian Kastl; Sylvan Long; Joey Richards; and, Lisa Venechuk. stratigraphic relationships observed with all adjacent units, thereby ensuring in nearly all instances that at least two students examined the stratigraphy of every contact Grosfils had defined previously. These data, presented on the poster, were compiled to complement Grosfils' quadrangle-wide work interpreting the stratigraphy; they also help ensure that the final results are more robust and internally self-consistent. The sixth student collected statistical data using ArcGIS for all of the material units defined to date, providing information that is allowing us to carefully compare the bulk quantitative characteristics of the units. All six students will remain involved during the coming fall as the mapping concludes. In a new effort during this final stage one student, a math major performing his senior thesis, will explore classification techniques using the integrated suite of datasets in order to define material units on a purely mathematical basis. This will allow for direct comparison with the quantitative (and other) properties of the existing material units, which were defined by Grosfils on the basis of backscatter and topography data alone.

Overview of Material Unit Stratigraphy: The stratigraphy within the quadrangle unfortunately cannot be organized into a single comprehensive sequence due to the presence and extent of (1) a morphologically and temporally diverse "garbage bag" plains unit that cuts several broad swaths across the quadrangle, and (2) a few extensive, crater-related, radar-dark depositsmost notably from the crater Yablochkina-which almost completely obscure stratigraphic details within the affected areas. In spite of these challenges, several local stratigraphic sequences can be defined, each covering $\sim 1 / 10$ to $\sim 1 / 6$ of the quadrangle. In total they cover approximately half of the quadrangle.

Each of the local stratigraphic regions is characterized by a common sequence of transitions from one predominant style of geological activity to another. This could suggest that each local region records a similar sequence of transitions occurring at different times and/or rates, or that some/all of the local regions went through a general coarse sequence of geologic style transitions at about the same time and rate. In the text that follows we present the general stratigraphic sequence characteristics observed; however, because of the ambiguities imposed by the presence of the "garbage bag" units and crater-related dark deposits which separate the local stratigraphic regions, we have observed no compelling evidence to test the hypotheses for if/how the local region stratigraphies are related. 
Tessera. Tessera is consistently the oldest material unit where it is observed as part of a local stratigraphic sequence. Tessera blocks are embayed or crosscut by all surrounding units, and in no location do we observe tessera forming at the expense of any other unit. Within individual tessera blocks it is clear that a rich and complex deformational history is preserved; however, it is not yet clear if major blocks/areas of tessera preserve similar histories.

Transition 1. In each local region the preserved stratigraphy suggests that a complex era of intermingled plains emplacement and deformation dominated for some interval following tessera formation. This era yielded three distinct units which locally are older than everything but the tessera; however, they do not occur in a consistent sequence relative to one another, exhibiting variable temporal relationships in different areas of the quadrangle. In some cases deformed beltseither elevated and clearly constructed from a distinct material unit or so heavily deformed that the precursor unit failed to survive-are locally the oldest unit preserved. In other areas, plains characterized by pervasive extensional deformation and preserved as elevated kipukas are locally the oldest unit. Finally, in many areas a local contact indicates that the "garbage bag" plains are the oldest feature other than tessera. These plains have, relative to other plains in the quadrangle, an intermediate radar backscatter and a highly blotchy appearance. They are distinctive yet have frustratingly defied further subdivision, and they display stratigraphic contact relationships which are often ambiguous locally but, when taken as a whole, indicate clearly a prolonged history of spatially and temporally patchy emplacement and modification for the unit.

Transition 2. In each local stratigraphic sequence, the next interval is characterized predominantly by extensive plains volcanism. The plains have a darker backscatter than the other plains units in the quadrangle, and the embayment observed with other material units as well as the superposition locally on different lineament sets both hint at a fairly thin, low viscosity material. Emplacement of this unit appears to have occurred over a prolonged interval, and though younger than the "garbage bag" plains in the majority of areas it is clearly contemporaneous in some locations. The dark plains are never older than the lineated plains or deformed belts, but locally they predate all other units with which they are in contact.

Transition 3. The final distinct era of geological activity within the quadrangle is characterized predominantly by edifice-related volcanism and emplacement of a final regional plains unit with a distinctly brighter radar backscatter than the other plains in the quadrangle. The majority of the bright regional plains occurs in a single continuous and spatially extensive unit with no evident source. Onlap relationships reveal the unit is thicker in the middle and thin at the edges, and unlike the older plains it appears to define a brief (possibly single) emplacement event. Other bright plains units generally appear to have local sources (a volcano, etc.) but are similar in stratigraphic position. Complementing the bright plains, several large (>100 km diameter) edifices formed and the lobate surface flows from these constructs are everywhere superimposed on the surrounding materials, including the major bright plains unit. Similarly, there are several extensive plains units characterized by overlapping small shield deposits. The duration of time over which the small shields were emplaced is almost by definition unconstrained, but like the major edifices these small edifice plains are everywhere younger than the materials against which they abut; in no location are the small edifice plains and a major volcanic edifice in stratigraphic contact.

Other Selected Observations. There are four other brief observations we choose to note here. [1] Continued mapping of three giant radiating dike swarms reveals that two were emplaced over a stratigraphically lengthy period; the third falls within the deposits from Yablochkina and is thus stratigraphically ambiguous. On the older end, dikes both cut and are buried by the dark regional plains; at the younger end, other dikes and localized edifice volcanism at the same centers are the most recent features observed locally, in some cases across quite extensive areas. [2] Corona and related deposits, mostly in a relict state (highly modified remnants are all that remain) appear to have formed predominantly prior to the era characterized by extensive regional plains emplacement. Lineated plains and the "garbage bag" plains unit occur upon the elevated rims which have been preserved, and the rims are embayed by the dark plains and younger deposits. [3] Continued study of a potential pyroclastic deposit has revealed that the combination of remote sensing, backscatter and morphological characteristics is inconsistent with an eolian or lava flow origin, but consistent with pyroclastic emplacement ${ }^{4}$. Study of this enigmatic deposit is continuing. One major impact crater in V14 is older than surrounding units, but deposits from most are clearly younger than their surroundings. There are insufficient craters to date the surface.

Major Work Remaining: We are in the process of: finalizing unit definition, contact types and stratigraphic interpretation sequences; performing several quantitative analyses as part of the unit finalization process; and, analyzing the complex tectonic history preserved in the quadrangle.

\footnotetext{
4 Long and Grosfils, Potential pyroclastic deposit in the Nemesis Tessera (V14) quadrangle of Venus, \#1194, LPSC XXXV, 2004.
} 
PRELIMINARY GEOLOGY OF THE NIOBE QUADRANGLE (V-23), VENUS. V. L. Hansen ${ }^{1},{ }^{1}$ Department of Geological Sciences, University of Minnesota Duluth, 231 Heller Hall, 1114 Kirby Drive, Duluth, MN 55812; vhansen@d.umn.edu

Introduction: V-23 encompasses approximately 8.4 million square kilometers of Venus equatorial region extending from $0-25 \mathrm{~N}$ and $90-120 \mathrm{E}$. The southern region is marked by highlands, and the central and northern regions preserve huge expanses of lowlands. Understanding processes that affect Venus' lowlands is critical to Venus evolution models. V-23 provides an excellent opportunity to study lowland processes.

Niobe Quadrangle: V-23 includes a lowland region comprised of Niobe and Sogolon Planitiae and highland and mesoland regions that include the northern part of Ovda Regio and Haasttse-baad and Gegute Tesserae. The division between Niobe and Sogolon Planitiae is generally topographic with Sogolon comprising a relatively small, circular basin; Gegute Tessera separates two basins within Niobe, one within $\mathrm{V}-23$, and one within $\mathrm{V}-24$ to the east. Lowlands extend north, east and west of the map area. The lowlands within the map area host five coronae, four loosely clustered in the central east side of the map area (Dhisana, Allatu, Omeciuatl, and Bhumiya Coronae), and one residing in the northwest part of the map area (Maya Corona, 23N/97E). In southeastern V-23 flows that emanate from the 300 $\mathrm{km}$ diameter Rosmerta Corona (centered at $\sim 0 \mathrm{~N} / 124.5 \mathrm{E}$ in $\mathrm{V}-24$ to the east) flow to the northwest across topographic lows within Haasttsebaad Tessera. A long narrow deformation belt, Unelanuhi Dorsa ( 100 km wide and over $2000 \mathrm{~km}$ long), trends northwest parallel to the northeastern boundary of Ovda Regio and extends into V-22 to the west. One small unnamed volcano occurs in the NW corner. V-23's vast lowland displays generally $\mathrm{N}$ striking fractures and ENE- to E-trending wrinkle ridges. The lowland also hosts tens to hundreds of thousands of individual eruptive centers, called shields [1-3]. The shields and associated eruptive materials appear to coalesce into a thin regionally extensive layer, called 'shield-terrain' [4-6], which locally masks (thus postdates), and is deformed by (thus also predates), secondary structures. Shieldterrain forms a regionally thin, locally absent veneer that seems to vary in thickness across the lowland. In general, wrinkle ridges concentrate where shieldterrain is presumed slightly thicker and fractures dominate where shield-terrain is presumed slightly thinner. Isolated kipukas of ribbon-terrain [7] locally poke through shield-terrain, preserving evidence of surface processes that predated shield-terrain emplacement. Ribbon-terrain fabrics are similar to ribbon fabrics that characterize high-standing crustal plateaus such as nearby Ovda and Thetis Regiones; ribbon-bearing kipukas may preserve evidence of ancient collapsed crustal plateaus [7, 8]. At least 24 impact craters reside within $\mathrm{V}-23$; the average and median impact crater density for $\mathrm{V}-23$ craters is 2.97 and 3.02 craters $/ 10^{6} \mathrm{~km}^{2}$, respectively, significantly higher than the global average $\left(2.25\right.$ craters $\left./ 10^{6} \mathrm{~km}^{2}\right)$ [crater values from 9].

Geologic Relations: The stratigraphically lowest materials in V-23 that can be delineated with the current data sets include various tessera-terrain units (unit tt) and fracture terrain, unit ft; tesseraterrain includes: ribbon-tessera-terrain of Ovda Regio, unit ttO; ribbon-tessera-terrain of Gegute and Haasttse-baad Tesserae, unit GHtt; and inliers of ribbon-tessera-terrain, unit tti. Each tessera-terrain unit within V-23 hosts ribbon structures, and commonly hosts fold ridges. In general folds and ribbons trend perpendicular to one another, although in the case of ribbon-terrain inliers which are the topographically lowest occurring ribbon-terrain exposures, fold ridges are more difficult to delineate with confidence. Topographically the ribbon-terrain units reside, from highest to lowest: units ttO, ttGH, and tti. Terrain units ttO and $\mathbf{t t G H}$, confined to southern and eastern V-23, occur as relatively large expanses comprising the northeast part of Ovda Regio, and the northwestern part of Haasttse-baad Tessera and western Gegute Tessera, respectively. Unit ttO extends into V-35, V-34, and V-22 (listed in clockwise fashion). Unit ttGH extends eastward into $\mathrm{V}-24$ and southward into V-35; this unit may represent two different tessera terrain units, or it may reflect a coherent deformation. The boundary between unit ttO and unit ttGH is defined by the orientation of ribbon and fold fabrics within each terrain. The boundary between the geographic location of Haasttse-baad Tessera and Gegute Tessera may be topographic; further detailed mapping must be conducted to reveal is there is clear evidence to distinguish this unit as two units, or if it should be considered a single unit based on current data resolution. Haasttse-baad Tessera to the south sits topographically higher and hosts better defined long-wavelength $(\sim 20 \mathrm{~km})$ folds, whereas Gegute Tessera sits topographically lower and its structural fabric is defined by ribbons and poorly defined fold 
axis ridges (ribbons and folds generally trend perpendicular to one another). Haasttse-baad Tessera also preserves better defined intratessera basin deposits (unit ittH), perhaps as a result of its higher elevation. Tessera-terrain unit tti occurs in numerous kipukas across central, northern and eastern V-23. The highly digitate boundaries of unit tti reflect the detailed structural topography that results from the ribbon-fold fabric and the interaction with younger overlying deposits.

Ribbon-fold fabrics in unit ttO describe a coherent pattern; folds trend NW parallel to the NW margin of Ovda Regio, curving to a more northward trend to the east and into V-35 to the south [10]. Ribbon structures generally trend perpendicular to fold crests, as do late graben [11]. Intratessera basins [12] generally trend parallel to the fold troughs. In southwestern V-23 the structural fabrics preserved in unit ttO and the intratessera basins describe more complex patterns. Here folds trend north with local sinuous traces; ribbons trend NNE and NW; aerially extensive intratessera basins comprise two general trends, parallel to NW-trending fold troughs in the northeast, and parallel to north-trending folds in the south.

Structural fabric patterns in unit GHtt delineate it from unit ttO. Near the boundary between Haasttse-baad Tessera and Ovda Regio, folds in unit GHtt trend NE perpendicular to NW-trending ribbons. Intratessera basins trend NE parallel to fold troughs, in contrast with unit ttO fold troughs and intratessera basins that trend NW. To the north within unit GHtt folds trend NE with parallel trending intratessera basins; ribbons generally trend normal to fold crests.

Terrain units tti and bt (basal terrain) outcrop in isolated kipukas (islands in volcanic flows) dotted around the quadrangle. Relative age among individual kipukas is not constrained. Some surface flows spatially away from the kipukas could have formed at the same time as the terrain within the kipukas, or surfaces could have formed prior to the terrain hosted within the kipukas because the strain fabrics recorded in the kipukas could certainly have formed in a spatially localized fashion. The kipukas host two different types of textural terrain, ribbons and fractures. Locally buried ribbon-terrain consists of regions that appear to have ribbon fabrics that are partially obscured by local surface flows, presumably shield-terrain, unit st, discussed below. Each of these terrains is exposed in variably sized kipukas with extremely detailed contacts that mark the overlap of thin surficial cover; the contact between lower textural terrain and surficial cover illustrates the delicate details of the structural topography of the underlying terrain.
The most aerially extensive terrain across the map area comprises shield-terrain (unit st) defined by tens of thousands of individual edifies called shields. The map area hosts over 40,000 to one million eruptive centers across $\sim 5$ million $\mathrm{km}^{2}$ of lowland. Individual shields are radar-dark or -bright, quasi-circular to circular features (shield, dome, cone, flat-topped, or flat), with or without a central pit. Shield deposits typically coalesce to form a thin, regionally extensive but discontinuous veneer or veil, herein called 'shield-paint'. Shield-paint conforms to delicate local topography, providing evidence of its thin character, indicating generally low material viscosity (during emplacement), and arguing for local sources. Edifice, or eruptive center, density across shieldterrain is difficult to determine; however, detailed mapping of five $2^{\circ} \times 2^{\circ}$ impact crater-free regions using co-registered normal and inverted, right- and left-illumination Magellan SAR imagery indicates edifice density ranges from 3,550-10,500 and 15,65033,675 shields $/ 10^{6} \mathrm{~km}^{2}$ [5,6]. Shield-paint covers, yet is locally deformed by extensional fractures and wrinkle ridges indicative of time transgressive formation relative to local deformation and/or reactivation. The regional-scale crust was strong throughout shield-paint formation.

V-23 hosts five coronae-all of which are probably 'old' coronae [13]. One feature 'Atse Estsan Corona' is probably not a corona, and not considered here as one of the five coronae. Maya Corona, the largest, occurs as an isolate corona in the NW part of the map area, whereas the other four, Dhisana, Allatu, Omeciuatl, and Bhumiya Coronae, occur relatively close together in the central east map area.

\section{References:}

[1] Guest J.E. et al. (1992) JGR, 97, 15949-15966. [2] Head, J.W. et al. (1992) JG, R 97, 13153-13198.

[3] Crumpler L.S. et al. (1992) in Venus II 697-756.

[4] Aubele J (1996) LPSC XXVII, 49-50. [5]

Hansen V.L. (2003) LPSC XXXIV, 1152.pdf. [6]

Hansen V.L. (2004) GSAB, in review. [7] Hansen

V.L. \& Willis J.J. (1998) Icaru,s 132, 321-343. [8]

Ghent R.R. \& Tibuleac I.M. (2002) GRL 29, 15944

[9] Herrick R.R. et al. (1997) in Venus II, 1015-1046.

[10] Bleamaster L.F. \& Hansen V.L. (2004) USGS

Geologic Investigations Series, I-2808. [11] Ghent

R.R. \& Hansen V.L. (1999) Icarus, 139, 116-136.

[12] Banks B.K. \& Hansen V.L. (2000) JG,R 105, 17655-17667. [13] Chapman M.G. \& Zimbelman J.R. (1998) Icaru,s 132, 344-361. 
GEOLOGICAL MAPPING OF QUADRANGLES V-3, V-7, AND V-57, VENUS: PRELIMINARY RESULTS. M. A. Ivanov $^{1,2}$ and J. W. Head ${ }^{2}{ }^{1}$ Vernadsky Inst., RAS, Moscow, Russia, mishaivn@mtu-net.ru, ${ }^{2}$ Brown University, Providence, Rhode Island, USA, james_head_iii@brown.edu.

Introduction Here we present the preliminary results of geological mapping in three quadrangles (V-3, V-7, V-57) mapped under the USGS Program of geological mapping of Venus. The areas of mapping are widely distributed and significantly enlarge both the lateral extent and total area of geological mapping already accomplished by us in four quadrangles (V-4, V-13, V-55, and V-61, Fig.1) [1,2]. The new quadrangles characterize a variety of regional topographic provinces and geological settings and are test areas for the applicability of proposed mapping techniques and models of regional to global stratigraphy and models of the geologic history of Venus [3-5].

General characteristics of the map areas Meskhent Tessera quadrangle (V3, 50-75N, 60-120E): The area of the quadrangle is the transitional region between the large lowland to the east (the Atalanta Planitia basin) and the highlands to the west (Ishtar Terra, Fortuna Tessera). There are three major occurrences of tessera within the V-3 quadrangle: Fortuna Tessera to the NW occupies the eastern portion of Ishtar Terra, a large tessera arc consisting of Dekla Tessera in the SW corner of the quadrangle, and the western portion of Tethus Regio that is dominated by Meskhent Tessera. The occurrences of tessera, which is the oldest material unit, correspond to prominent topographic highs that are separated by local lowlands populated with a variety of material and structural units.

Large deformational belts of grooves and ridges occur predominantly within the elongated lowland of Audra Planitia (about $1000 \mathrm{~km}$ long and 500-600 km wide) between Fortuna and Dekla Tesserae. There the ridge belts tend to be in contact with the arc of Dekla Tessera and the groove belts populate the surface of the lowland near the southern edge of Fortuna Tessera. Occurrences of the deformational belts there are roughly parallel to the strike of the Dekla arc. Another large occurrence of groove belts is in the centralsouthern portion of the quadrangle. The strike of the belts there is almost orthogonal to the orientation of the Dekla arc and deformational belts within Audra Planitia. The relationships among tesserae, ridge belts, and groove belts are consistent throughout the map area. The plains deformed into ridge belts embay tessera massifs and are cut by structures of groove belts.

The regional slopes away from the uplands of Ishtar Terra, Dekla Tessera, and Tethus Regio are characterized by extensive occurrences of shield plains. The plains embay older units that are exposed in the central portions of the highlands and are embayed by regional plains within the lowlands. Regional plains, the surface of which is deformed by networks of wrinkle ridges, form the most widespread unit in the map area and occur at the mid-level of the regional stratigraphic column.

The younger volcanic plains (lobate plains, tectonically undeformed and superposed on regional plains) are not very abundant within the quadrangle. These plains occur mostly in a broad topographic trough separating Ishtar Terra and Tethus Regio where they are in close spatial association with two coronae (Ops and Tusholi). Another occurrence of lobate plains is related to Fakahotu Corona. This corona is at the westernmost continuation of a chain of coronae interconnected by belts of fractures and graben. Vast aprons of younger volcanic flows typically surround coronae of this chain (Nightingale and Earhart Coronae within the V-4 quadrangle). At Fakahotu Corona there is evidence for tectonic activity that predates regional plains and for young volcanic flows that are superposed on regional plains.

The Lakshmi Planum quadrangle (V-7, 50-75N, 300360E): The northern half of the quadrangle is occupied by the roughly circular complex structure of Lakshmi Planum, which is about $2000 \mathrm{~km}$ across and stands $2-3 \mathrm{~km}$ above the surrounding terrains. The high mountain ranges border Lakshmi and divide the map area into two large provinces: 1 ) exterior of Lakshmi, and 2) interior of Lakshmi.

Exterior of Lakshmi: From the south, west, and northwest, a broad zone of complexly deformed terrain surrounds the planum. The zone consists mostly of tessera massifs, fragments of densely lineated plains, and curvilinear groove belts. In places, small fields of shield plains occur in close spatial association with groove belts. Vast regional plains deformed by wrinkle ridges embay all these material and structural units. Regional plains predominantly make up the surface of extensive lowlands surrounding Lakshmi.

In the southeastern corner of the quadrangle, large lava flows emanate from a distinct source (Muta Mons) and flow down toward the vast lowland of Sedna Planitia where they coalesce and form extensive occurrences of lobate plains. Lobate plains are mostly tectonically undeformed and clearly embay units and structures of the transition zone to the south of Lakshmi and are superposed on the surface of regional plains within Sedna Planitia, thus manifesting relatively young volcanic activity. At the western edge of the map area, large Omosi-Mama Corona appears to be another source of extensive young lobate plains.

Bordering mountain ranges: The mountain ranges that almost completely outline the interior of the plateau are lowest at the southern edge of the plateau (Danu Montes, 1.5-2 $\mathrm{km}$ higher than the surface of Lakshmi) and are significantly higher to the west (Akna Montes, $3 \mathrm{~km}$ higher), north (Freyja Montes, 3-3.5 km higher), and especially east (Maxwell Montes, 5-10 higher). The mountain ranges consist of tightly packed elongated parallel ridges 5 to $10 \mathrm{~km}$ wide and morphologically resemble the ridge belts common elsewhere on Venus [6]. In places, there is some evidence for embayment of the mountain ranges by regional plains from the outside of Lakshmi. At the contacts with the plains that make up the interior of Lakshmi, there is abundant evidence for embayment of the mountain ranges by the plains. Along Akna and Freyja Montes, however, the interior plains are sometimes tilted toward the plateau center and appear to be slightly ridged conformal to the strike of the mountain ranges.

Interior of Lakshmi: Within the interior of Lakshmi there are relatively small and embayed outcrops of heavily deformed materials morphologically similar to either tessera or groove belts elsewhere on Venus. The most widespread material unit of the interior is plains deformed by a network of wrinkle ridges. By morphology, albedo, and apparent 
stratigraphic position, these plains are most similar to the regional plains elsewhere on Venus $[7,8]$.

Stratigraphically higher are plains with either uniform low radar albedo or plains consisting of numerous brighter and darker flows. Both types of plains bear almost no tectonic deformation, are clearly related to two major volcanic centers, Colette and Sacajawea Paterae, and are analogous to the youngest lava plains on Venus such as smooth and lobate plains surrounding distinct volcanic centers [1,9-11].

Although all types of interior plains show distinct similarities to specific varieties of plains outside Lakshmi, the interior plains are completely confined within the planum and thus have been mapped as separate units.

The Fredegonde quadrangle ( $V-57,50-75 S, 60-120 E)$ : The area of the quadrangle covers the transition from the upland of Lada Terra to the west to extensive elongated lowland of Aino Planitia to northeast. The eastern portion of Lada Terra within the map area almost lacks occurrences of tessera and the oldest units exposed there are densely lineated plains and ridge belts. Small fragments of these units heavily embayed by regional plains occur in the central, central-northern, and central-southern portions of the quadrangle. Elongated occurrences of ridge belts correspond to distinct topographic ridges that are oriented in NW and N directions.

The most important features in the quadrangle are several large coronae interconnected by swarms of grooves. The coronae and groove belts make up large corona-groove chains that form prominent ridge-and-trough topographic complexes and extend for several thousands of kilometers in a NE direction toward the lowland of Aino Planitia. The general strike of the corona-groove chains is almost orthogonal to the preferential orientation of the ridge belts. In many aspects the corona-groove chains within the map area are similar to zones at the margins of large equidimensional basins such as Lavinia (V55) and Atalanta (V4) Planitiae. Near the basins of Lavinia and Atalanta Planitiae, the corona/groove zones tend to be roughly parallel to the edges of the basins. In the case of the eastern portion of Lada Terra, however, the deformational belts are oriented perpendicular to the general elongation of Aino Planitia. Individual structures of the groove swarms (groove belts) are embayed by regional plains and thus are older.

Regional plains deformed by wrinkle ridges occur in the middle part of the regional stratigraphic column, form the most extensive material unit within the map area, and cover the majority of the surface of the quadrangle including both the surface of the upland of Lada Terra and the lowland of Aino Planitia. Large fields of shield plains, fragments of which are mostly embayed by regional plains, occur in places within the quadrangle.

The coronae from the corona-groove zones appear to be distinct sources of relatively young volcanism. Vast lava flows that form the upper unit of regional plains (pwr2) and lobate plains occur in close spatial association with DunneMusun and Ambar-ona Coronae that occupy a broad topographic high in the center of the quadrangle. Another locus of young volcanism is associated with Xaratanga Chasma and several large coronae in the NW corner of the quadrangle.

Summary Despite the different locations and regional geological settings of the three mapped areas, they all have distinct features that are similar not only for these quadrangles but also for the previously mapped areas (V-4, V-13, V55, and V-61). The important result of our preliminary map- ping in the new areas is that for all of them the set of material units and tectonic structures appears to be very similar. The most complete stratigraphic column characterizes the Lakshmi Planum quadrangle (V-3) and consists of 13 units (from older to younger): Tessera terrain (t), Densely lineated plains (pdl), Ridged and grooved plains (prg), Mountain belts (mb, Lakshmi), Shield plains (psh), Regional plains (two units, $\mathrm{pwr}_{1}$ and $\mathrm{pwr}_{2}$, characterize the Lakshmi exterior and two units, $\operatorname{lpwr}_{1}$ and lpwr $_{2}$, occur in the interior of the planum), Smooth plains (ps), Interior smooth plains (lps, Lakshmi), Lobate plains (pl), and Interior lobate plains (lpl, Lakshmi). Five of these units characterize specific features within the planum interior and may be correlative to their counterpart outside Lakshmi. The same set of units (except for the specific Lakshmi interior units) characterizes the surface within the Fredegonde and in the Meskhent Tessera quadrangles. Within V-3, however, the upper unit of regional plains (pwr2) and smooth plains (ps) appears to be missing. The stratigraphic order of the units within all three new quadrangles is the same and appears to be similar to the stratigraphic column found for the four previously mapped quadrangles.

Thus, similar sequences of volcano-tectonic events were documented within seven quadrangles (V-3, V-4, V-7, V-13, $\mathrm{V}-55, \mathrm{~V}-57$, and V-61) that cover about $11 \%$ of the surface of Venus in large contiguous zones within both hemispheres of the planet. Such a similarity does not support a spot-like or regional, independent distribution of units/events, which is predicted by the nondirectional model of the geologic history of Venus [5]. On the other hand, the similar sequences of events shown by a specific set of material and structural units in different areas are in agreement with the alternative, directional, model of the history $[3,4]$.

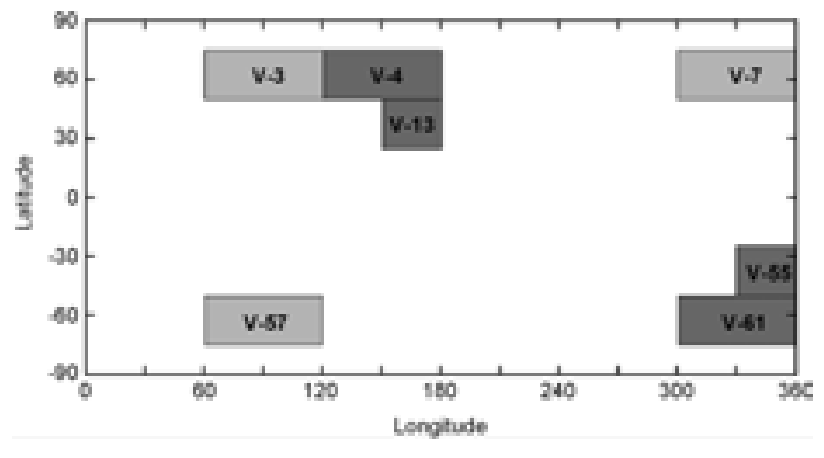

Fig. 1. Position of seven quadrangles where the mapping was either accomplished (V-4, V-13, V-55, and V-61) or is in progress (V-3, V-7, and V-57).

References: 1) Ivanov, M.A. and J.W. Head, USGS Geol. Inv. Ser., Map I-2684, 2001a; 2) Ivanov, M.A. and J.W. Head, USGS Geol. Inv. Ser., Map I-2792, 2003; 3) Basilevsky, A.T. and J.W. Head, PSS, 43, 1523, 1995; 4) Basilevsky, A.T.,et al., in: Venus II, S.W. Bougher et al. eds., Univ. Arizona Press, 1047, 1997; 5) Guest, J.E., and E.R. Stofan, Icarus, 139, 56, 1999; 6) Banerdt W.B., et al. , in: Venus II, S.W. Bougher et al. eds., Univ. Arizona Press, 901, 1997, 7) Head, J.W. and A.T. Basilevsky, Geology, 26, 35, 1998; 8) Basilevsky, A.T. and J.W. Head, JGR, 103, 8531, 1998; 9) Price, M., et al., JGR, 101, 4657, 1996; 10) Namiki, N. and S.C. Solomon, Science, 265, 929, 1994; 11) Ivanov, M. A. and J. W. Head, JGR, 106, 17515, $2001 \mathrm{~b}$. 
GEOLOGICAL MAPPING OF FOUR QUADRANGLES ON VENUS: IMPLICATIONS FOR "DIRECTIONAL" AND "NON-DIRECTIONAL" MODELS OF GEOLOGIC HISTORY. M. A. Ivanov"1,2 and J. W. Head $^{2},{ }^{1}$ Vernadsky Inst., RAS, Moscow, Russia, mishaivn@mtu-net.ru, ${ }^{2}$ Brown University, Providence, Rhode Island, USA.

Introduction: Here we present the results of geological mapping in four quadrangles (V-4, V-13, V-55, and V61) mapped under the USGS program of geological mapping of Venus [1,2]. The areas of mapping are widely distributed and comprise about $6 \%$ of the surface of Venus. We believe that such a fraction of the surface mapped provides the possibility to assess to the first order the applicability of proposed end-member models of Venus' geologic history.

General characteristics of the map areas: $V-4$, Atalanta Planitia quadrangle. The Atalanta Planitia quadrangle $(50-75 \mathrm{~N}, 120-180 \mathrm{E})$ covers the central and western part of Atalanta Planitia, the floor of which is $\sim 2 \mathrm{~km}$ deep and heavily flooded by volcanic deposits. Tesserae, coronae, or linear deformational belts are not well developed or abundant within the Atalanta Planitia basin itself. The basin, however, is surrounded by coronae of Tethus Regio to the west [3,4], Ananke Tessera [5] and Vellamo Planitia [6,7] to the southwest, and an extensive zone of ridge belts to the east $[8,9]$.

$V-13$, Nemesis Tesserae quadrangle. The Nemesis Tesserae quadrangle $(25-50 \mathrm{~N}, 150-180 \mathrm{E})$ covers the area between Atalanta Planitia (north), Vellamo Planitia (west), and Llorona Planitia (southwest). The central portion of Ganiki Planitia consists of elongated deformed lowland flooded by volcanic deposits and surrounded by the Vedma Dorsa deformation belt to the west [8-10] and Nemesis and Athena Tesserae to the east. In contrast to more equidimensional lowlands (basins) such as Atalanta and Lavinia Planitiae, the area of the Nemesis Tesserae quadrangle represents the class of elongated lowland areas on Venus confined between elevated regions. The most important volcanic feature within the quadrangle is Baltis Vallis, the longest $(\sim 7,000 \mathrm{~km})$ channel on Venus [11-13]. Baltis Vallis runs through the whole central elongated lowland of Ganiki Planitia and forms a regional stratigraphic marker [13].

V-55, Lavinia Planitia Quadrangle. The Lavinia Planitia quadrangle (25-50S, 330-360E) covers the central and northern part of Lavinia Planitia and parts of its margins. The distinct lowland of the planitia is flooded by vast volcanic plains and populated by prominent deformational belts of extensional and contractional structures. Lavinia Planitia is one of several large, equidimensional basins ( 1.5-2 km deep) that have been cited as evidence for the region being the site of large-scale mantle downwelling [14]. The basin of Lavinia Planitia is surrounded by Dione Regio to the west [15], Alpha Regio tessera [16] and Eve Corona [17] to the northeast, and an extensive rift zone and corona belt to the east and south [18-19]. No tessera or intermediate to large volcanic edifices [20] are observed in the basin, and coronae are not well developed or abundant there. All these features tend to concentrate along the margins of the planitia.

V-61, Mylitta Fluctus quadrangle. The northern third of the Mylitta Fluctus quadrangle (50-75S, 300-360E) covers the southern portion of Lavinia Planitia, which represents a class of equidimensional lowlands on Venus [14]. The southeastern portion of the map area shows the western part of the upland of Lada Terra, the summit of which is $\sim 3 \mathrm{~km}$ high. The key geological theme of the quadrangle is that it portrays a transition zone from lowlands to uplands. Plains of different origin cover the majority of the area. Coronae are common features within the quadrangle and are concentrated mostly within Lada Terra while the territory of Lavinia Planitia lacks coronae [17,21-23,1]. Distinct complexes of lava flows are in close spatial association with coronae situated within Lada Terra. The area of the Mylitta Fluctus quadrangle lacks occurrences of tesserae, and tectonic features are mostly concentrated in several deformation belts that consist of either contractional or extensional structures. The most prominent belt, Kalaipahoa Linea ( 2,200 km long), outlines the northern edge of the Lada Terra.

Results of mapping: Despite the different locations and regional geological settings of the mapped areas, they each bear distinctly similar geological records. One of the most important results of the mapping is that for all four quadrangles the set of material units and tectonic structures appears to be very similar. The complete stratigraphic column defined at the scale $1: 5 \mathrm{M}$ and applicable to all four areas consists of ten material units (from older to younger): Tessera terrain $(\mathrm{t})$ is among the most deformed regions on Venus characterized by multiple sets of tectonic structures. Densely lineated plains (pdl) are heavily dissected by numerous subparallel narrow and short lineaments. Ridged and grooved plains (prg) commonly form compact elongated belts consisting of tightly packed ridges. Shield plains (psh) display numerous small volcanic edifices on their surface. Wrinkleridged plains (two units, $\mathrm{pwr}_{1}$ and $\mathrm{pwr}_{2}$ ) cover the majority of the surface and typically form a background with other units and structures being either older or younger. Smooth plains (ps), and lobate plains (two members, $\mathrm{pl}_{1}$ and $\mathrm{pl}_{2}$ ) form small and large fields of lava flows that are typically tectonically undeformed.

Specific structural assemblages occur along with the material units. From apparently older to younger these are as follow: Sets of tessera-forming structures (ridges and grooves), ridge belts, groove belts (gb), and rift zones (rt). Pervasive wrinkle ridges form regional networks that deform all material units predating smooth and lobate plains. These major structural assemblages in all mapped areas are seen at a certain range of stratigraphic positions. Sets of tesseraforming structures where they occur are consistently the oldest features; the ridge and groove belts postdate tessera and predate shield plains and regional plains; rift zones deform many older units and appear to be contemporaneous with emplacement of lobate plains.

Many units appear to be laterally continuous throughout much of the area by direct surface exposure (e.g., pwr) or stratigraphic relationships inferred from topography. Although not all local sequences contain all units, there are no regions within the mapped areas that show different sequences of stratigraphic units, or comparable sequences of material units and structures that appear to be formed at different times.

Discussion and conclusions: Results of the mapping in the four quadrangles provide the possibility to address a very important issue concerning the overall character of the geologic history of Venus. Two end-member models of the geologic history of Venus describing observed sequences of 
material units and tectonic structures have been proposed so far.

In the first model [24], regional sequences of units are interpreted to be formed by independent volcano-tectonic regimes that occur in different places at different times. Thus, the sequences of units and structures represent local to regional time-dependent styles of endogenous activity. This "nondirectional" model considers the geologic record of Venus as being produced without pronounced trends in either volcanism or tectonics. This model predicts a "nonsynchronous" nature for geologic records in different places, implying that the sequences of units and structures are nonsynchronous and stratigraphic columns characterizing specific regions are not time-correlative at least globally. Important requirements of this model are quasi-stationary rates of geological processes and a spot-like or regional distribution of specific sequences on Venus.

In the second approach, geological mapping of 36 different $1000 \mathrm{x} 1000 \mathrm{~km}$ areas distributed randomly across the surface of Venus revealed similar stratigraphic sequences of units $[25,26]$ and the sequence of mapped units and structures was interpreted to be broadly correlative because of their widespread nature and consistent sequential occurrence. Mapping of a global geotraverse demonstrated the lateral correlation of many of these units [27]. This mapping was interpreted to mean that the apparently similar sequences of units and structures mapped in different regions were manifestations of a set of specific global trends of volcanic and tectonic activity that describe the geologic record of Venus. In [24], this interpretation was called a "directional" model, with the general global stratigraphic correlation implying broad synchronism of units and structures. These results and this model suggest that the rates of geological processes changed through time and that specific large-scale volcano-tectonic regimes prevailed during different episodes of the geologic history $[25,26]$.

Similar stratigraphic columns appear to characterize all four mapped quadrangles. The columns show tessera at the bottom and smooth and lobate plains at the top. Throughout the mapped areas distinct trends of volcanic and tectonic events were documented. The most obvious case is represented by tessera that commonly occurs at the base of either local or regional stratigraphic columns. This situation holds true not only within the mapped areas but also elsewhere on Venus [5]. The systematic appearance of tessera at the beginning of the observable geological record strongly suggests radical changes in the deformational history of Venus. Ridge belts and groove belts occupy the middle portion of stratigraphic columns and in each case predate vast regional plains. There are no examples of prominent zones of tightly packed contractional structures that appear at different levels of the stratigraphic columns.

The overall trends in the structural history for all four mapped quadrangles suggest that deformation decreased from an initially very high level associated with tessera to clearly lower levels associated with deformation of densely lineated plains material, ridged and grooved plains material, wrinkle ridged plains material, and finally, to essentially no extensive brittle deformation of the latest flows of smooth and lobate plains.

Volcanism was initially widespread and partly coincident with tessera formation (for example, unit pdl), then became concentrated into widely distributed small individual sources (the small shields of unit psh), then changed style to vast flooding of the majority of the area, and lastly was con- centrated over a few distinct volcanic sources. The volcanic activity in the Nemesis Tesserae quadrangle apparently waned after the tectonic episode of wrinkle ridge formation.

Although there is evidence that small volcanic edifices were formed over a large portion of the visible geological record [27], the rate at which these edifices formed has changed dramatically during this time span [28]. Within all the mapped areas the vast majority of small edifices appears relatively early, predating regional plains. Only a few small volcanoes (small shields) coincide with the formation of young lobate plains (shield clusters in V-61 area).

Thus, distinct changes of morphological appearance in the specific units and structural assemblages as a function of time were documented in the mapped areas. These changes suggest that major trends of endogenous activity have operated through the visible part of the geological record of Venus and were responsible for specific styles of volcanism and tectonics. The existence of such trends is consistent with the directional model and is not in agreement with the nondirectional model.

References: 1) Ivanov, M.A. and J.W. Head, USGS Geol. Inv. Ser., Map I-2684, 2001a; 2) Ivanov, M.A. and J.W. Head, USGS Geol. Inv. Ser., Map I-2792, 2003; 3) Pronin, A.A. and Stofan, E.R., Icarus, 83, 452-474, 1990; 4) Stofan, E.R. and Head, J.W., Icarus, 83, 216-243, 1990; 5) Ivanov, M.A. and J.W. Head, JGR, 101, 14861, 1996; 6) Aubele, J.C., LPSC (Abstr.), XXV, 45-46, 1994; 7) Aubele, J.C., LPSC (Abstr.), XXVI, 59-60, 1995; 8) Kryuchkov,V.P., EMP, 50/51, 471-491, 1990; 9) Frank, S.L. and Head, J.W., EMP, 50/51, 421-470, 1990; 10) Stewart, E. M. and Head, J. W., 2000, LPSC (Abstr.), XXXI, \#1692, 2000; 11) Baker, V.R., et al., JGR, 97, 13421-13444, 1992; 12) Baker, V.R., et al., in: Venus II, S.W. Bougher et al. eds., Univ. Arizona Press, 757-793,1997; 13) Basilevsky, A.T., and Head, J.W., JGR, 23, 1497-1500, 1996; 14) Bindschadler, D.L., et al., JGR, 97, 13,495-13,532, 1992b; 15) Keddie, S.T., and Head, J.W., JGR, 100, 11,729-11,754, 1995; 16) Bindschadler, D.L., et al., JGR, 97, 13,563-13,578, 1992a; 17) Baer, G., et al., JGR, 99, 8355-3869, 1994; 18) Stofan, E.R.,et al., JGR, 97, 13,347-13,378, 1992; 19) Magee, K.P., and Head, J.W., JGR, 100, 1527-1552; 1995; 20) Head, J.W., et al., JGR, 97, 13,153-13,197 1992; 21) Stofan, E. R., et al., GRL, 28, 4267-4270, 2001; 22) Crumpler, L.S., et al., Science, 261, 591-595, 1993; 23) Crumpler, L.S. and Aubele, J.C. in: Encyclopedia of Volcanoes, Academic Press, 727-770, 2000; 24) Guest, J.E., and E.R. Stofan, Icarus, 139, 56, 1999; 25) Basilevsky, A.T. and J.W. Head, PSS, 43, 1523, 1995; 26) Basilevsky, A.T.,et al., in: Venus II, S.W. Bougher et al. eds., Univ. Arizona Press 1047, 1997; 27) Ivanov, M. A. and Head, J. W., JGR, 106, 17515-17556, 2001; 28) Addington, E.A., Icarus, 149, 16, 2001; 29) Ivanov, M.A., et al., LPSC (Abstr.), XXXI, \#1205, 2000. 
CONTINUED GEOLOGIC MAPPING OF THE GREENAWAY QUADRANGLE (V-24), VENUS. N.P. Lang and V.L. Hansen. University of Minnesota-Duluth, Duluth, MN 55806. lang0604@tc.umn.edu

Introduction: The Greenaway quadrangle (herein referred to as $\mathrm{V}$-24) occupies an $\sim 8,400,000 \mathrm{~km}^{2}$ equatorial swath of lowlands and highlands on Venus. This region $\left(0-25^{\circ}\right.$ N., $120-150^{\circ}$ E.) comprises parts of Niobe and Llorona Planitiae and is bounded by crustal plateau Thetis Regio to the south, Rusalka Planitia to the east, and Gegute Tessera to the west. The northern three-fourths of the quadrangle are part of the vast lowlands, or planitiae, which cover $\sim 80 \%$ of Venus.

Southern V-24 marks the northern edge of Aphrodite Terra and hosts the highest topography in the quadrangle with elevations reaching $\sim 1 \mathrm{~km}$ above the Mean Planetary Radius (MPR) of 6051.84 km. Northern Aphrodite Terra abruptly slopes north to the lowlands comprising Niobe and Llorona Planitiae, which are cut by a NE-trending topographic arch hosting coronae. This arch divides V-24 into two NE-trending elongate basins, which both drop to elevations of $\sim 1.5$ $\mathrm{km}$ below MPR. Both basins serve as depocenters for coronae and shield-sourced material.

$\mathrm{V}$-24 mapping is part of a larger ongoing project addressing the geologic and tectonic evolution of planitiae. Particularly, we are addressing planitia resurfacing mechanisms; V-24 is resurfaced by both coronae and shields. Eight coronae are identified in V24 with four located along the NE-trending topographic arch, two in Haasttse-baad Tessera, and two along the NE side of Gegute Tessera. Corona flow material, if present, is relatively localized extending at most a couple hundred $\mathrm{km}$ from the source. Shields, identified across all V-24, occur as either a) 100-200 $\mathrm{km}$ diameter clusters associated with coronae, or b) large tracts of shields with no discernable patterns over $>10^{6} \mathrm{~km}$. The expansive presence of shields in V-24 implies that they likely play the dominant role in resurfacing here.

Geology: In an attempt to better constrain the geologic history of V-24, we have divided the quadrangle into six topographically distinct geographic regions based on Magellan altimetry data: Niobe Planitia, Marginal Plains, Llorona Planitia, Haasttse-baad Tessera, the Southeastern Highlands, and Gegute Tessera. The geologic history of one region may or may not be interrelated to the geologic history of another region.

Niobe Planitia. Niobe Planitia in V-24 is a topographic basin bounded by Gegute Tessera to the west, the Marginal Plains to the east, and Haasttse-baad Tessera to the south. Flow material from Rosmerta Corona, Abundia Corona, and Boann Corona (in V-12) spill into the basin. Timing between the flows is inde- terminable; however, the flows broadly parallel the basin trend suggesting they most likely post-date basin formation. Material sourced from the Marginal Plains flows into the eastern part of the basin; the source(s) of this material is indeterminable.

Kipuka of ribbon-bearing tessera terrain outcrop in the basin's middle. Ribbons have both NW and NE trends. Numerous NW-trending lineaments cut through both the kipuka of tessera terrain and the plains material fu. Wrinkle ridges define an arcing NE to easterly trend across Niobe Planitia.

Niobe Planitia holds the lowest density of shields in $\mathrm{V}$-24. Either shield volcanism was not common here or earlier shields and related products are covered by later corona-sourced volcanic flows.

Marginal Plains. The Marginal Plains consists of the $\sim 500 \mathrm{~km}$ wide NE-trending topographic arch separating Niobe and Llorona Planitiae. Four coronae dot the arch and display variable amounts of volcanism. Kubebe Corona and unnamed coronae A and B display flow material extending $200 \mathrm{~km}$ past their annuli, whereas Kamadhenu Corona volcanism is apparently in the form of a shield field (unit Ksf). A degraded circular topographic rim along the western margin of the topographic arch may define a possible fifth corona; a cluster of shields is identified inside the rim.

Graben and lineaments outcrop with a sinuous NEtrend along the arch top, linking the coronae, and are most likely genetically related to corona formation and evolution. Graben continue to the northeast past Kamadhenu Corona extending into the southern part of $\mathrm{V}-12$; graben concentration becomes more confined here and cut NW-trending graben. Graben confinement may be real and attributed to strain partitioning or graben may be covered by later flow material.

The Marginal Plains hosts a high concentration of shields. Numerous shields cluster in and around the coronae; however, many shields occur in no discernable pattern and are not associated with individual coronae.

Kipuka of ribbon-bearing tessera terrain outcrop in a curvilinear fashion in the middle of the arch defining the crest of a broad fold. Ribbons here describe NW and NE trends.

Llorona Planitia. Llorona Planitia in V-24 is also a topographic basin bounded by the Marginal Plains to the west and the Southeastern Highlands to the south. This region is characterized by numerous outcrops of basal materials, lumped and mapped as basal materials undifferentiated (unit bu); unit bu hosts lineaments defining a broad NW trend across the basin. Unit bu 
has a low topographic expression and is embayed by shields and shield-sourced material. Lineaments with trends similar to those in unit bu outcrop though shield-sourced material across the basin suggesting unit bu is more expansive and underlies much of the shield deposits.

Kipuka of ribbon-bearing tessera terrain also outcrop across the basin and are spatially associated with unit bu. Wrinkle ridges define easterly trends across the basin.

A dark halo associated with the Bourke-White impact structure obscures the geology in most of northern Llorona Planitia. Flow material from Ituana Corona in $\mathrm{V}-25$ to the east flows into the NE corner of the Llorona Planitia.

Haasttse-baad Tessera. Haasttse-Baad Tessera is composed of several inliers of ribbon-bearing tessera terrain. Ribbons define NW to NE trends. Numerous folds, fractures, and intra-tessera basins are also identified post-dating ribbon formation. Haasttse-baad Tessera is flooded by flow material from Rosmerta and Blai Coronae. Rosmerta Corona material extends $>1000 \mathrm{~km}$ and spills into three adjoining quadrangles. Blai Corona material is more localized, filling local topographic lows. NW-trending graben, presumably associated with the formation of Rosmerta Corona, cut through western Haasttse-baad Tessera providing numerous conduits for Rosmerta Corona material to spill onto Niobe Planitia.

Southeastern Highlands. This region marks the transition from Haastse-baad Tessera to the Llorona Planitia basin. The region is characterized by suites of NE-trending fractures and lineaments outcropping in an E-W-trending $1000 \times 300 \mathrm{~km}$ topographic warp that extends into V-25 and is embayed by shield material. The structures outcrop again to the SW along the eastern margin of Haasttse-baad Tessera where they continue into V-36. Similar trending structures also outcrop to the NE of the warp in V-25.

Gegute Tessera. Gegute Tessera is a N-S elongated inlier of ribbon-bearing tessera terrain extending west into V-23. Suites of NE and NW-trending ribbons occur across the inlier. Folds and intra-tessera basins occur locally post-dating ribbon formation similar to Haasttse-baad Tessera.

Discussion. V-24 is an ideal location to study planitia resurfacing processes; planitia here are resurfaced through a combination of corona and shieldsourced flows. Corona-sourced flows are responsible for resurfacing parts of Haasttse-baad Tessera and Niobe Planitia; however, the rest of V-24 is resurfaced via shields.

Despite dividing V-24 into six topographic regions, derivation of a detailed geologic history for $\mathrm{V}-24$ is difficult due to minimal interaction between mapped material units. Mapped material units represent material deposited via some process (i.e. volcanism) during a specific event of geologic history. When individual material units are non-discernable or non-traceable, we lump the material into a more general composite unit. Composite units in V-24 are tessera terrain (t), basal materials undifferentiated (bu), and the widespread plains unit flows undifferentiated (fu). Composite units are not material units because they represent multiple materials lumped together potentially recording multiple geologic histories. Hence, composite units cannot be used to correlate material units and/or robustly constrain geologic histories. In order to correlate units and/or constrain geologic histories, stratigraphically coherent material units must either interact or be stratigraphically placed in reference to a widespread marker bed [1].

However, based on broad map relations, a general geologic history is discernable. Where present, ribbon-bearing tessera terrain represents the locally oldest deformed crust. Segments of unit bu may or may not be as equally old or older than tessera terrain. Although corona and shield activity may post-date tessera terrain, their timing cannot be more robustly constrained.

References. [1] Compton, R.R., (1985) Geology in the Field, John Wiley and Sons, New York, p. 85. 
GEOLOGIC MAPPING OF THE HELEN PLANITIA QUADRANGLE (V52), VENUS. I. López ${ }^{1}$ and V. L. Hansen $^{2},{ }^{1}$ Dpto. de Matemáticas y Física Aplicadas y Ciencias de la Naturaleza. Universidad Rey Juan Carlos, C/Tulipán s/n, 28933 Móstoles, Madrid, Spain (i.lopez@escet.urjc.es), ${ }^{2}$ Department of Geological Sciences. University of Minnesota-Duluth, 1114 Kirby Drive, Duluth, MN 55812 (vhansen@d.umn.edu).

\section{Introduction:}

The Helen Planitia Quadrangle (V52) is located in the southern hemisphere of Venus between $25^{\circ} \mathrm{S}-50^{\circ} \mathrm{S}$ and $240^{\circ} \mathrm{E}-270^{\circ} \mathrm{E}$, covering a surface of 8.000 .000 $\mathrm{km}^{2}$ between the mesolands of Parga Chasmata and the lowlands of Helen Planitia. V52 is bounded to the east by the corona-dominated volcanic rise of Themis Regio and to the west by Wawalag Planitia. The area includes a large number and morphological variety of coronae, large volcanoes, and other volcanic and structural features distributed along the mapped materials, allowing the study of their relative age relationships, interactions and evolutionary sequence.

\section{Mapping methodology:}

The mapping philosophy employed for the mapping of V52 follows USGS guidelines [1] with the modifications outlined by [2]. Detailed geologic mapping has been carried out in Lambert Conformal Conic projection using left-looking full resolution images (75m/pixel), left and right-looking normal and inverted Magellan SAR images (225-250 $\mathrm{m}$ /pixel), and left-looking synthetic stereo radar images (450 m/pixel). We do not follow a pure stratigraphic sequence from older to younger for the description of the materials. Instead, we use local geographical temporal sequences where materials are in contact and relative temporal relationships can be established.

\section{Unit materials:}

The Helen Planitia Quadrangle (V52) preserves a variegated assemblage of structures (primary and secondary) and materials. V52 represents a transitional area between the mesolands of Parga Chasmata and the lowlands of Helen Planitia. This topographic transition has its reflection in the different deformational styles and units displayed, and because of this, we defined two different domains for the description of the map units: Parga Chasmata and Helen Planitia domains.

Parga Chasmata Domain (PCD). This domain is composed of several major units including tesseraterrain units, basal materials, corona-related flows, shield-dominated units, and local volcano-related flows. In northwestern V52, preserved in local elevated areas, flows and shield-related materials of volcanic basal units embay ribbon-bearing tesseraterrain and small kipukas of densely-deformedterrain. Undifferentiated volcanic materials, including flows and shield-related materials, in turn embay this assemblage of basement materials. In central and eastern PCD tessera-terrain and basal materials of Parga Chasmata form the basement over which flood lava flows that emanated from chasma-related coronae and volcanic features, as well as from chasma fractures, are emplaced. Geologic mapping revealed that corona-related flows and tectonic suites evolved in intimate spatial and temporal relation with the chasmata. Locally, large corona flows are postdated by volcano- and shield-related units.

Helen Planitia Domain (HPD): This domain is composed of several major map units, including a basement composed of three different tessera-terrain inliers and two basal units that are overlaid by shieldand volcano-related flows and undifferentiated volcanic materials that dominate most of the HPD. In western HPD tessera-terrain materials and a basal volcanic unit underlie the undifferentiated volcanic materials and other locally restricted shield-related materials. Central and eastern HPD are composed of several major units that include a basement represented by two different tessera-terrain units and another basal unit that underlie an undifferentiated volcanic unit, two shield-related units, and two volcano-related units. The HPD is areally dominated by shield-related materials whose contact with the undifferentiated volcanic materials is difficult to trace due to the discontinuous character of the shieldrelated materials.

\section{Structures:}

V52 displays a variety of secondary structures that variably deform all units. Tectonic structures are divisible into four suites:

-Structures associated with tessera-terrain. Tessera-terrain inliers, distributed across V52, preserve different patterns of intersecting structures: ribbons, fractures, graben, and folds.

-Regionally extensive fold belts and wrinkle ridges. Two different styles of contractional deformation occur in V52: dorsa in which strain is concentrated and sub-parallel regional wrinkle ridges that reflect distributed strain. The major wrinkle ridge trends present in V52 are: a) north-northeast- and north-northwest-trending wrinkle ridges that form part of the circum-Themis-trend of [3] that dominate southeastern V52, b) northwest-trending wrinkle ridges of the Helen Planitia trend of [3] that dominate 
western V52, and c) north-trending wrinkle-ridges that extend over central V52.

-Regional fracture trends. Northwest-striking parallel fractures are locally reoriented around tectonomagmatic features and dominate northwestern V52. North-striking fractures are also locally reoriented around tectonomagmatic features and dominate southern V52. Fracture spacing varies in areas where these fractures are grouped forming fracture belts (e.g. Ajina Fossae) that connect and interact with different tectonomagmatic features, suggesting a genetic association between the tectonomagmatic features and the fracture belts. An

$2000 \mathrm{~km}$-long and $600 \mathrm{~km}$-wide zone of the northwest trending Parga Chasmata dominates northern V52.

-Structures related to tectonomagmatic features. Fourteen well-defined coronae, five large structures whose classification is problematic, and two novae are distributed across the map area. The large tectonomagmatic structures in V52 show a strong spatial correlation with Parga Chasmata and other smaller deformation belts, so we define two different groups of structures based on their association with these fracture belts: structures spatially associated with Parga Chasmata and structures outside the influence of Parga Chasmata. All these features display different suites of local radial and concentric fractures that interact with the regional fracture trends. Three radial fracture suites, interpreted as dike-related structures [e.g. 4], are located in central V52 in the transition between the Parga Chasmata and the Helen Planitia Domains.

- Localized deformation. Different suites of parallel kilometer-scale lineaments, interpreted as extension fractures based on their narrow, linear geometry, cut different basal materials in the Parga Chasmata and Helen Planitia domains.

\section{Craters:}

V52 hosts eleven impact structures that range from 6 to $44 \mathrm{~km}$ in diameter and two shock features. Impact-related structures (rim and central peak) are mapped as primary structures for each crater, whereas crater-ejecta material and crater-floor material are mapped as undifferentiated crater material. Two craters (Rose and Wollstonecraft) show extensive far-field outflows. We consider the stratigraphic position of individual impact craters. Implications for material ages are not statistically robust [5] and therefore not considered.

\section{Geologic history and resurfacing styles:}

Across V52 tessera-terrain inliers and other basement materials form the substrate over which different volcanic units were emplaced. The various suites of secondary structures, deformation histories, and the lack of contact relationships between material units argues against the consideration of all tesseraterrain and basement materials of V52 as a unique coherent synchronously formed basement layer for the entire quadrangle [e.g. 6]. A varied assemblage of volcanic materials resurfaces V52. We have identified multiple sources that contribute to resurfacing including coronae, large volcanoes, flows from rift-related fractures, medium-sized volcanoes and a large number of small shields, which contribute to resurfacing at scales from tens to thousands of kilometers and occur across the map area.

Regions adjacent to chasmata (i.e. PCD) were resurfaced by extensive lava flows that originate from chasmata structures, coronae and volcanic centers along the chasmata; individual flows extend more than $1000 \mathrm{~km}$ from eruptive centers. Medium-sized volcanoes and steep-sided domes decorate the many corona-related flow units. Local shield clusters associated with large tectonomagmatic features and individual groups of shields postdate the corona- and volcano-related flows. South of Parga Chasmata (i.e. HPD) tectonic and volcanic styles change, with undifferentiated volcanic materials, volcano- and shield-related volcanic activity dominating over corona-related materials. The lack of temporal constraints in most of the cases prevents us from interpreting stratigraphic significance of this change for resurfacing style.

The result of this geologic mapping is inconsistent with global stratigraphy models [6]. The view that emerges is one of local complex histories $[7,8]$.

References:

[1] Tanaka, K.L. et al., (1994) The Venus Geologic Mapper's Handbook, $2^{\text {nd }}$ ed., USGS OpenFile Report 94-438, 68 p. [2] Hansen V. L. (2000). Earth Planet. Sci. Lett., 176, 527-542. [3] Billoti F. and Suppe, J. (1999) Icarus, 139, 137-159. [4] Ernst et al. (1995) Earth Science Reviews, 39, 1-58. [5] Campbell B.A. (1999). J. Geophys. Res., 104, p. 21951-21955. [6] Basilevsky A.T. and Head J.W (1998). J. Geophys. Res., 103, p. 8531-8544. [7] Phillips, R.J. and Hansen, V.L. (1998) Science, 279, p. 1492-1497. [8] Guest J.E. and Stofan, E.R. (1999) Icarus, 139, p.55-66. 
GEOLOGIC MAPPING OF THE BELLONA FOSSAE (V15) QUADRANGLE, VENUS. J. R. Zimbelman, CEPS/NASM MRC 315, P.O. Box 37012, Smithsonian Institution, Washington, D.C., 20013-7012; jrz@nasm.ei.edu.

Introduction: This report summarizes results from on-going mapping support by NASA PG\&G grant NAG5-11743. The original proposal identifies topical problems for both Mars and Venus, with science objectives that make use of geologic mapping results. This report gives results presented at the 2004 mappers meeting held in Flagstaff, Arizona.

Background: Venus mapping was carried out in support of the science objective of identifying and interpreting stratigraphic and structural relationships in the northern lowland plains of Venus, to provide constraints for hypotheses of global resurfacing. Geologic mapping of the Kawelu Planitia (V16) quadrangle was completed using FMAP mosaics that preserve the full resolution of the Magellan Synthetic Aperture Radar (SAR) data [1]. Detailed stratigraphic information obtained for lobate plains surrounding the volcano Sekmet Mons, located primarily in V16 but also on the eastern side of the Bellona Fossae (V15) quadrangle, provided new insights into the sequence of volcanic resurfacing on this section of the northern lowlands [2]. Experience gained during the mapping and revision of the V16 map was crucial to carrying out the mapping in V15.

Regional Setting: The Bellona Fossae quadrangle (Fig. 1) covers a portion of the northern lowlands that divides Kawelu Planitia to the east and Ganiki Planitia to the west [3]. Highest elevations in the quadrangle

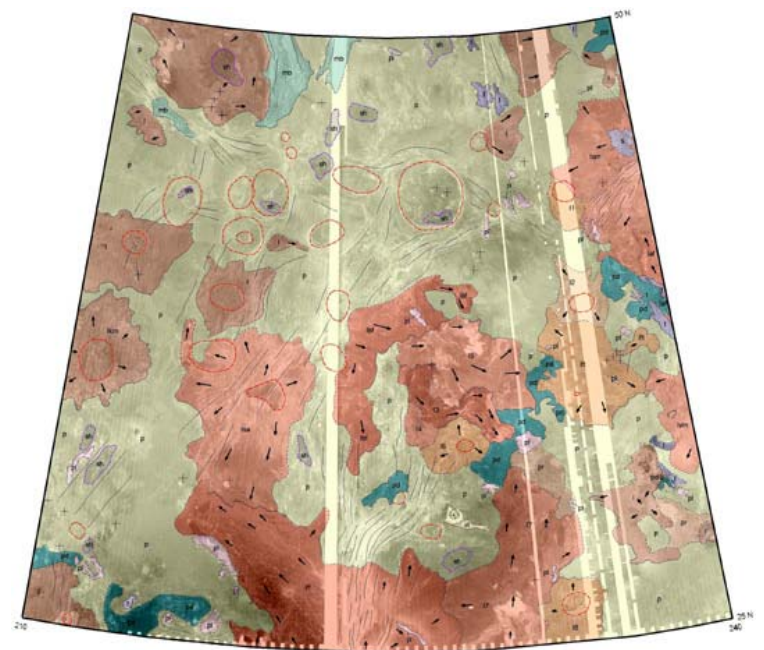

Figure 1. Geologic map of V15 quadrangle, Lambert projection. Fig. 2 shows unit relative stratigraphy, Fig. 3 shows detail of some lobate plains units (center), and Fig. 4. shows corona chains (center left). correspond to Fea Fossae (south center) and Bellona Fossae (center), intensely fractured zones that reach elevations of 2 to $4 \mathrm{~km}$ above the Venus datum, with the two planitiae at elevations of 0 to $2 \mathrm{~km}$ east and west of the fracture zones [3]. Lobate (flow) units associated with the Sekmet Mons volcano enter the quadrangle along its eastern margin, and isolated lobate units occur around other potential volcanic centers. A series of coronae, mostly lacking significant topographic relief, are in the center of the quadrangle.

Stratigraphy: Units were mapped using FMAP SAR mosaics, and the composite stratigraphy is shown schematically in Fig. 2. The oldest units, based on contact relations with all adjacent units, are isolated patches of tesserae. However, there is no independent way to establish the relative age variations that might exist between the widely separated tesserae patches. The southern portion of the Iris Dorsa mountain belt extends into the northwestern corner of the quadrangle

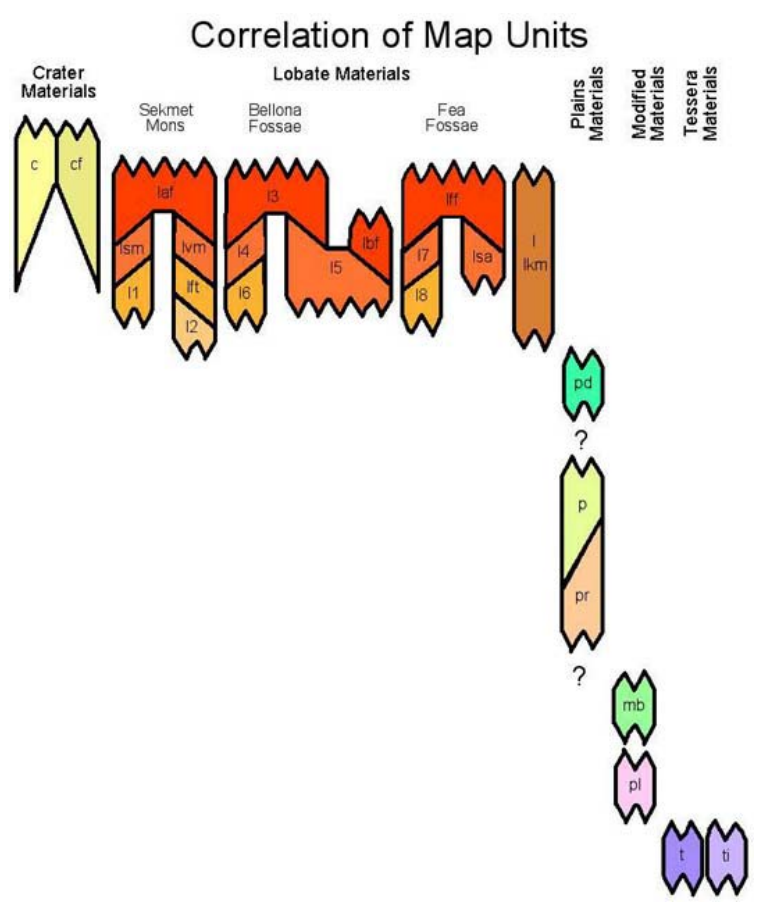

Figure 2. Relative stratigraphy of geologic units in V15 map. Hachured lines indicate uncertainty in vertical extent of unit, but relative vertical positioning is consistent with mapped relationships. Sloping lines indicate time-transgressive contacts. Unit colors above appear different from Fig. 1 due to SAR background merged with semi-transparent unit colors on the map. 
from V5 (Pandrosos Dorsa) to the north [4]. Regional plains cover most of the quadrangle, but once again there is no independent way to demonstrate that these plains are a single (or continuous) material unit. A host of lobate plains units are scattered throughout the quadrangle, identified either by a nearby named feature or a number (top of Fig. 2). The correlation chart is a compromise in an attempt to portray the stratigraphic information expressed within the quadrangle while also showing the considerable uncertainty that exists for the relative placement of some units. An outcome of the 2002 mappers meeting was a decision to clarify what each mapper intends to show by their correlation chart; the V15 correlation chart follows the general guidelines agreed to at the 2002 meeting.

Volcanic materials and structures: Important information about the relative emplacement of discreet lobate plains units provides insight into the sequence of emplacement (Fig. 3), similar to results obtained from

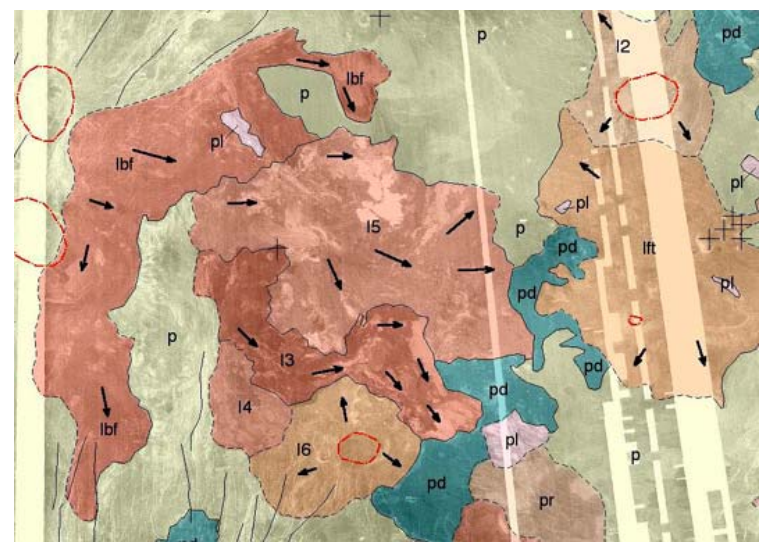

Figure 3. Example of lobate plains units, interpreted to be discreet groups of volcanic flows (center of Fig. $1)$.

detailed mapping of lobate plains around Sekmet Mons in the V16 quadrangle [2]. In contrast to the lobate plains, which are among the youngest materials exposed in V15, a series of coronae are arrayed in chains across the central portion of the quadrangle (Fig. 4). The coronae generally lack much topographic relief, and appear to be among the older volcano-tectonic structures in this area, similar to results reported previously [e.g. 5, 6]. It is anticipated that the combination of stratigraphic constraints for the lobate plains and structural cross-cutting relationships for some of the coronae might aid in piecing together the sequence of events preserved in the geology of the V15 quadrangle. When combined with previous mapping of adjacent quadrangles [e.g. 4, 7], results from mapping at the quadrangle scale should provide important new constraints for evaluating models for the emplacement of the 'regional plains' of Venus, such as through a global

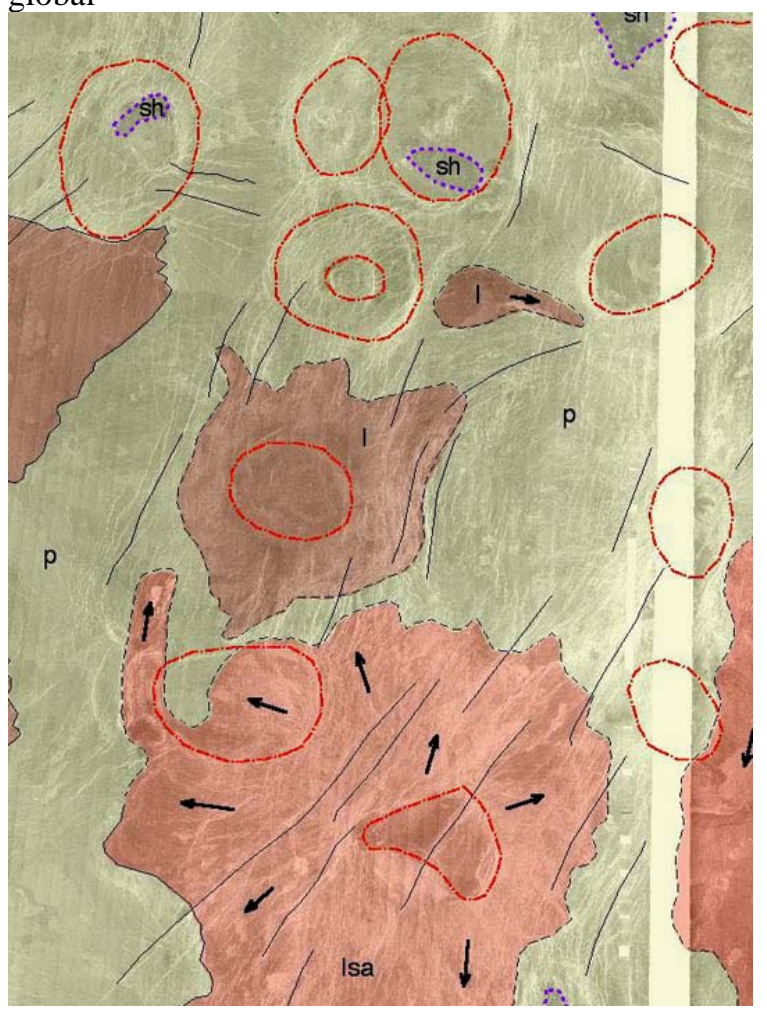

Figure 4. Example of two parallel coronae chains (center left of Fig. 1).

resurfacing process [e.g. 8] or the existence of a continuous global stratigraphy [e.g. 9, 10].

References: [1] Saunders R. S. et al. (1992) JGR, 97, 13067-13090. [2] Zimbelman J. R. (2003) JGR, 108, DOI:10.1029/2002JE001965. [3] U. S. Geological Survey (1998) Map I-2457, scale 1:10,000,000. [4] Rosenberg E. and McGill G. E. (2001) U.S. Geol. Survey Map I-2721, scale 1:5,000,000. [5] Stofan E. R. et al. (1992) JGR, 97, 13347-13378. [6] Chapman M. G. and Zimbelman J. R. (1998) Icarus, 132, 344-361. [7] Zimbelman J. R (1994) LPS XXV, 1553-1554. [8] Banerdt W. B. et al. (1997) Venus II (Bouger S. W. et al., eds.), Univ. of Arizona Press, 901-930. [9] Basilevsky A. T. and Head J. W. (1998) JGR, 103, 8531-8544. [10] Head J. W. and Basilevsky A. T. (1998) Geology, 26, 35-38. 
GEOLOGICAL MAPPING OF EUROPA: UPDATE AND LINEAMENT SEQUENCING. P.H. Figueredo ${ }^{1}$, T. Hare ${ }^{2}$, K. Tanaka ${ }^{2}$, R. Greeley ${ }^{1}$, D. Senske ${ }^{3} .{ }^{1}$ Dept. Geological Sciences, Arizona State University, Tempe, AZ 852871404, ${ }^{2}$ U.S.G.S. Flagstaff, ${ }^{3}$ JPL - figueredo@asu.edu

\section{Introduction}

Understanding the global distribution of Europan geologic units in space and time is necessary for the synthesis of the results of the Galileo mission, comparison with global stress and thermal models, and preparation for future exploration by JIMO. To address these issues, we are producing the first global geological map of Europa. We are using the published global photomosaic of Europa (U.S.G.S. Map I-2757) as a basemap, expanded with additional Galileo SSI images at their original resolutions. The map is being produced entirely on ArcGIS for analysis and combination with other datasets [1]. One of the main objectives of this project is to establish a global stratigraphic framework for Europa. In the absence of a welldeveloped cratering record, this goal will be achieved using the satellite's global network of lineaments (ridges, ridge complexes and bands; cf. [2]). Here we present an update on our mapping efforts and our progress towards lineament sequencing.

\section{Mapping update}

Different team members are responsible for mapping different classes of features, to allow cross-checking and uniform criteria for the distinction of units and sub-units. Because of our focus on stratigraphy, we opted for the distinction and mapping of allostratigraphic and lithostratigraphic units in our global map (cf. [3]). Using this method, we expect to use the major tectonic and chaos formation events to bracket any other geologic feature or event. Before mapping, we identified, processed, and incorporated into our GIS database all the available observations, and expanded the Europa nomenclature with 14 lineaments and one region that are key for stratigraphic studies [1]. We consider only the most prominent lineaments, those that extend for $100 \mathrm{~km}$ or more, and any lineament that determines the timing between prominent features. Features $>20 \mathrm{~km}$ in width or diameter are mapped as geologic units; smaller features are marked with structural symbols. Given the uneven resolution of the base photomosaic, we first mapped and established crosscutting and superposition relationships within all highresolution Galileo observations. The stratigraphic relationships derived from the high-resolution mosaics are then extrapolated onto the global, lower resolution context.

We have mapped lineaments over the entire northern hemisphere of Europa, and chaos terrain within most regional resolution (100s m/pixel) mosaics (Fig- ure 1). Stratigraphic studies thus far, however, are focused on the northern trailing region of the satellite, which has the best image coverage of Galileo and Voyager data and allowed us to draw from the results of previous mapping projects [4-7]. Almost 900 lineaments were mapped and catalogued; those without official nomenclature were assigned an arbitrary cata$\log$ number.

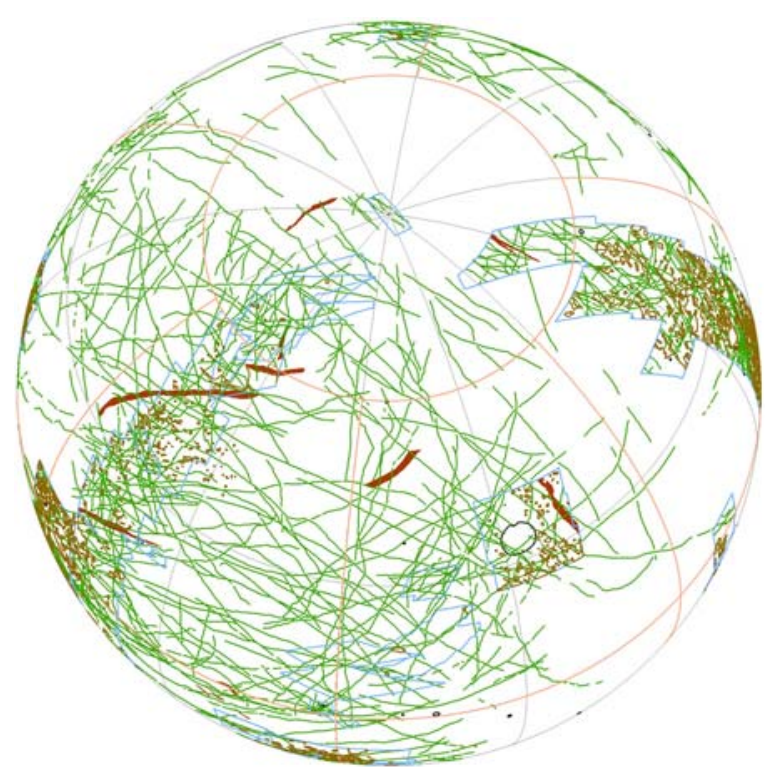

Figure 1. Orthographic view of the features mapped thus far in the northern hemisphere of Europa; the trailing side is in the foreground. For geologic mapping, we informally divided Europa into quadrants, shown by orange lines. The outlines of high-resolution mosaics appear in blue, lineaments in green, wide bands in maroon, chaos in brown, and impact craters in black.

\section{Sequencing results, discussion, and future steps}

In our analysis we assume that lineaments formed relatively quickly in a single event and that there were no reactivations. These assumptions are justified by the very few examples indicating otherwise. Timesequence information is synthesized and displayed in a correlation chart with data from nearly 200 lineaments in the area comprised between 140 to $250^{\circ}$ longitude ([8], Figure 2). In the chart, lineaments are represented by horizontal lines (labeled) connected by vertical lines with the lineaments that constrain their timing. We stress that this basic chart is a preliminary, 
working version and is being expanded and modified with information from the ongoing mapping of the other regions of Europa. Once completed, major 'stratigraphic' markers will be identified and the information in the chart will be converted into a more standard time-sequence chart.

Even at this preliminary stage, the chart enables an assessment of the relative timing of lineaments on distant regions of Europa. For example, we can determine for the first time that the Tyre impact event occurred before Ino Linea developed, and that the southern branch of Autonoë Linea is much younger than Argiope Linea. At this point we see no evidence of "patchy" resurfacing, where tectonic activity moves from one area to another, although we have explored only $\sim 20 \%$ of the surface. In this sense, we note that currently the chart incorporates very little stratigraphic constraints from impact craters and chaos regions. Local and regional relations indicate varying development and expression of stages of chaos formation. After we tie in these regional observations into the global stratigraphy, we should be able to determine, for example, if and when global, contemporaneous chaotic resurfacing occurred, or if there is evidence of fracturing and chaotic disruption sweeping westward with time as nonsynchronous rotation proceeded.

We are currently developing and testing a GIS routine tailored to automatically generate lineamentby-lineament stratigraphic charts (discussed in detailed in [9]). This routine will test the consistency of our mapping observations in order to expose hidden inaccuracies as part of an iterative revision process.

References: [1] Figueredo et al. (2003) Planet. Mappers Meet. abst.; [2] Greeley et al. (2000) JGR 105: 22559; [3] Skinner and Tanaka (2003) LPSC 34, \#2100; [4] Prockter et al. (1999) JGR 104: 16531; [5] Senske et al. (1998) LPSC 29, \#1743; [6] Kadel et al. (2000) JGR 105: 22657; [7] Figueredo and Greeley (2004) Icarus 167: 287; [8] Figueredo et al., LPSC 35, \#1118; [9] Hare et al., this meeting.

Figure 2. Preliminary correlation chart of lineaments in the northern trailing hemisphere [8], from youngest to oldest, top to bottom. Only the crosscutting relationships that constrain the stratigraphic position are shown as vertical lines, and lineaments can "float" within their respective vertical lines. At this time, lineaments labeled blue are locally the most recent; lineaments labeled red are locally the oldest; lineaments labeled green extend horizontally elsewhere in the chart. Question marks indicate uncertain relationships.

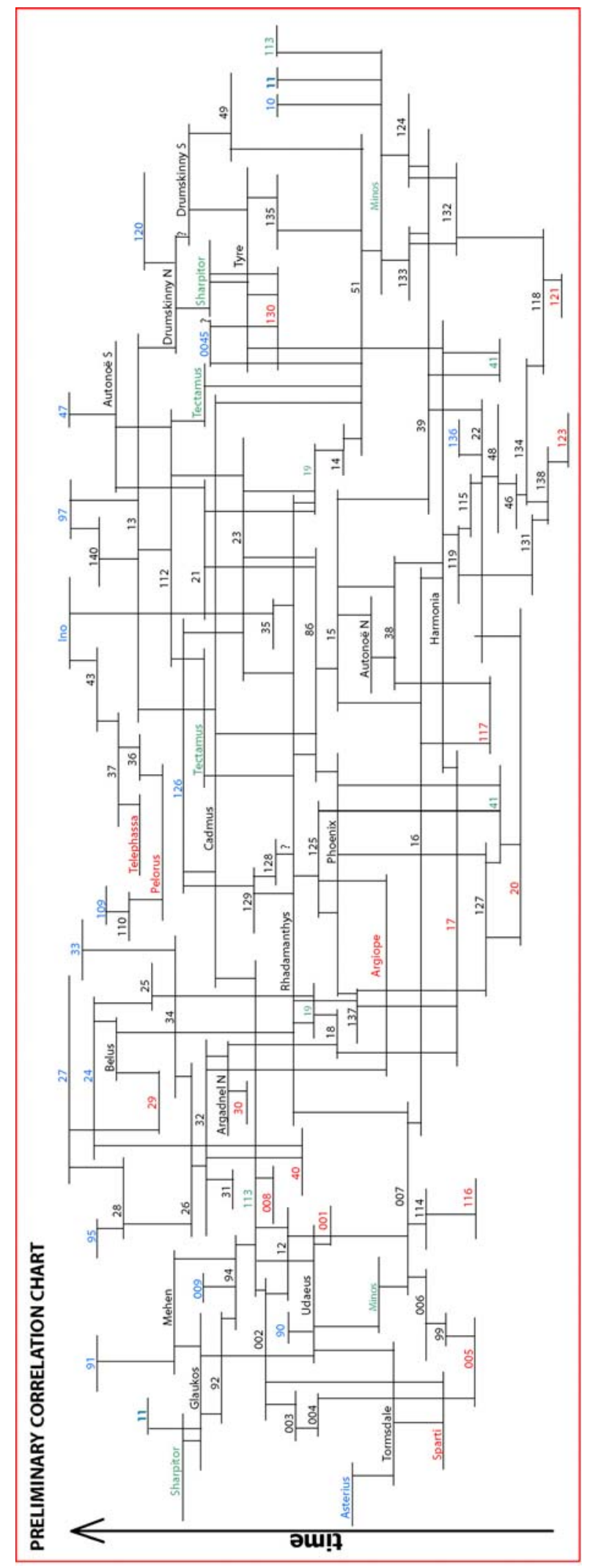


GEOLOGICAL MAPPING OF GANYMEDE: A PROGRESS REPORT. G. Wesley Patterson ${ }^{1}$, James W. Head ${ }^{1}$, Geoffrey C. Collins ${ }^{2}$, Robert T. Pappalardo ${ }^{3}$, Louise M. Prockter ${ }^{4}$, Baerbel K. Lucchitta ${ }^{5}$ and Jennifer Savage ${ }^{2} .{ }^{1}$ Department of Geological Sciences, Brown University, Providence, RI 02912 (Gerald_Patterson@brown.edu); ${ }^{2}$ Wheaton College, Norton, MA 02766, ${ }^{3}$ LASP, University of Colorado, Boulder, CO 80309; ${ }^{4}$ Applied Physics Laboratory, Laurel, MD 20723; ${ }^{5}$ USGS, Flagstaff, AZ, 86002.

Introduction: The Galilean satellites represent a series of bodies that contrast distinctly in their physical properties, surface geology, and thermal evolution [1-4]. Their conditions of formation are very likely linked to the early history of the proto-Jovian nebula, with their disparate characteristics related to the radially varying conditions in the earliest period of their formation $[5,6]$. The reasons for these differences in geological evolution represent one of the most fundamental problems in comparative planetology [6,7]. Why are the surfaces of Ganymede and Callisto so strikingly different? What are the factors involved in their geological evolution? What roles do internal (e.g., possible presence of liquidwater ocean at depth) and external forces (e.g., tidal interactions) play in explaining the differences between Ganymede and Callisto?

One of the most basic constraints on these questions is the geological record of Ganymede as revealed in imaging and other remote sensing data. To that end, we are in the process of compiling a global geologic map of Ganymede (at the 1:15M scale) that will represent the most recent understanding of the satellite on the basis of Galileo Mission data. This contribution builds on important previous accomplishments in the study of Ganymede [8-12] and seeks to further clarify: 1) the major geological processes operating on Ganymede, 2) the characteristics of the geological units comprising its surface, 3) the stratigraphic relationships of geological units and structures, 4) the geological history inferred from these relationships, 5) the crater size-frequency distributions on key geological units and structures, and 6) the cratering chronology of Ganymede, which can be used to compare to other Solar System bodies. Here we summarize our progress toward the completion of this global mapping project.

Discussion: The Voyager mission provided important information about the nature of the surface of Ganymede at moderate resolution and these data were used to subdivide the surface into two major terrain types (dark and bright terrain), define the major geologic structures on the satellite, define a series of geologic units, and produce geologic maps (e.g., [13-15]). The Galileo mission provided a host of new data (highresolution monochromatic, color, and stereo imagery, polarimetry, near-infrared spectral imagery, etc.) and the first task we undertook in developing a global geologic map of Ganymede was to reassess the units identified at Voyager resolution using this new data [16, 17]. The result of this reassessment was a revised Description Of Map Units (DOMU) which are divided into five terrain types: 1) bright, 2) dark, 3) reticulate, 4) palimpsest, and 5) crater material. We are currently using this revised
DOMU to produce a preliminary global geologic map, a portion of which can be seen in Figure 1 .

Bright material: This material has been subdivided into four units: grooved, subdued, irregular, and undivided. The grooved unit is arranged in domains characterized by parallel, roughly evenly spaced grooves and ridges oriented in a single dominant direction. The subdued unit is similar to the grooved unit but appears smooth or finely grooved at Galileo and/or Voyager resolution except where secondary craters and crater chains are superposed. The irregular unit is similar to the subdued unit but contains isolated grooves with no preferred orientation. The undivided unit represents all materials of sufficiently low resolution that morphological properties and/or age relationships cannot be determined.

The inclusion of structure as a distinguishing characteristic for bright material here is a result of the scale at which we are mapping. While at high-resolution the faults which constitute the grooved terrain are clearly visible and could be mapped individually, at the regional scale such a map would be incomprehensible due to the density of features $[9,16]$.

Dark material: This material has been subdivided into three units: cratered, lineated, and undivided. The cratered unit represents large areas of low albedo material with moderate to high crater density commonly occurring as polygons bounded by bright units. The lineated unit is similar in character to the bright grooved unit but with lower albedo and depressions tending to be more sinuous and shallower and the undivided unit represents all materials of sufficiently low resolution that its material properties cannot be determined. This also may include irregularly shaped large patches and small slivers of low albedo material interspersed within light terrain of indistinct morphology or areas too small to be identified by morphologic criteria other than albedo.

The inclusion of structure as a distinguishing characteristic for the lineated unit is predicated on the scale at which we are mapping (as with the bright material units). However, furrows, which were previously included as a distinguishing characteristic of dark terrain units, are being mapped as separate structures [17].

Reticulate material: This terrain consists of a single unit. It is often associated with and surrounded by bright grooved, bright subdued, and/or dark lineated units but can be distinguished from them by its variable albedo and presence of grooves with two dominant directions (typically orthogonal to each other). Previous maps (e.g., [13,14]) have separated this terrain into bright and dark units based on albedo and associated 
them with bright and dark terrains respectively. We find differences in albedo for this terrain to be highly variable and inhomogeneous on a local scale and have therefore chosen to combine them into a single unit and designate it as a material separate from both bright and dark materials.

Palimpsest material: This material consists of two units: palimpsests and palimpsest interior plains. The palimpsest unit is characterized by flat, generally circular to elliptical structures occurring predominately (but not exclusively) on dark terrain units. These structures lack rims but can have internal, concentric ridges. The palimpsest interior plains unit is characterized by smooth, circular to subcircular patches of high albedo material commonly found at or near the center of palimpsests.

Previous mappers (e.g., [13-15]) chose to subdivide palimpsests into three stratigraphic units based on shape (from circular to irregular), apparent degradation, and the presence of specific structures. However, it remains unclear whether or not irregularly shaped bright patches are indeed palimpsests as they appear to lack features identified as characteristic of this terrain type [18]. Furthermore, the interpretation of degradation state can be subject to resolution and lighting conditions. This has led us to combine these units into a single palimpsest unit in which structures will be superposed.

Crater material: This terrain consists of seven units: bright craters, partly degraded craters, degraded craters, secondary craters, dark crater material, basin rugged material, and basin smooth material. The first three units separate craters into a stratigraphic sequence (from youngest to oldest respectively) based on degradation state, which we feel can be more clearly determined then for palimpsests. The secondary crater unit is characterized by fields of uniform, small pits surrounding large bright craters, partly degraded craters, and some palimpsests. Dark crater material appears to be predominately associated with bright craters and forms dark patches on their floors or rims. The basin material units are used to define the prominant Gilgamesh basin.

Preliminary map: Using the revised DOMU described above, we are in the process of compiling the global geologic map. Our procedure for accomplishing this task is for at least two researchers to concurrently map in $60^{\circ} \times 60^{\circ}$ quadrangles (Fig. 1). Each quadrangle is mapped independently and, after completion, they are compared for discrepancies in the locations of terrain types and boundaries. These discrepancies are discussed and reconciled to produce a single preliminary quadrangle (as shown in Fig. 1). We have completed a number of these quadrangles, spanning from $-30^{\circ}$ to $30^{\circ}$ lat. and $115^{\circ}$ to $295^{\circ}$ lon. and they cover all terrain types described except basin materials and span a wide range of resolutions and lighting conditions.
We are proceeding with this mapping scheme for the entire imaged surface of Ganymede. Upon completion of the global map, we will review the results with all participating researchers to discuss and reconcile any other discrepancies or issues before finalizing the map.

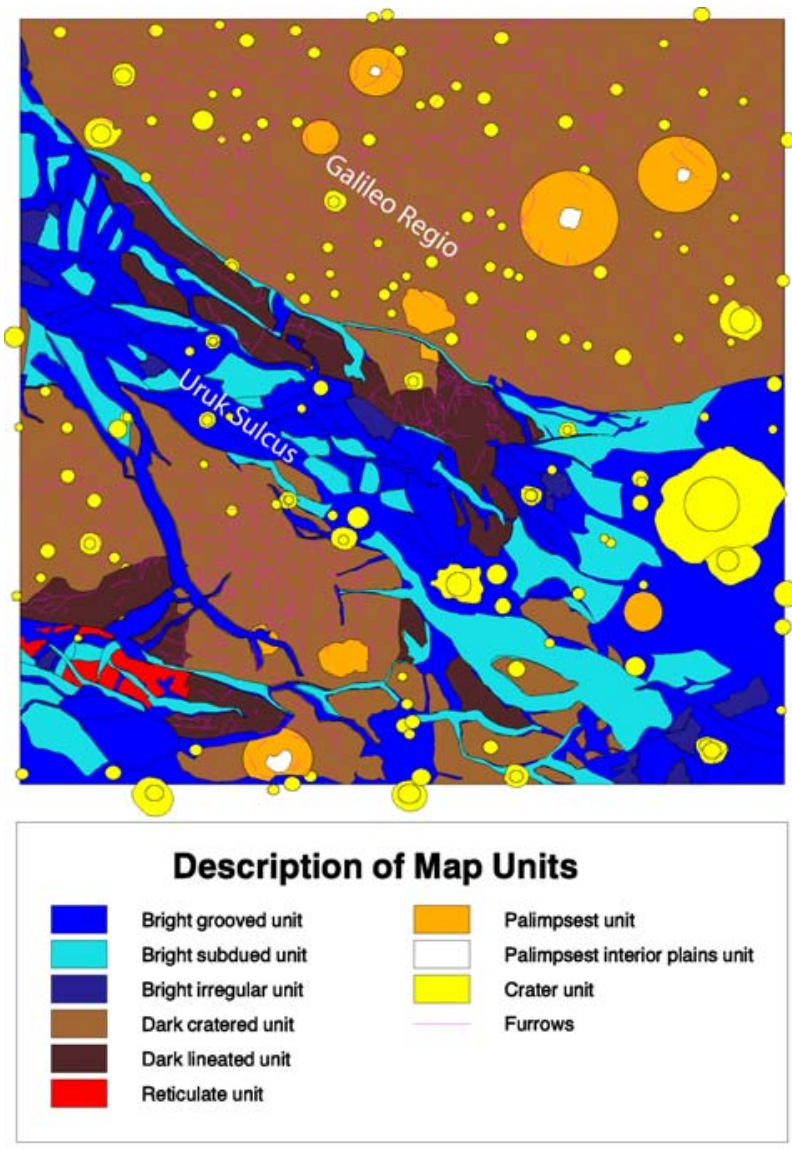

Fig. 1. Preliminary geologic map of Uruk Sulcus region (-30 to $30^{\circ}$ lat. and $115^{\circ}$ to $175^{\circ}$ lon.) utilizing revised DOMU presented here.

References: [1] R. Greeley, The New Solar System, 253262, 1999; [2] R.T. Pappalardo, The New Solar System, 263276, 1999; [3] W.B. McKinnon and E.M. Parmentier, Satellites, 718-763, 1986; [4] G. Schubert et al., Satellites, 224-292, 1986; [5] D.J. Stevenson et al., Satellite, 39-88, 1986; [6] T.V. Johnson, Physics Today, 57, 77-83, 2004; [7] D.J. Stevenson, Physics Today, 57, 43-48, 2004; [8] B.K. Lucchitta, Icarus, 44, 481-501, 1980; [9] E.M. Shoemaker et al., Sats. of Jupiter, 435, 1982; [10] S. Murchie et al., JGR, 91, E222-E238, 1986; [11] R.T. Pappalardo et al., Icarus, 135, 276-302, 1998; [12] L.M. Prockter et al, Icarus, 135, 317, 1998; [13] J.E. Guest et al., USGS Map I-1934, 1988; [14] D.E. Wilhelms, USGS Map I-2242, 1997; [15] B.K. Lucchitta et al., USGS Map I-2289, 1992; [16] G.C. Collins et al., PGG Planetary Mappers Meeting, 2003; [17] G.W. Patterson et al., PGG Planetary Mappers Meeting, 2003; [18] K.B. Jones et al., Icarus, 164, 197-212, 2003. 
GEOLOGIC MAPPING OF IO: UPDATE. D.A. Williams and R. Greeley, Department of Geological Sciences, Arizona State University, Box 871404, Tempe, Arizona, 85287 (David.Williams@asu.edu).

Introduction: On September 21, 2003, NASA's Galileo Mission to Jupiter ended after almost 14 years in space and 35 orbits of Jupiter. As part of the ongoing Galileo data analysis, we have produced three regional geologic maps of selected areas of Io's antijovian hemisphere, which was poorly-imaged by Voyager but well-imaged by Galileo. In this abstract we discuss the third of our three regional maps, covering the Zamama-Thor region, and we discuss our new proposal to produce a global geologic map of Io using combined Galileo and Voyager data.

Mapping the Zamama-Thor Region: The Zamama-Thor region (map, Figure 1) is located in the leading antijovian quadrant between $15-45^{\circ} \mathrm{N}$ and 130 $180^{\circ} \mathrm{W}$. Unlike previously mapped regions, this region contains two sites of large-scale changes that occurred either before or during the Galileo mission. The Zamama eruptive center formed since the Voyager flybys, and has been seen by Galileo to include a hotspot source, an intermittently-active plume, a linear flow field, a bright red diffuse deposit, and a source from two steep shield-like structures [1, 2]. The Thor eruptive center is the source of the largest plume (500 km high, I31, Aug. 2001) seen on Io to date. It was part of a Pillanian-style eruption [3] that produced a dark diffuse unit and a ring of white (but not red) diffuse material. Geologic mapping indicates that 11 geomorphologic material units can be defined and characterized, all variations on five principal materials: plains, patera floors, flows, mountains, and diffuse deposits. The common theme present with all Ionian material units is a complex, intimate interaction between silicate, sulfurous, and probably sulfur dioxide volcanic magmas with silicate- and sulfur-bearing country materials, including the effects of exposure to Io's heavy radiation environment. These interactions produce the broad color palette observed in Io images [4]. These interactions also manifest themselves through volcanic, tectonic, and gradational processes, including the degradation of raised plateaus like that surrounding Reshef Patera by multiple underground magma sources, as evidenced by a forked canyon and several smaller paterae whose floors are covered with dark materials. Our current work involves integrating our mapping analyses with other observations (NIMS, PPR, topographic) to better understand the geologic activity in this region. A manuscript is nearly completed and will be submitted soon. The geologic map of the Culann-Tohil region ( $2^{\text {nd }}$ of 3 maps) was just published [5].

New Proposal: Global Geologic Mapping of Io: We have submitted a new proposal to the NASA Outer Planets Research Program (April 2004) to produce a new global geologic map of Io from combined Galileo and Voyager data. With the recent end of the Galileo
Mission, an era of Io exploration has closed. Integration of the various Galileo data sets (Solid State Imager SSI, Near-Infrared Mapping Spectrometer, NIMS, Photopolarimeter-Radiometer, $P P R$ ) is underway, and the observations from these data sets have profound implications for the nature of Io's interior and surface, and for the development of models of Io's geologic evolution to its present state (e.g., [6]). Global geologic mapping is the one critical missing element that is required for incorporating these new observations to refine our models of Io. The systematic characterization of Ionian surface features and their distribution in time and space is essential for identifying the volcanic and tectonic processes working on and within Io. Consequently, the objectives of this proposal are to produce a new global geologic map of Io and to interpret the surface evolution of the satellite in light of the emerging models for the thermal and structural state of Io's interior. Specifically, this project will include (1) geologic mapping of Io using a new combined Galileo-Voyager photomosaic (in production by the USGS), (2) analysis of surface changes in volcanic activity since Voyager and throughout the course of the Galileo mission (1996-2001) by comparison of integrated Voyager and Galileo SSI, NIMS, and PPR data sets, and (3) development of a GIS-type database of the Voyager and Galileo data sets. Production of this map will permit us to synthesize the current knowledge of the surface of Io, building on the discoveries from the recently completed Galileo Mission. This map will serve as a framework for the continuing analysis of Galileo data, will be a useful tool for correlating ongoing ground-based telescopic observations of Io with known sites of active volcanism, and will be a key element in planning any future spacecraft observations of Io from upcoming missions. At present, the New Horizons/Pluto Jupiter flyby (which includes Io observations) is tentatively scheduled for February 2007, and the next mission specifically to the Jovian system (the Jupiter Icy Moons Orbiter, JIMO) will be developed in the next decade; thus, the proposed map would serve as a critical base for any geological and geophysical investigations of Io in the interim.

References: [1] Keszthelyi et al., JGR 106, 33,02533,052, 2001; [2] Schenk et al., Icar 169, 98-110, 2004; [3] Turtle et al., Icar 169, 3-28, 2004; [4] Geissler et al., Icar 140, 265-282, 1999; [5] Williams et al., Icar 169, 80-97, 2004; [6] Keszthelyi et al., Icar 169, 271-286, 2004.

Figure 1 (next page). Preliminary geomorphologic map of the Zamama-Thor region of Io's antijovian hemisphere. Basemap is the near-terminator I32TERMIN02 mosaic (360 m/pixel). 


\section{Geomorphologic Map of the Zamama-Thor Region of lo}
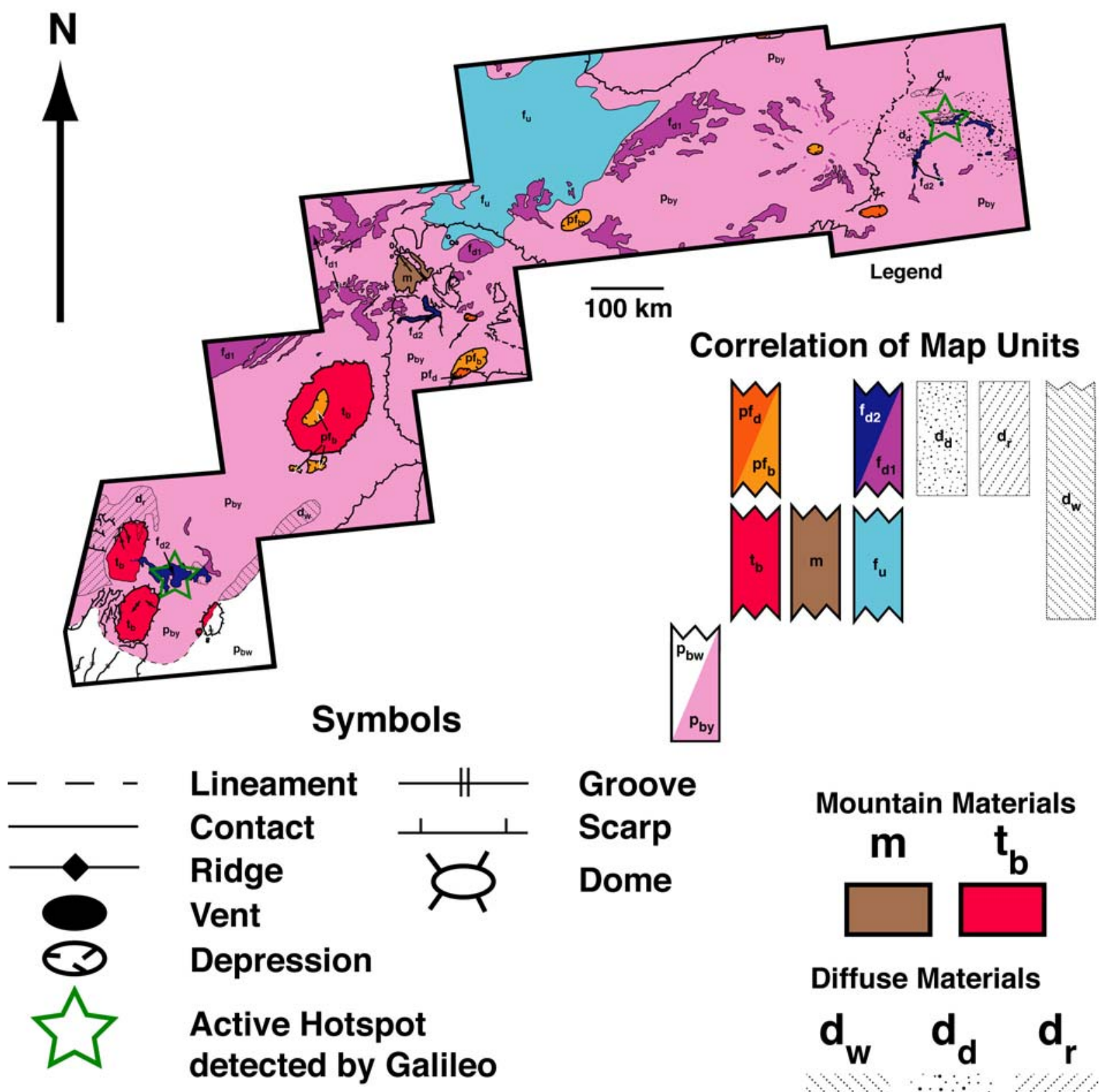

Mountain Materials

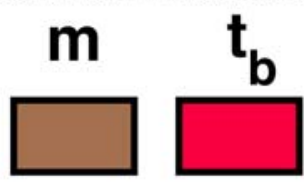

Diffuse Materials<smiles>[AlH]CO[AlH2]</smiles>

Patera Floor Materials Plains Material

Flow Materials
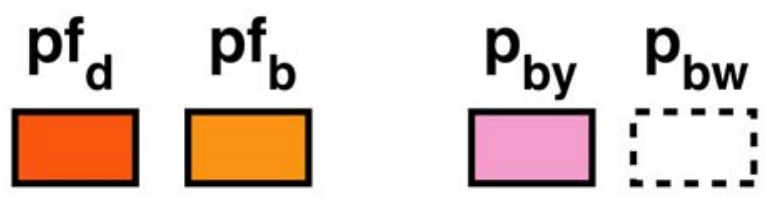

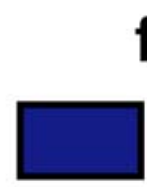

2

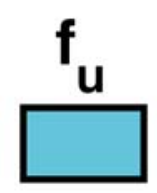


THE LUNAR GEOLOGIC MAPPING PROGRAM: 2004 STATUS. L. Gaddis ${ }^{1}$, K. Tanaka ${ }^{1}$, T. Hare ${ }^{1}$, J. Skinner $^{1}$, B.R. Hawke ${ }^{2}$, M. Staid ${ }^{3}$, P. Spudis ${ }^{4}$, B. Bussey ${ }^{4}$, C. Pieters ${ }^{5}$, and D. Lawrence ${ }^{6},{ }^{1}$ U.S. Geological Survey, Astrogeology Program, 2255 N. Gemini Drive, Flagstaff, AZ (lgaddis@usgs.gov); ${ }^{3}$ PGD/SOEST, Univ. Hawaii, Honolulu, HI; ${ }^{4}$ Johns Hopkins Univ., Baltimore, MD; ${ }^{5}$ Dept. Geological Sciences, Brown Univ., Providence, RI; ${ }^{6}$ Los Alamos National Laboratory, Los Alamos, NM.

Introduction: The NASA-funded Lunar Geologic Mapping Program is underway. This new program for systematic, global lunar geologic mapping will incorporate digital, multi-scale data from a variety of sources. At present, we are defining and testing digital mapping tools and methods for a systematic mapping program to begin in future years. As part of this pilot effort, a 1:2.5 M mapping scale will be used to map a single quad encompassing the Copernicus crater region (Figure 1). Two science tasks are also being pursued as part of this project: (1) a study of the character of the boundary between the Copernican and Eratosthenian time-stratigraphic systems, and (2) spectral classification of mare basalt types.

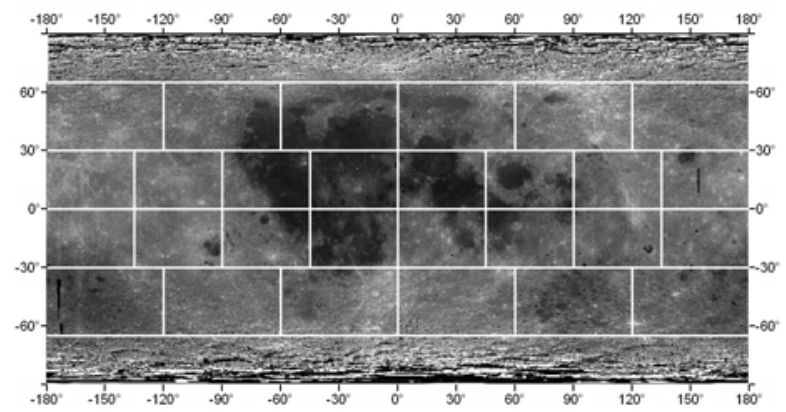

Figure 1. Mapping quad scheme for lunar geologic maps at 1:2.5 M scale. Image base is Clementine 750-nm albedo.

Background: Lunar geologic mapping came of age when the five Lunar Orbiter (LO) missions in 1966 and 1967 provided a photographic image base for the Moon with $\sim 500$ to $1 \mathrm{~m}$ resolutions [1-3]. Forty-four geologic maps at 1:1 $\mathrm{M}$ scale were made from the LO data, followed by 1:5 M near side, north, south, east, west and central far side geologic maps [49].

Shoemaker and Hackman [10] established the foundation for the lunar geologic mapping of the 1960's and 1970's. Well-established stratigraphic methods were applied to the materials observed in and near Copernicus crater ( $90 \mathrm{~km}$ dia.). Copernicus was selected for mapping because (1) state-of-the-art data from Earth and from orbit could be used, (2) it showed the effects of impact cratering and basin formation, volcanism, and tectonic modification, and (3) it provided both young and old units for determination of a local stratigraphic sequence.

Digital Geologic Mapping and Image Bases: A digital mapping approach will be used to map geologic units in the Copernicus quad. Drafting and analysis tools such as the Geographic Information System (GIS) by ESRI ArcView, GRASS, Adobe Photoshop and Illustrator, and Deneba Canvas will be tested and evaluated [11-13] for this project.

We are populating a GIS project with digital lunar image bases. The primary image base for lunar geologic mapping is the controlled Clementine global mosaic of "albedo" at 750-nm [14]. To this base is added the multispectral Clementine UVVIS bands and colorratio data $(\mathrm{R}=750 / 415 ; \mathrm{G}=750 / 950 ; \mathrm{B}=415 / 750)$; NIR data will be added when available. Additional bases include digital LO mosaics [15] and Clementine topography and shaded relief data [16]. Derived maps of Clementine optical maturity, $\mathrm{FeO}$, and $\mathrm{TiO}_{2}$ content [17-23], and LP measured elemental abundance maps [21, 24-28] will also be added. Use of these digital data will support image manipulation and enhancement, and derivation of products such as spectral banddepth maps, slope and image texture maps, densitysliced albedo and color, etc.

Mapping Approach: We are using these digital data to evaluate the use both of rock-stratigraphic units [29, 30] and unconformity-based units (UBUs) [31]. Although the former approach has the weight of history and may be adequate for this new lunar geologic mapping program, the latter approach emphasizes description of unconformable unit boundaries rather than just unit characteristics and has the advantage of emphasizing relative-age information associated with unit contacts. UBU mapping relies on careful delineation of secondary features and textures that may result from much later activity, and results in units that describe geologic events and epochs of regional significance that may include assemblages of diverse lithologies.

Lunar Science: The Copernicus crater region provides an excellent scientific focus for this program of lunar geologic mapping. First, we will incorporate results from an evaluation of the boundary between the Copernican and Eratosthenian systems using Clementine UVVIS soil maturity information. Hawke et al. [32, 33] determined the origin of selected lunar ray segments using Earth-based spectral and radar data as well as Clementine $\mathrm{FeO}, \mathrm{TiO}_{2}$, and optical maturity (OMAT) maps. This study confirmed previous results [34] that some lunar rays are bright because of compositional contrast with the surrounding terrain, the presence of immature material, or some combination of the 
two. The working distinction between the Eratosthenian and Copernican systems is that Copernican craters still have visible rays whereas Eratosthenian-aged craters do not. Compositional rays can persist far longer than $1.1 \mathrm{Ga}$, the currently accepted age of the Copernican-Eratosthenian boundary. Hence, the mere presence of rays is not a reliable indicator of crater age. It is not valid to assign a Copernican age to craters based only on the presence of rays.

We are investigating the use of the OMAT parameter to define the Copernican-Eratosthenian boundary $[32,33,35]$. In particular, we're evaluating the hypothesis of Grier et al. [36] that if the ejecta of Copernicus crater were slightly more mature, it would be indistinguishable from the background in an OMAT image. The commonly accepted age of Copernicus is $\sim 0.8 \mathrm{Ga}[37,38]$, so the saturation of the OMAT index may occur at this age. However, several workers have presented evidence that the Copernicus ejecta blanket is fully mature [e.g., 34]. We're using the OMAT data, integrated with Clementine multispectral and topographic data and LP compositional data, to examine the apparent maturity of Copernican-age craters and to evaluate the possibility of redefining the $\mathrm{C} / \mathrm{E}$ boundary. If the hypothesis of Grier et al. [36] is confirmed, it may be possible to use the radiometric ages of exotic materials from the Apollo 12 site to date the $\mathrm{C} / \mathrm{E}$ boundary since a ray from Copernicus crosses the site. These analyses will be incorporated into a geologic mapping effort for the Copernicus quad. Results will help to constrain the assignment of relative ages (and absolute ages in some cases) to lunar geologic units using the new global, remote sensing data.

The second science component of our lunar mapping project is the classification of mare basalt types using Clementine UVVIS and NIR data. We are pursuing an approach that allows objective classification of mare composition, maturity, and highland contamination based on a multiple endmember spectral mixture analysis (MESMA) [39]. This technique was applied to Clementine UVVIS data to map surface compositions using large spectral reference libraries while limiting the number of materials used to model each location [40]. For this study, Clementine UVVIS and NIR images were merged to produce 9-band reflectance cubes from 0.41 to $2.0 \mathrm{~m}$ based on the most recent global calibrations [14, 41, 42]. A large spectral library was created by including optically mature soils and unweathered crater materials from a range of lunar mare and highland materials as a function of their maturities. The MESMA algorithm was then used to identify the best 3 or 4 endmember solution for each location in terms of the \% abundance of materials such as mature mare soils, fresh mare crater materials, and foreign mare or highland components. The result- ing abundance maps will be further processed using statistical and spatial classifiers before converting results into vectorized maps of spectrally defined lunar units in terms of their interpreted composition and maturity. Results will help to facilitate the identification of mare basalt types, impact melts, exhumed materials (such as olivine) and highland contamination effects in the Copernicus quad.

Summary: The major product of this work is a renewed, reinvigorated lunar geologic mapping program. This program will take advantage of new data and new integrative analysis methods to advance the science of lunar geology. Products will include a systematic lunar mapping scheme, a tested method for formatting and releasing digital lunar map bases, geologic maps for two lunar quads (submitted for publication as USGS I-maps), and a draft lunar geologic mappers' handbook with recommendations on the integration of information such as spectral color, chemistry, mineralogy, elevation, morphology etc. in interpretation of lunar geologic map units.

References: [1] Hansen, 1970, NASA SP-242. [2] Kosofsky and El-baz, 1970, NASA SP-200. [3] Bowker and Hughes, 1971, NASA SP-206. [4] Wilhelms and McCauley, 1971, USGS I-703. [5] Lucchitta, 1978, USGS I-1062. [6] Wilhelms et al., 1979, USGS I-1162. [7] Wilhelms and Elbaz, 1977, USGS I-946. [8] Scott et al., 1977, USGS I-1034. [9] Stuart-Alexander, 1978, USGS I-1047. [10] Shoemaker and Hackman, 1962, Symp. 14 IAU, 289-300. [11] Hare and Tanaka, 2001a, LPS XXXII, \#1725. [12] Hare and Tanaka, 2001b, Plan. Mappers Mtg, Albuquerque, NM. [13] Hare et al., 2003 ISPRS 2003, LPI. [14] Eliason et al., 1999, LPS XXX, \#1933. [15] Becker et al., 2004, LPS XXXV, \#1791. [16] Rosiek et al., 2002, LPS XXXIII, \#1792. [17] Lucey et al., 1995, Science 268, 1150. [18] Lucey et al., 1998, JGR 103, 3679-3699. [19] Lucey et al., 2000a, JGR 105, 20,29720,305. [20] Lucey et al., 2000b, JGR 105, 20,377-20,386. [21] Lawrence et al., 2002, JGR 107, 2001JE001530, 13-1 to 13-26. [22] Elphic et al., 2000, JGR 105, 20,333-20,346. [23] Gillis et al., 2003, JGR 108, 3-1 to 3-18. [24] Lawrence et al., 1998, Science 281, 1484-1489. [25] Lawrence et al., 2000, JGR 105, 20,307-20,332. [26] Prettyman et al., 2002a, LPS XXX, \#2012. [27] Prettyman et al., 2002b, Moon Beyond 2002, Taos, N.M., \#3069. [28] Feldman et al., 2002, JGR 107, E3. [29] Wilhelms, 1972, USGS Int. Report: Astrogeology 55, 36 pp. [30] Wilhelms, 1987 USGS Prof. Paper 1348, 302 pp. [31] Skinner and Tanaka, 2003, LPS XXXIV, \#2100. [32] Hawke et al., 2004a, LPS XXXV, \#1477. [33] Hawke et al., 2004b, Icarus, in press. [34] Pieters et al., 1985, JGR 90, 12393. [35] Hawke et al., 1999, New Views of the Moon II, \#8035. [36] Grier et al., 2001, JGR 107, E3, 10.1029/2001JE001506. [37] Bogard et al., 1994, GCA 58, 3093-3100. [38] Stoffler and Ryder, 2001, Sp. Sci. Rev. 96, 9-54. [39] Roberts et al., 1998, Rem. Sens. Env. 65, 267. [40] Li and Mustard, 2003, JGR 108 (E6), 5053. [41] Eliason et al., 2003, LPS XXXIV, \#2093. [42] Staid et al., 2004, http://astrogeology.usgs.gov/Projects/ClementineNIR. 
MARTIAN IMPACT CRATER RESOURCES FOR PLANETARY MAPPERS. N. G. Barlow ${ }^{1}$ and the Mars Crater Consortium, ${ }^{1}$ Dept. Physics and Astronomy, NAU Box 6010, Northern Arizona University, Flagstaff, AZ 86011-6010, Nadine.Barlow@nau.edu.

Introduction: Impact craters are important features for planetary mappers because they provide constraints on the ages of planetary surfaces [1, 2, 3], insights on erosional/depositional processes operating in the area [4, 5], and information about target properties and/or atmospheric conditions at the time of crater formation [6, 7]. New imaging, compositional, thermophysical, and topographic data from the Mars Global Surveyor and Mars Odyssey missions have greatly extended the amount of information about Martian impact craters. The Mars Crater Consortium is working to provide Martian impact crater data in an updated and easily accessible format for the entire planetary community.

Mars Crater Consortium: The Mars Crater Consortium (MCC) was founded in 1997 by Joe Boyce, David Roddy, and Nadine Barlow to discuss the potential value of merging the numerous crater datasets derived from Viking analysis, identify necessary data still to be collected, and encourage research collaborations on problems related to Martian impact craters. Researchers interested in any aspect of Martian impact cratering (geologic/geomorphic analysis, computational or experimental studies, or terrestrial analog studies) are welcome to participate in the MCC. Since 1998, the MCC has held annual meetings at the US Geological Survey in Flagstaff where discussions include research reports, demonstrations of new software and data analysis tools, nomenclature standards [8], and future workshops. More details about the MCC can be found at www.marscraterconsortium.nau.edu.

Martian Crater Databases: A primary reference source for Martian impact craters 5-km-diameter has been Barlow's Catalog of Large Martian Impact Craters, compiled from the Viking 1:2,000,000 photomosaic series in the 1980's. The Catalog consists of size, location, and geomorphic information on 42,283 impact craters distributed across the entire Martian surface. The Catalog is currently being revised with Mars Global Surveyor (MGS) and Mars Odyssey (MO) data [9]. Ejecta and interior morphologies are being revised, crater latitude and longitude values are being updated to the MOLA-based MDIM 2.1 coordinate system, a new numbering system is being instituted, a new preservation system has been developed [10], and thermal inertia and MOLA-derived morphometric information are being added. Completion of the revision is expected by December 2004.
The revised Catalog ("Catalog 2.0") will be accessible to the planetary community in two formats. An on-line Geographic Information System (GIS)-based format will be available through the USGS's Planetary Interactive GIS on-the-Web Analyzable Database (PIGWAD) system [11, 12]. Catalog 2.0 will serve as the primary dataset for this GIS crater inventory, but crater databases compiled by other researchers will be integrated into the system to provide the most complete crater inventory available for Mars. At the present time, the following crater datasets are included in this effort: Barlow's Catalog of Large Martian Impact Craters (version 1.0), Boyce's compilation of onset diameters for rampart and non-rampart layered ejecta craters [13], Roddy's morphometric database of interior and ejecta features associated with 4300 craters in the western hemisphere of Mars [14], Kuzmin's inventory of "fluidized" versus "dry" ejecta morphologies [15], and Costard's listing of craters displaying layered ejecta morphologies [16]. We anticipate acquiring the MOLA-based morphometric datasets by Garvin et al. [17] and Mouginis-Mark and Boyce [18] in the near future. New crater compilations can be added to the integrated crater inventory through submission to the MCC, who will review all submissions for format consistency and applicability of content.

Researchers requiring a non-GIS version of Cata$\log 2.0$ can request a dBase or ASCII copy from Nadine Barlow (Nadine.Barlow@nau.edu).

GIS-Based Crater Analysis Tools: Ken Tanaka, Trent Hare, and Nadine Barlow are developing GISbased analysis tools to be used with the integrated crater inventory. The tools being developed will (1) ingest MOLA DEM and rectified MOC NA and THEMIS VIS and IR images, (2) measure crater diameters and other distances, (3) measure areas of outlined features and study areas, (4) permit work in any projection, but calculate areas using equal-area projections for accurate area calculations and geodetic distances, (5) develop and maintain focused projects involving multiple contributors, (6) fine-tune registration of image data, (7) stretch image data in both gray scale and color to improve visualization, (8) select spectral bands (for TES and THEMIS data) and display using RGB channels, (9) create customized feature-label legends that help users discriminate feature attributes, (10) produce spreadsheets of various attributes, measurements, calculated parameters (e.g., lobateness values, ejecta mobility ratios), and customized statistics 
produced by geospatial analysis of crater features and other gridded or vector datasets, (11) generate crater density plots in standard cumulative, incremental, and relative formats, and (12) operate automatic crater recognition techniques when such techniques become mature. The MCC recommends the software tools to be developed and tests the resulting products before they are released to the entire planetary community. An example of such a tool is shown in Figure 1.

Summary: Members of the Mars Crater Consortium are actively compiling Martian impact crater data for distribution to the planetary community. Efforts to make these data available through an on-line GISbased system are maturing and development of on-line crater data analysis tools is proceeding.

References: [1] Tanaka K. L. (1986) PLPSC $16^{\text {th }}$, in JGR, 91, E139-E158. [2] Barlow N. G. (1988), Icarus, 75, 285-305. [3] Hartmann W. K. and Neukum G. (2001) Space Sci. Rev., 96, 165-194. [4] Grant
J. A. and Schultz P. H. (1993) JGR, 98, 11025-11042. [5] Craddock R. A. and Howard A. D. (2002) JGR, 107, 10.1029/2001JE001505. [6] Barnouin-Jha O. S. et al. (1999) JGR, 104, 27117-27131. [7] Stewart S. T. et al. (2001) LPS XXXII, Abstract \#2092. [8] Barlow N. G. et al. (2000) JGR, 105, 26733-26738. [9] Barlow N. G. (2003) $6^{\text {th }}$ Intern. Conf. on Mars, Abstract \#3073. [10] Barlow N. G. (2004) GRL, 31, 10.1029/2003GL019075. [11] Hare T. M. and Tanaka K. L. (2004) LPS XXXV, Abstract \#1765. [12] Barlow N. G. et al. (2003) ISPRS WG IV/9: Extraterrestrial Mapping Workshop, Advances in Planetary Mapping 2003, LPI, Houston. [13] Boyce J. M. et al. (2000) LPS XXXI, Abstract \#1167. [14] Roddy D. J. et al. (1986) LPS XVII, 718-719. [15] Kuzmin R. O. et al. (1988), Solar System Res., 22, 121-133. [16] Costard F. M. (1989) Earth, Moon, \& Planets. 45, 265-290. [17] Garvin J. B. et al. (2003) $6^{\text {th }}$ Intern. Conf. on Mars, Abstract \#3277. [18] Mouginis-Mark P. J. et al. (2004) submitted to JGR.

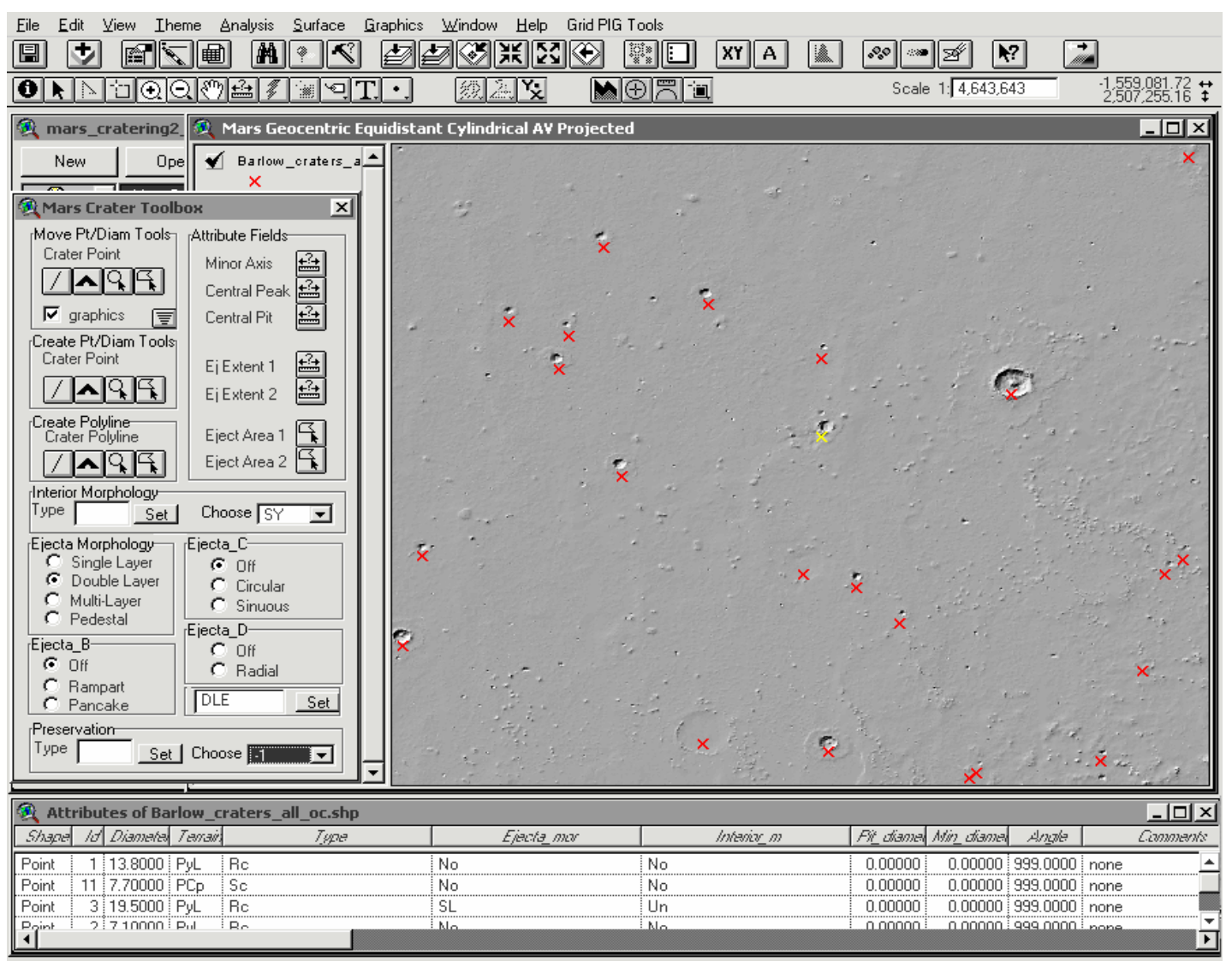

Figure 1: Example of the types of tools being developed to assist in Martian crater analysis. This toolbox shows features which are being used to revise the Barlow crater catalog. This interface can be customized to meet the needs of each user. 
GEOLOGIC MAPPING IN THE HELLAS REGION OF MARS. David A. Crown ${ }^{l}$ and Scott C. Mest ${ }^{2,3}$, ${ }^{1}$ Planetary Science Institute, 1700 E. Ft. Lowell Rd., Suite 106, Tucson, AZ, 85719, ${ }^{2}$ Department of Geology and Planetary Science, University of Pittsburgh, Pittsburgh, PA $15260,{ }^{3}$ Geodynamics, NASA Goddard Space Flight Center, Greenbelt, MD 20771, crown@psi.edu and smest@kasei.gsfc.nasa.gov.

\section{Introduction:}

Geologic mapping studies with Viking Orbiter, Mars Global Surveyor (MOC and MOLA), and Mars Odyssey (THEMIS) data sets are being used to characterize ancient highland terrains surrounding the Hellas impact basin and their modification through Martian history. Scientific objectives include identifying sequences and styles of highland degradation, documenting highland stratigraphy, and providing constraints on volatile inventories and climatic conditions. The current work focuses on two Mars Transverse Mercator (MTM) quadrangles, 20272 and -25272 , in the Tyrrhena Terra region of Mars north of Hellas basin, and three Mars Transverse Mercator (MTM) quadrangles, -35237, 40237, and -45237, in southeast Hesperia Planum east of Hellas basin. The current MTM quadrangle mapping is part of a larger and ongoing effort to explore the geologic history of the Hellas region of Mars. Imaging datasets at a variety of resolutions, thermophysical properties from THEMIS daytime and nighttime images, and topographic characterization using both MOLA DEMs and PEDR profiles are being integrated to assess Martian surface geology and define and describe map units.

\section{Geologic Mapping of Tyrrhena Terra:}

Geologic mapping of MTM quadrangles -20272 and -25272 reveals a surface that has undergone significant modification by impact, fluvial, and eolian processes $[1$; map status: map has been revised following peer review and has undergone subsequent map coordinator review]. Most of the materials mapped are ancient, from the Middle Noachian to Early Hesperian Epochs. Only surficial deposits such as dune material and talus, which have very limited exposure, show evidence for activity in the Amazonian Period.

Dominant events in the geologic development of this area include the formation of Hellas basin and large impact craters early in Mars' history. During the Early and Middle Noachian Epochs, widespread intercrater plains formed by accumulation of some combination of sedimentary (fluvial and eolian), volcanic (may include flow sequences and (or) pyroclastic deposits), and impact-related materials. The materials composing the plains are layered but not consistently so across the highlands in the map area. The lack of evidence for volcanic flow features and the eroded nature of the plains suggests the uppermost layers are dominated by sedimentary and impact deposits.

Fluvial processes shaped the intercrater plains, forming well incised networks of valleys and degrading plains surfaces. As fluvial activity waned, numerous impacts continued to affect Tyrrhena Terra; evidence for this is shown by craters that truncate and (or) bury valley segments. Craters do not appear to have caused redirection of flow or ponding of water indicating there was little to no flow within these channels following cratering. Variation in valley widths and depths along valley lengths, which is uncharacteristic of sapping valleys, and the fact that several valleys head near crater rim crests, suggest a significant component of surface runoff not derived from groundwater was involved, such as from direct precipitation or water derived from melting snow or ice. High infiltration rates presumably characterize the surface and near-surface materials, and the formation of valley segments likely includes a combination of sapping and runoff processes, with larger valley segments shaped in runoff dominated phases or as greater volumes of groundwater collected in the surface drainage system.

Impact craters in the region show degraded morphologies, such as eroded ejecta blankets and rims, as well as interior walls incised with numerous gullies and floors containing deposits of relatively smooth fill material. Sedimentation within Millochau crater appears to be related in part to erosion of the interior crater rim by numerous gullies, but may also include contributions from eolian and lacustrine activity [2]. The Late Noachian and Early Hesperian Epochs also included emplacement of smooth plateau material in the southeast corner of the map area. Valley floor materials, believed to consist of materials eroded from the highlands and deposited in the channels via fluvial and eolian processes, show dune-forms in high-resolution MOC images, suggesting that they are composed of easily mobilized material. Sources of fine-grained sediment could include material deposited by the valley networks that characterize the area, ejecta of several large and fairly young impact craters, and material blown from Hellas basin and the surrounding highlands. 


\section{Geologic Mapping of Southeast Hesperia Planum:}

MTM quadrangles $-35237,-40237$, and -45237 include the eastern part of the highlands of Promethei Terra, the ridged plains of southeast Hesperia Planum, Arrhenius crater, and knobby plains [3]. A preliminary geologic map has been completed using Viking Orbiter and MOC images. Current work focuses on integrating THEMIS visible and infrared images and MOLA topographic datasets. Geologic units identified can be divided into four major categories: highland materials (mountainous material, cratered-plateau material, basin-rim unit), plains materials (ridged plains material, knobby plains material), crater materials (well preserved, moderately degraded, and highly degraded material and crater floor material), and surficial materials (debris apron material). Mapped structures include scarps, ridges, channels, and crater rim crests.

Numerous large impact craters that display a range of preservation states are observed. Many craters have prominent rims, well-defined ejecta blankets and rugged floors, whereas others are extensively degraded and exhibit low-relief morphologies, gullied rims, and filled interiors. Many craters have complex interiors; crater floors contain smooth, lineated, and pitted regions, as well as display central peaks, mounds, and lobate features. Many craters in the region show well-developed gullies on their interior rims along with associated debris forming aprons/fans that extend to the crater floor. Gullies are observed to start at different heights along crater rims and are typically, but not exclusively, found on pole-facing slopes. Intercrater regions of the cratered plateau and basin-rim units exhibit small channels and gullies. Lobate debris aprons extend from some highland massifs.

Within some craters interiors as well as within the highlands in the southern part of the map area, dark and mottled albedo areas, some with lobate margins, are evident in Viking Orbiter images. A similar observation was made by Mest and Crown [4] south of Reull Vallis. In MOC images, these deposits appear to be some type of blocky lag deposit that may indicate a geographically or latitudinally distinct style of surface degradation, which may or may not be related to the proposed ice-cemented mantle described by other researchers. In THEMIS nighttime images, the deposits in crater interiors appear as prominent bright zones.

Large expanses of ridged and knobby plains cover low-lying regions adjacent to cratered highlands. Ridged plains exhibit prominent orthogonal ridge trends characteristic of Hesperia
Planum as well as numerous ridge rings. Ridged plains occur primarily in two exposures, at elevations of $\sim 700$ and $\sim 1100 \mathrm{~m}$. Ridged plains display smooth and pitted surfaces, rampart craters, channels, and scarps, some of which appear to be structural and others that appear to be lobe margins. In MOC images, the channels are seen to be fluvial features incised in the surface surrounded by lateral zones of surface erosion. Along with the upper reaches of Reull Vallis to the west, these channels reflect significant drainage from Hesperia Planum to the south.

Greeley and Guest [5] identified knobby plains adjacent to the crater Arrhenius and interpreted the knobs to be erosional remnants of a more extensive unit, although a volcanic origin for some of the knobs was not ruled out. In the map area, knobby plains are more extensive than mapped previously. Knobby plains are concentrated in low-lying regions (at elevations between $\sim 500$ and $1000 \mathrm{~m}$ ) but are not found in all low areas. Knobby surfaces are found superposed on ridged plains, within crater ejecta, and in crater interiors, and a gradational contact between knobby and ridged plains is evident. A complex local stratigraphy is suggested by relationships between knobs, pedestal craters, and layering within plains units. Individual knobs vary in size, shape, and spacing. Most knobs are equant to irregular with flat, rounded, or pitted upper surfaces. Knobs occur in clusters, some of which exhibit linear to curvilinear patterns, and are associated with pedestal craters, buried craters, and buried wrinkle ridges.

Ongoing analyses as part of geologic mapping of MTM quadrangles $-35237,-40237$, and -45237 include morphologic and statistical analyses of knobs, examination of layering within and thicknesses of plains units, studies of crater modification, and use of crater populations to constrain stratigraphic ages and assess elevation- or age-dependencies.

References: [1] Mest, SC and DA Crown, Geologic map of MTM -20272 and -25272 quadrangles, US Geol Surv, in review, 2003. [2] Mest, SC and DA Crown, Geologic analysis of Crater Millochau, Mars, Icarus, in review. [3] Crown, DA and SC Mest, Geologic map of MTM -35237, -40237, and -45237 quadrangles, US Geol Surv, in prep, 2003. [4] Mest, SC and DA Crown, Icarus, 153, 2001. [5] Greeley, $\mathrm{R}$ and JE Guest, US Geol Surv Misc Inv Ser Map I1802B, 1987. 
MTM QUADRANGLES -15257 \& -20257: WESTERN HESPERIA PLANUM, MARS. Melissa A. Farley and Tracy K.P. Gregg, both at Dept. of Geology, 876 Natural Sciences Complex, University at Buffalo, Buffalo, NY 14260-3050. Email: mafarley@acsu.buffalo.edu; tgregg@geology.buffalo.edu, and David A. Crown, Planetary Science Institute, Tucson, AZ, dcrown@psi.edu

Introduction: Hesperia Planum, Mars, plays two significant roles in Martian geology and stratigraphy. First, it is considered to be the type location for Martian ridged plains [1]; second, its crater size-frequency distribution marks the base of the Hesperian system [2]. Tyrrhena Patera is a low-lying volcano located within the western portion of Hesperia Planum. Detailed investigations of the summit region [3] agree with earlier, more regional studies [4], suggesting that Tyrrhena Patera shield materials are most likely composed of pyroclastic deposits. The most recent materials erupted at Tyrrhena Patera, however, appear to be lava flows associated with a large ( 1000 km x $250 \mathrm{~km})$ lava flow field to the southwest of the summit [5]. Geologic mapping and impact crater statistics [3] revealed that regions previously mapped as Hesperia Planum [2] in fact are either older Tyrrhena Patera shield materials or Amazonian-aged lava flows.

The interest in MTM Quadrangles -15257 and 20257 (Figure 1) is the contact between what was considered to be Hesperia Planum materials $[1,3]$ and the Noachian-aged highlands to the west. Using MOLA, MOC, and THEMIS data in conjunction with Viking Orbiter images, we have identified three key results from photogeologic mapping. First, Tyrrhena Patera shield materials extend all the way to the Noachian-aged highlands west of Hesperia Planum. This implies that the Tyrrhena Patera shield materials are likely the result of pyroclastic flows, because no lava flows have been identified and, given Mars' current atmosphere, airfall deposits are unlikely to have reached more than a few tens of kilometers from the summit [4]. Second, no lava-flow features or volcanic source vents have been identified within Hesperia Planum materials, suggesting that these Martian ridged plains may not be flood lavas after all. Third, THEMIS data in particular (both thermal and visible) reveals much more fluvial erosion in this region than was visible in Viking Orbiter and MOLA data.

Tyrrhena Patera shield materials: Dissected shield materials surround Tyrrhena Patera. Mapping reveals that these materials extend at least as far as $700 \mathrm{~km}$ northwest of the summit region. Shield materials are characterized by a smooth to mottled surface, typically bound by steep, erosional scarps. However, as distance from the summit region increases, the bounding scarps become shallower and more difficult to identify (Figure 2). The scarps are interpreted to be eroded eruptive or cooling units of pyroclastic flows erupted from Tyrrhena Patera. Mapping reveals that west of the Tyrrhena Patera summit, shield materials embay the Noachian highlands to the west.

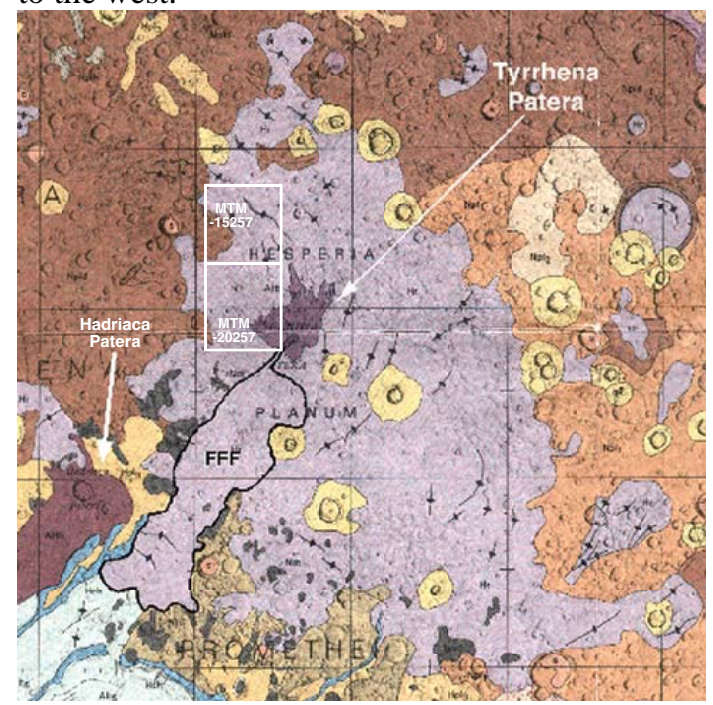

Figure 1. MTM Quadrangles -20257 and 15257 (white boxes) on the 1:15M geologic map of Mars [1]. The lavender color indicates Martian ridged plains; the deep purple is Tyrrhena Patera. An Amazonian-aged lava flow field (outlined in black and labeled "FFF"), erupted from Tyrrhena Patera, is also shown.

Hesperia Planum: Previous 1:500K mapping of the Tyrrhena Patera summit region [3] indicated a region north of the summit caldera complex that was identified as "ridged and etched plains." These materials are also found in MTM Quadrangle -20257. THEMIS images (both visible and thermal) reveal that this unit is actually comprised of interfingered plains materials, some of which appear to be variably eroded shield materials erupted from Tyrrhena Patera. Other portions appear to be lobate flow deposits, originating somewhere north of Tyrrhena Patera and flowing southwards to embay the shield materials. (Figure 3). We are currently investigating these lobate deposits to 
determine their nature and origin. A sedimentary origin seems more likely than a volcanic one at present, because we have not yet been able to identify any volcanic vents north of Tyrrhena Patera.
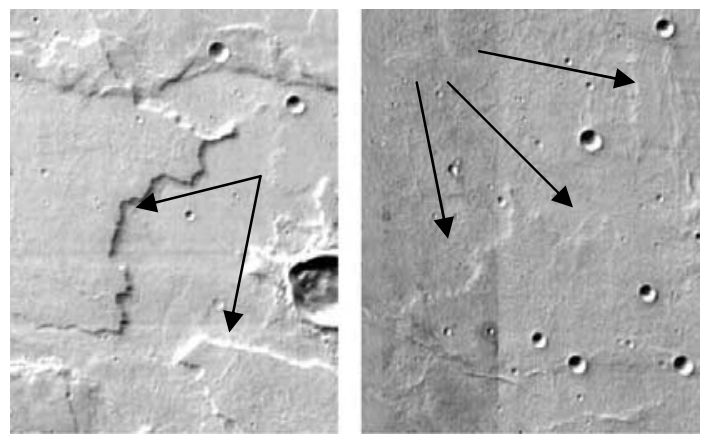

Figure 2. THEMIS daytime infrared images I04129002 (left) and I04204002 (right) showing scarps (arrows) within Tyrrhena Patera shield materials. Left image, with steep, welldefined scarps, is $\sim 150 \mathrm{~km}$ northwest of Tyrrhena Patera summit; right image with less obvious scarps, is $\sim 330 \mathrm{~km}$ NW from summit. Each image is $\sim 30 \mathrm{~km}$ wide; north is at the top.

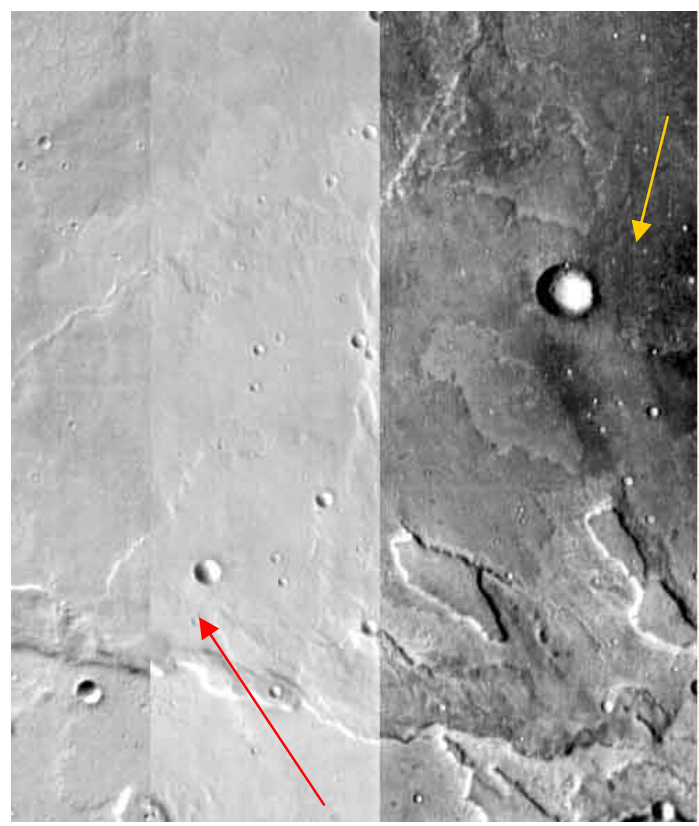

Figure 3. THEMIS daytime infrared mosaic (I00821002, I07486017, and I04129002) of plains $150 \mathrm{~km}$ northwest of Tyrrhena Patera summit; north is at the top and mosaic is $\sim 45 \mathrm{~km}$ wide. Yellow arrow shows flow direction of dark, lobate deposit from the north; red arrow shows flow direction of channel-fill deposits from the Tyrrhena Patera summit region.
Channels and Erosion: THEMIS data have revealed many more channels and erosional features than were visible in Viking Orbiter images. A region northwest of the Tyrrhena Patera summit, which we informally termed "peanut-butter cookie terrain” (Figure 4), can now be interpreted to be erosional remnants of Tyrrhena Patera shield materials. The nature of the erosion remains under investigation.

Channel heads here are morphologically similar to terrestrial sapping channels [5], and the overall orthogonal pattern suggests strong structural control. The floors of these channels are covered with channel-parallel striations, and are locally bound by a straight ledge that follows the mesas (Figure 4). We are still trying to determine if the erosive agent here was (or is) water, ice, or some other volatile.

THEMIS images also display a number of geologic units found on the floors of the channels surrounding Tyrrhena Patera. The youngest unit appears to be a smooth, infilling deposit. Other units are interpreted to be variably dissected and gullied outcrops of Tyrrhena Patera shield materials.

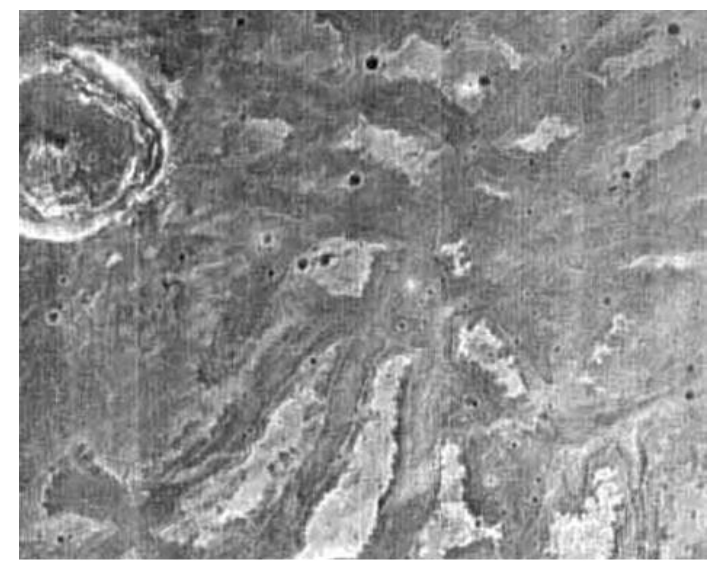

Figure 4. THEMIS nighttime infrared mosaic (I06407014 and I06045006). "Peanut butter cookie terrain" with orthogonal channels and channel-parallel striations on floors. Image width is $\sim 35 \mathrm{~km}$.

References: [1] Greeley, R. and J.E. Guest, 1982, USGS Misc. Inv. Series I-1802-B, 1:15M. [2] Tanaka, K., 1986, J. Geophys. Res. 91:E139-E158; Tanaka, K., et al., 1992, in Mars, Arizona State University Press, Tucson, AZ. [3] Gregg, T.K.P., D.A. Crown and R. Greeley, 1998, USGS Misc. Inv. Series I-2556, 1:500K. [4] Glaze, L.S. and S. Baloga, 2001, J. Geophys. Res. 107, 10.1029/2001JE001830. [5] Laity, J.E. and M.C. Malin, 1985, Geol. Soc. Amer. Bull. 96:203-217. 
1:500,000 GEOMORPHIC MAPPING OF SOUTHEASTERN MARGARITIFER SINUS, MARS II: GEOLOGIC EVOLUTION IN MTMS-20012 AND -25012. C.M. Fortezzo and J.A. Grant ${ }^{1},{ }^{1}$ Center for Earth and Planetary Studies, National Air and Space Museum, Smithsonian Institution, Washington, D.C. 20013-7012, fortezzoc@nasm.si.edu.

Introduction. Geologic mapping of MTMs 20012 and -25012 within the Margaritifer Sinus region $(0-45 \mathrm{~W}, 0-30 \mathrm{~S})[1-4]$ at $1: 500,000$ continues (Figure 1). This work builds on neighboring maps [5,6], and includes the definition of drainage basin morphometry and hypsometry. Results indicate regional modification by an extended period of fluvial processes associated with precipitation-recharged groundwater sapping [1-4] focused toward the Chryse trough $[7,8]$. On the western flank of the trough, the Uzboi-LadonMargaritifer (ULM) system flows northward, draining $11 \times 10^{6} \mathrm{~km}^{2}$ or $\sim 9 \%$ of the Martian surface [7]. The ULM system incised and infilled the terrain as it crossed relief associated with the ancient multiringed impact basin $[8,9]$. The signature of the ULM drainage system on topography is pronounced in MOLA data of the region (Figure 1). By contrast, the Samara and Paraná-Loire Valles valley networks on the eastern flank of the trough are two of the most well integrated valley systems on Mars [1]. They drain more than $540,000 \mathrm{~km}^{2}$, or $\sim 0.5 \%$ of Mars. All drainages within the Margaritifer Sinus were active from the Late Noachian to the Mid-Hesperian, and resulted in storage and subsequent release of water from Margaritifer basin at the head of Ares Vallis [2] (Figure 1).

Geologic History of Margaritifer Sinus. The geologic history of this region is discussed at length by [1-3] and is summarized here. Previous mapping at $1: 2,000,000$ and $1: 500,000[2,5,6]$ determined that the Ladon and Holden impact basins [8,9] are the oldest features in Margaritifer Sinus. Three subsequent resurfacing events in the Noachian deposited competent materials that may be volcanic or of sedimentary origin [3].

During the Late Noachian and the Early Hesperian, segments of the ULM system and other valleys in the area were incised and low-lying areas were infilled. Channel and valley formation in this region coincided with increased geomorphic activity elsewhere on Mars [1-3,11]. Later, in the Early to Mid-Hesperian (N5 ages of 200 to 70), a localized resurfacing event emplaced material that embays all valleys and channels (Figure 2).

The ULM, Samara and Paraná-Loire systems all discharge into Margaritifer basin, a depositional plain lying $\sim 2 \mathrm{~km}$ below the MOLA datum. Smooth plains that embay most adjacent surfaces (except those cut by chaos or buried by materials emplaced during the fourth resurfacing event) characterize the

\section{MOLA Topography of ULM System Contour Interval is $1.0 \mathrm{Km}$}

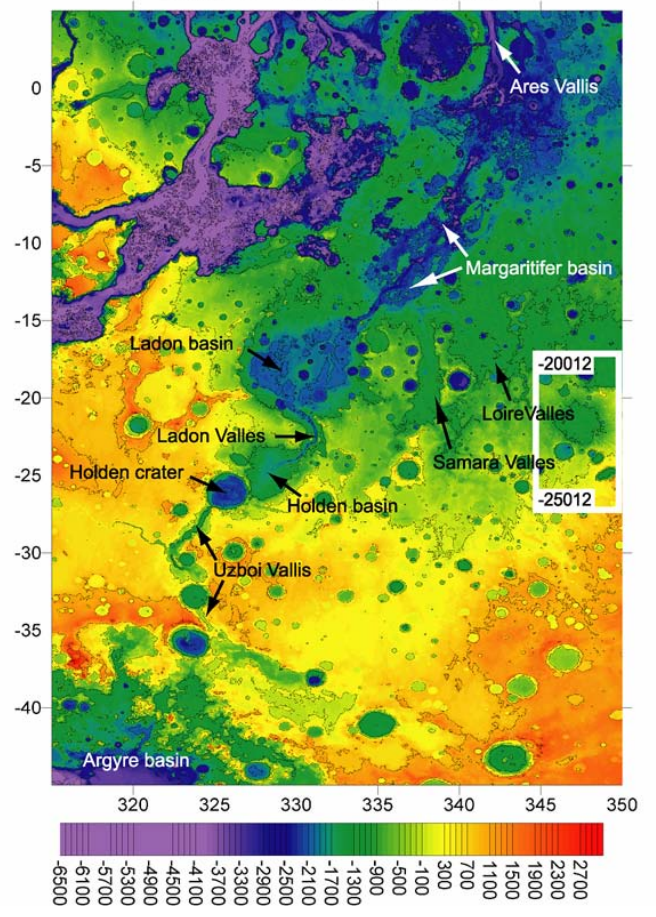

Figure 1. MOLA topography in Margaritifer Sinus. White box shows the location of the mapping area.

depositional floor of the basin and the northeastern extent is indistinct due to collapse of Margaritifer and Iani Chaos. Nevertheless, the plain extends at least to the head of Ares Vallis and maybe well beyond [2]. It is likely that discharge into Margaritifer basin resulted in considerable ponding, subsurface infiltration and storage of water [2].

Collapse within and adjacent to Margaritifer basin and formation of Margaritifer and Iani Chaos began shortly after cessation of channel and valley formation in the Early to Middle Hesperian and likely released the stored water thereby causing incisement of Ares Vallis. Hence, it appears that formation of Ares Vallis was the final stage in a long history of repeated water collection, transport, storage and discharge in the Margaritifer Sinus region.

Mapping of MTM -20012 and -25012. THEMIS IR images in combination with Viking MDIM 2.1 (Figure 2) are used to constrain the contacts and interpret features of this area. Erosional and depositional features related to fluvial activity and volcanism are dominant in this area although impacts, chaotic terrain, gravity driven erosion 
processes and eolian processes are also important contributors to the geomorphology of the area.

The Paraná Valles multidigitate valley network flowed east-west into the ancient impact basin (Paraná basin) but is truncated on the west by a later resurfacing event and chaotic terrain. Loire Valles heads at the western edge of the chaotic terrain and forms a well integrated valley trending westnorthwest to the western edge of the mapping area. Paraná basin has a number of valleys flowing into it from its circumference but Loire Valles is the only outlet. Interestingly, within the Loire Valles there are multiple channels flowing back to the east (Figure 2a), indicating that Loire Valles may have flowed into the basin at some point in the past.

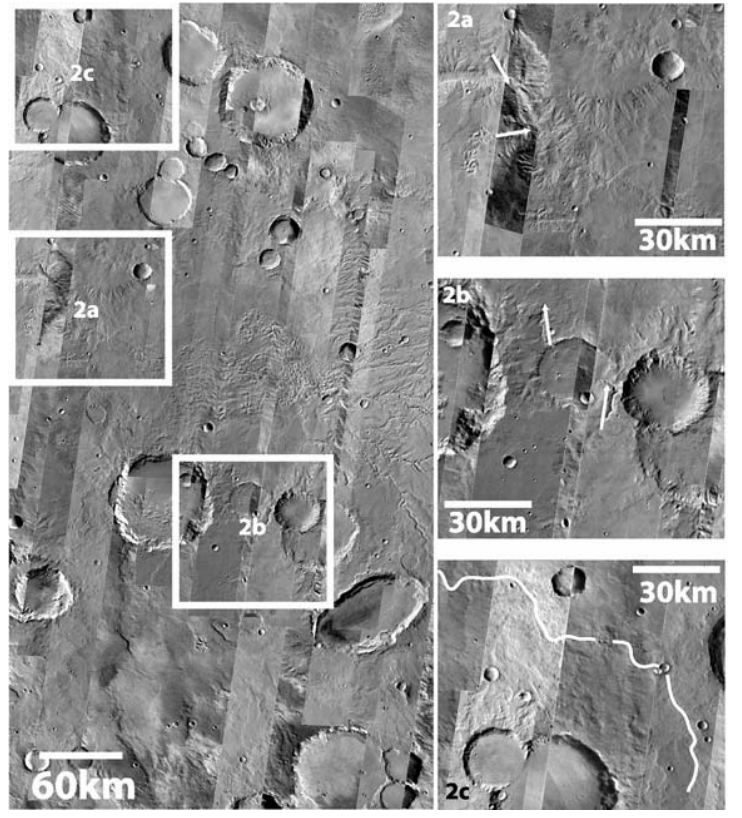

Figure 2. Entire mapping area shown using Viking MDIM 2.1 overlain by THEMIS daytime IR images. (2a) Image showing eastern trending valleys. (2b) Breached crater with input and outlet valleys. (2c) Long channel interrupted by craters.

In the south, valleys trend to the north and northwest but are again truncated by later resurfacing events. Large degraded craters serve as a buffer between the Paraná depositional basin and this similarly sized depositional area. One of these bounding craters is breached by a valley on its eastern rim (Figure 2b) and again on its northern rim. This valley flows north across the intercrater plains and into Paraná basin until it is embayed by the same resurfacing event that truncated the Paraná Valles valley network.

A long narrow channel is also present in the northwest portion of the map (Figure 2c) flowing west and northwest across the inter-crater plains.

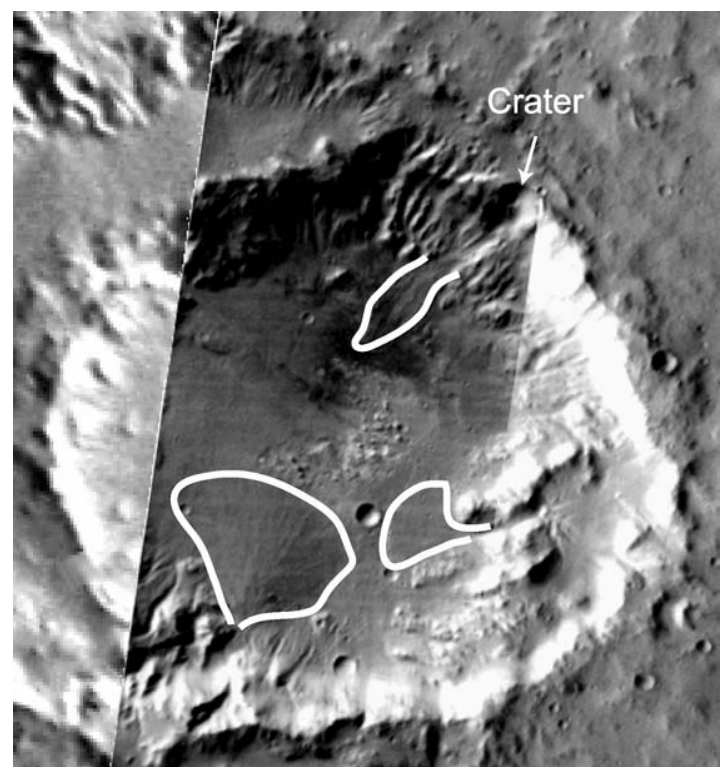

Figure 3. Crater with three debris fans.

Chaotic terrain is prevalent in two portions of this mapping area. The first is situated in the floor of the Paraná depositional basin and shows blocky terrain interspersed with what are interpreted as valley features. This feature is distinctly blocky and dissected on its eastern portion but becomes less so to the west. The second area of chaotic terrain in the northwest has a similar blocky texture but is obscured by a resurfacing event.

Gravity driven processes are prevalent on steep valley and crater walls. A crater in the southwest (Figure 3) displays three different debris fans that may be formed by two different processes. On the south and eastern flank there are two typical alluvial fans probably formed by landslides of dry material. In contrast, on the northern flank there is a debris fan that appears to be coming from a small crater on the rim.

This map will be submitted for review by the end of July, 2004.

References. [1] Grant, J.A. (2000) Geology, 28 223-226. [2] Grant, J.A. and T.J. Parker (2002) JGR, 107(E9), 5066. [3] Grant J.A. and D.A. Clark (2002) Planetary Mappers Meeting (abst.). [4] Williams, K.K. and J.A. Grant (2003) Planetary Mappers Meeting (abst.) [5] Parker, T.J. (1985) Master's Thesis, California State Univ, LA, 165. [6] Parker, T.J. (1994) Ph.D. Thesis, USC, LA. [7] Banerdt, W.B. (2000) Eos, 81, P52C-04. [8] Saunders, S.R. (1979) USGS I-1144, USGS. [9] Schultz, P.H. et al. (1982) JGR, 87, 9803-9820. [10] Grant, J.A. and T.J. Parker (2002) LPSC XXXIII. [11] Scott, D.H. and K.L. Tanaka (1986) USGS Misc. Inv. Series Map I1802-A, USGS. 
GEOLOGIC MAP OF THE MTM 85200 QUADRANGLE, PLANUM BOREUM REGION OF MARS. K. E. Herkenhoff, U. S. Geological Survey, 2255 N. Gemini Dr., Flagstaff, AZ 86001 (kherkenhoff@usgs.gov).

Introduction: The polar deposits on Mars probably record martian climate history over the last $10^{7}$ to $10^{9}$ years [1]. The area shown on this 1:500,000-scale map includes polar layered deposits and polar ice, as well as dunes on Olympia Planitia. This quadrangle was mapped in order to study the relations among erosional and depositional processes on the north polar layered deposits and to compare them with the results of previous 1:500,000-scale mapping of the south polar layered deposits [2,3].

The polar ice cap, areas of partial frost cover, the layered deposits, and two nonvolatile surface units-the dust mantle and the dark material--were mapped in the south polar region [4] at 1:2,000,000 scale using a color mosaic of Viking Orbiter images. We constructed Viking Orbiter rev 726, 768 and 771 color mosaics (taken during the northern summer of 1978; Fig. 1) and used them to identify similar color/albedo units in the north polar region, including the dark, saltating material that appears to have sources within the layered deposits [5] and have low thermal inertia [6]. Because the resolution of the color mosaics is not sufficient to map the color/albedo units in detail at 1:500,000 scale, contacts between them were recognized and mapped using higher resolution black-andwhite Viking Orbiter images.

No craters have been found in the north polar layered deposits or polar ice cap in the map area $[7,8]$. The observed lack of craters larger than $300 \mathrm{~m}$ implies that the surfaces of these units are no more than 100,000 years old or that they have been resurfaced at a rate of at least $2.3 \mathrm{~mm} / \mathrm{yr}$ [8]. The recent cratering flux on Mars is poorly constrained, so inferred resurfacing rates and ages of surface units are uncertain by at least a factor of 2 .

Stratigraphy and structure: The layered deposits (unit $\mathrm{Al}$ ) are recognized by their distinct bedded appearance, red color and lower albedo relative to the polar ice cap and frost deposits. In both polar regions, layers are apparent at least partly because of their terraced topography, especially where accented by differential frost retention $[13,14]$. MOC images show that layered deposit exposures are commonly rough, with evidence for deformed beds and unconformities [16]. No definite angular unconformities have been found within the south polar layered deposits [2,3], unlike the north polar layered deposits, where truncated layers have been recognized in higher resolution images $[7,13]$. Angular unconformities have been found in various locations within this map area, and are mapped using hachures on the side of the contact where layers are truncated.

The partial frost cover (unit Af) is interpreted as a mixture of frost and defrosted ground on the basis of its albedo, color, and temporal variability. Bass and others [17] found that frost albedo reaches a minimum early in the northern summer, then increases during the rest of the summer season. The increase in albedo is interpreted as resulting from condensation of $\mathrm{H}_{2} \mathrm{O}$ from the atmosphere onto cold traps in the north polar region [17]. Because the images used for the base and for mapping were taken in mid-summer, the extent of the high-albedo units shown on this map is greater than during early summer.

The albedo of the residual polar ice cap (unit Ac) is higher than all other units on this map. The contact with the partial frost cover (unit Af) is gradational in many areas, most likely because unit Af represents incomplete cover of the same material $\left(\mathrm{H}_{2} \mathrm{O}\right.$ frost $)$ that comprises unit Ac. The summer extent of the north polar cap was the same during the Mariner 9 and Viking missions [17], which suggests that it is controlled by underlying topography. Albedo patterns in these summertime images are correlated with topographic features seen in springtime images. Areas of the highest albedos must be covered by nearly pure coarsegrained ice or dusty fine-grained frost $[18,19]$. The presence of perennial frost is thought to aid in the long-term retention of dust deposits [20], so areas covered by frost all year are the most likely sites of layered-deposit formation. It is not known whether net deposition is currently occurring in the map area.

Dark dunes (unit Ad) appear to have sources within the polar layered deposits, where a dark, platy basal unit is exposed within the map area [21]. The dunes overlie the layered deposits in places and a large volume of dark, saltating material covers Olympia Planitia in the southern part of the map area. This material may have been deposited as dunes before the currently-exposed north polar layered deposits were laid down over them, perhaps recording an ancient climate that did not allow a perennial north polar cap to form.

Map status: Geologic mapping of the quadrangle is in progress, using ArcMap. The latest results will be discussed at the mappers meeting.

Acknowledgements: Joel Viers (USGS volunteer) prepared an ArcView project and assisted in the mapping of this quadrangle. This work was supported by the NASA Planetary Geology and Geophysics Program. 


\section{References:}

[1] Thomas P. et al. (1992) Polar deposits on Mars, in Mars, University of Arizona Press, 767-795.

[2] Herkenhoff K. E. and Murray B. C. (1992) USGS Misc. Inv. Series Map I-2304; Herkenhoff K. E. and Murray B. C. (1994) USGS Misc. Inv. Series Map I-2391; Herkenhoff K. E. (2001) USGS Misc. Inv. Series Map I-2686.

[3] Herkenhoff K. E. (1998) USGS Misc. Inv. Series Map I-2595.

[4] Herkenhoff K. E., and Murray B. C. (1990) JGR, 95, 1343-1358.

[5] Thomas P. C. and Weitz C. (1989) Icarus, 81, 185215.

[6] Herkenhoff, K. E. and A. R. Vasavada (1999) J. Geophys. Res., 104, 16,487.

[7] Cutts J. A. et al. (1976) Science, 194, 1329-1337.

[8] Herkenhoff K. E. and Plaut J. J. (2000) Icarus, 144, 243-253.

[9] Zuber M. T. et al. (1998) Science, 282, 2053-2060.

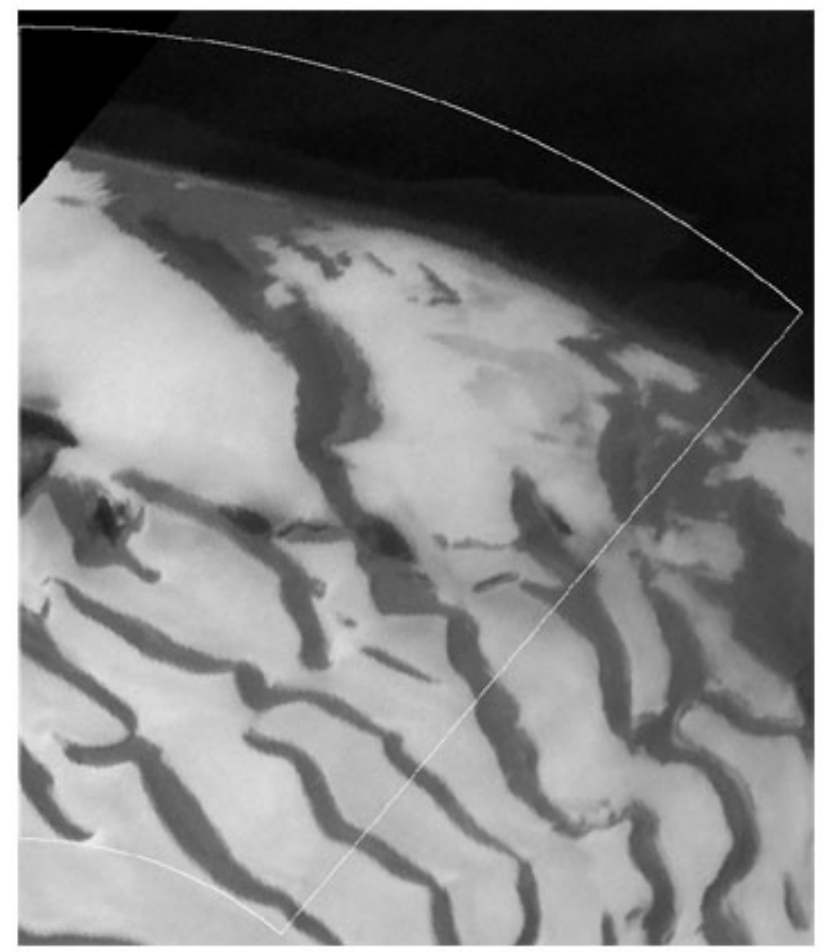

Red
[10] Smith D. E. et al. (1999) Science, 284, 14951503.

[11] Murray B. C. et al. (1972) Icarus, 17, 328-345.

[12] Cutts J. A. (1973) JGR, 78, 4231-4249.

[13] Howard A. D. et al. (1982) Icarus, 50, 161-215.

[14] Herkenhoff K. E. and Murray B. C. (1990) JGR, 95, 14,511-14,529.

[15] Blasius K. R. et al. (1982) Icarus, 50, 140-160.

[16] Edgett K. S. and Malin M. C. (1999) LPS XXX, Abstract \#1029; Malin M. C. and Edgett K. S. (2001) JGR, 106, 23,429-23,570.

[17] Bass D. S. et al. (2000) Icarus, 144, 382.

[18] Clark R. N. and Lucey P. G. (1984) JGR, 89, 6341-6348.

[19] Kieffer H. H. (1990) JGR, 95, 1481-1493.

[20] James P. B. et al. (1979) Icarus, 68, 422-461.

[21] Byrne, S., and B. C. Murray (2002) JGR, 107, 10.1029/2001JE001615; Edgett, K. S. et al. (2002) Geomorphology 52, 289-297.

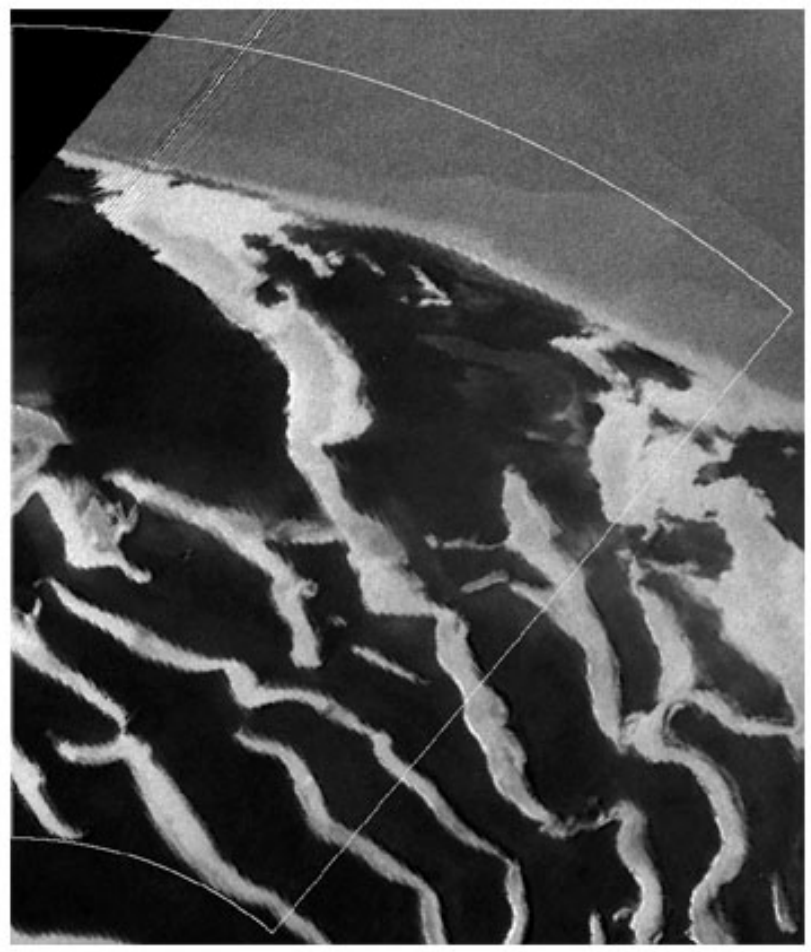

Red/Violet ratio

Figure 1. Mosaics of Viking Orbiter 1 images of the map area, taken almost a Mars year after the images used to create the photomosaic base map. Polar Stereographic projection (same as map base), north is up. Area shown in each mosaic $\sim 310 \mathrm{~km}$ across. $\mathrm{L}_{\mathrm{s}}=119$, MTM 85200 quadrangle outline shown by white lines. (left) Red filter mosaic. (right) Red/violet ratio mosaic. White corresponds to red/violet $=2.2$, totally black regions indicate no image coverage (upper left corner) or red/violet $<1.5$. 
NEW MAPPING EFFORTS IN THE ENIGMATIC ARABIA TERRA, MARS. B. M. Hynek ${ }^{1}$, B. M. Jakosky ${ }^{1}$, and R. J. Phillips $^{2},{ }^{1}$ Laboratory for Atmospheric and Space Physics, University of Colorado, ${ }^{2}$ Department of Earth and Planetary Sciences and McDonnell Center for the Space Sciences, Washington University. brian.hynek@lasp.colorado.edu

Introduction: High-resolution images, spectral data, altimetry, and gravity data from Mars Global Surveyor and Mars Odyssey shed new light on the already perplexing province of northwest Arabia Terra (herein called NWAT), covering an area of $\sim 7 \times 10^{6} \mathrm{~km}^{2}$ (roughly equivalent to that of the European continent). NWAT is primarily composed of degraded, Noachianage cratered terrain that was formed during the era of heavy bombardment, which ended $3.7 \mathrm{Ga}$. Originally, this region was considered a part of the ancient highlands that cover the southern part of Mars [1-2]. Several Viking-era observations hinted that NWAT differed from "typical” Martian highlands, including the paucity of valley networks [3] and subdued nature of the cratered terrain [4]. Recent surface and subsurface results from MGS and MO have revealed numerous additional unique properties, indicating that this area has had a history considerably different than the rest of the uplands or anywhere else on Mars.

\section{Perplexities of NWAT:}

Extremely Degraded Surface: For the first time, high resolution MOLA data have allowed the separation of abundant high-standing, degraded, heavily cratered inliers (erosional remnants) from intervening, relatively sparsely cratered, topographically lower, smooth material (Fig. 1). There is typically a kilometer of relief between these two adjacent units. These two terrain types occur predominately in NWAT and to the south in Margaritifer Terra and have not been identified on this scale elsewhere on the planet. We hypothesized that a major fluvial erosional event took place on this region of Mars and is primarily responsible for the landscape we see today [5].

Lack of Valley Networks: Valley network systems on Mars were first described from Mariner 9 images and remain the most convincing evidence that water carved the surface of the planet in the past and the climate was different than at present. Most of these systems date from the Noachian [3], although local or regional formation seems to have continued at reduced rates to more recent times [6-7]. At low and mid-latitudes, valley networks dominate the heavily cratered Martian uplands with a few geographic exceptions including Argyre, Hellas, Memnonia and NWAT (e.g., [3]). Lack of networks in the Argyre and Hellas impact basins and the Memnonia region are likely a result of burial by younger sedimentary and volcanic deposits [1-2]. The lack of valley networks on NWAT has always been a puzzle. Valley networks essentially cease along a northeast-trending curvilinear path in the middle of the heavily cratered upland material (Fig. 2).
Low Elevation: The global dichotomy separates the southern heavily cratered Martian uplands from the lowlying, sparsely cratered, smooth plains to the north. Typical elevations for the highlands, excluding the largest impact basins, range between 0 and $3 \mathrm{~km}$ above the Martian datum [8]. Conversely, NWAT has an average elevation of $-1.5 \mathrm{~km}$, roughly $3 \mathrm{~km}$ below typical highland terrain (Fig. 2).

Thin Crust: Zuber et al. [9] recently mapped the subsurface of Mars using a combination of MGS topography and gravity data (Fig. 3). Highland crust (excluding large impact basins) has a nominal thickness of 50-70 km and lowland crust is roughly $25 \mathrm{~km}$ thick. There is typically a sharp boundary between these two provinces and a strong correlation with the global dichotomy boundary that separates the highlands from the lowlands. NWAT, conversely, has a crustal thickness in between these two provinces (averaging $30-50 \mathrm{~km}$ ) and in this region the crustal thickness does not correlate with the global dichotomy boundary (Fig. 3).

Size-Frequency Distribution of Craters: Images show that the cratered uplands exhibit a dense crater population of moderate to large diameters, including most of the large craters found on the planet. These features are generally uniformly distributed across the southern highlands, not including regions of post-Noachian resurfacing. Although there are large craters on the boundaries of NWAT, the region of low elevation contains no craters of this magnitude, while statistically it should.

Subdued Terrain: Excluding the high-standing erosional inliers, the terrain in NWAT exhibits a subdued nature. Topography in low-lying regions appears muted and features are not readily visible. For example, craters often have partially buried rims and flat floors that are indicative of infilling. Valley networks flowing into this region sometimes disappear under mantling units that presumably blanket much of NWAT. Outcrops of thinly layered deposits, visible in high-resolution MOC images, are superposed on cratered terrain and corroborate the notion that large areas of NWAT are partially buried.

New Mapping Efforts: Understanding the history of this unique region of Mars is only possible after rigorous remapping. We are beginning efforts to complete detailed geomorphic/geologic mapping at 1:2,000,000 scale in NWAT, defined here as $0-40 \mathrm{~N}, 335 \mathrm{E}$ eastward across the prime meridian to $30 \mathrm{E}$. This area encompasses the highly degraded surface of NWAT and surrounding terrain including the northern plains (east and north), fretted terrain (north), "typical” highland terrain (east and south), and denuded, layered, and chaotic terrain (south). This mapping will be a combination of geologic and geomorphic mapping; however, geomor- 
phic mapping likely will dominate due to the highly modified nature of the surface and lack of distinct spectral signature over this region. We will map units on the basis of their apparent primary features and special care will be given to contact relations, hence allowing reconstruction of the geologic history.

MOLA data will be used to constrain the thickness of units, characterize their slopes and surfaces, and to test for lateral continuity across the mapped area. In some regions, TES-derived albedo and thermal inertia correlate well with defined geologic units [10] and we will integrate these data where appropriate. Such an analysis has important ramifications for understanding the thermophysical properties of the Martian surface and interpretation of surface types.

We plan to implement techniques similar to our previous work in Margaritifer Terra [5] with the addition of higher-resolution MGS products and new data from MO. MGS data has allowed the separation of high-standing degraded units from low-lying, smooth plains within NWAT (Fig. 1). This is an important distinction of terrain with two entirely different crater populations, much of which was originally lumped together as a single-age unit (i.e., unit $\mathrm{Npl}_{1}$ from [1-2]). We will map these major units and other terrain types within the study area.

Once mapping is complete, crater counts combined with superposition and crosscutting relationships will be used to determine the sequence and timing of events. Total crater densities as well as superposed crater densities will be calculated for each geologic/geomorphic unit to give a relative age and a younger limit of relative age, respectively. Clearly we will not be able to date the age of formation of geomorphic units; rather, these crater densities date the timing and duration of the surfacemodifying event. In the cumulative size-frequency curves, particular attention will be paid to any kinks, bends, or changes in slope of the crater curves for individual mapped units and for NWAT as a whole. Using the method of Frey and Grant [11], we plan to isolate resurfacing events, constrain their nature and timing, and compare them to results from independent analysis via geologic/geomorphic mapping. We will pay close attention to scale-dependent versus scale-independent resurfacing mechanisms, which can provide great insight as to the geomorphic agent(s) responsible for surface modification. Only when all these tasks are complete can we begin to reconstruct the geologic and geomorphic histories of NWAT to shed light on why this region is so unique.

References: [1] Scott D.H. and Tanaka K.S. (1986) U.S.G.S. Misc. Inv. Series Map I-1802-A; [2] Greeley R. and Guest J.E. (1987) U.S.G.S. Misc. Inv. Series Map I-1802-B; [3] Carr M.H. (1995) JGR, 100, 7479-7507; [4] Moore J.M. (1990) JGR, 95, 14,279-14,289; [5] Hynek B.M. and Phillips R.J. (2001) Geology, 29, 407-410; [6] Scott D.H. et al. (1995) U.S.G.S. Misc. Inv. Series Map I-2461; [7] Craddock R.A. and Howard A.D. (2002) JGR, 107, doi:10.1029/2001JE001505;
[8] Smith D.E. et al. (1999) Science, 284, 1495-1503; [9] Zuber M.T. et al. (2000) Science, 287, 1788-1793; [10] Arvidson R.E. et al. (2003) JGR, 108, doi:10.1029/2002JE001982; [11] Frey H.V. and Grant T.D. (1990) JGR, 95, 14249-14263.

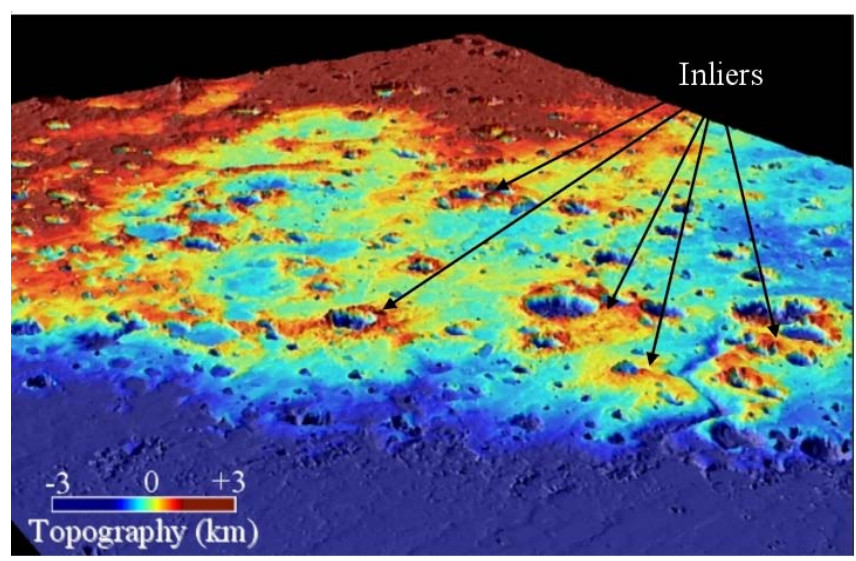

Figure 1. SE-looking oblique view of NWAT showing numerous ancient erosional inliers.

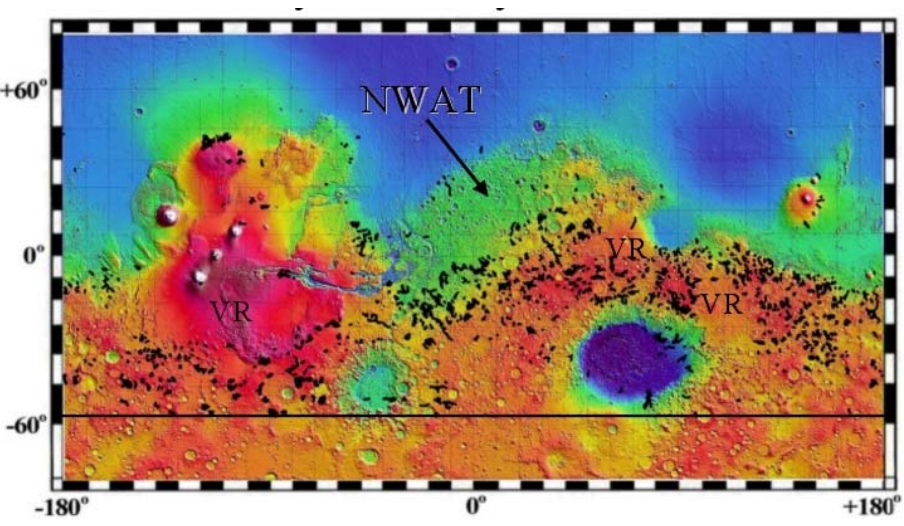

Figure 2. MOLA topography and valley networks from Carr [3] overlaid. NWAT has a paucity of networks. $\mathrm{VR}=$ younger volcanic resurfacing.

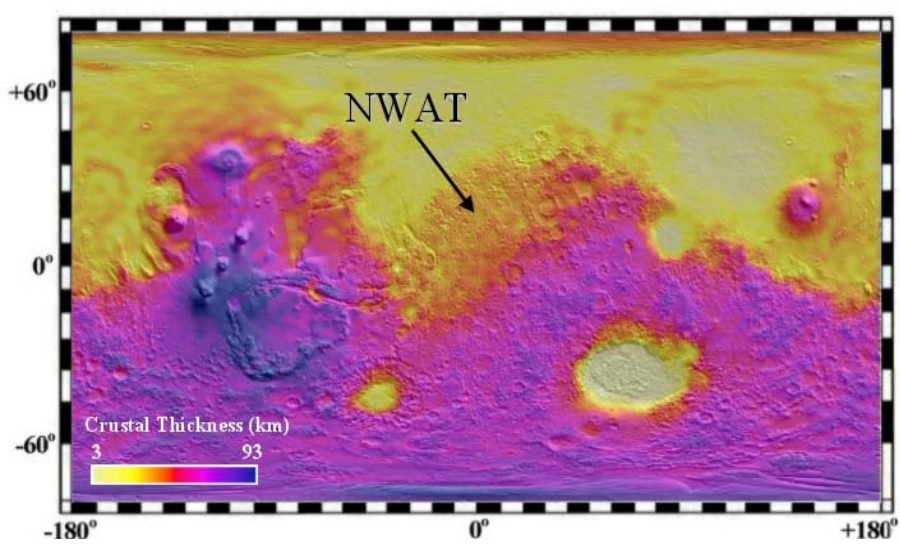

Figure 3. Global crustal thickness map of Zuber et al. [9]. The crustal structure of NWAT is unlike the highlands or lowlands. 
INITIAL 1:1,500,000-SCALE GEOLOGIC MAPPING RESULTS OF PLANUM AUSTRALE, MARS. E.J. Kolb ${ }^{1}$ and K.L. Tanaka ${ }^{2},{ }^{1}$ Arizona State University, Dept. of Geological Sciences, Tempe, AZ 85287, eric.kolb@asu.edu, ${ }^{2}$ Astrogeology Team, U.S. Geological Survey, 2255 N. Gemini Dr., Flagstaff, AZ 86001, ktanaka@usgs.gov.

Introduction: In this abstract we outline the initial results of our geologic mapping study of the north and south polar layered deposits (PLD) of Mars at 1:1.5M scale. The specific goals of this project are three-fold: (1) Construction of stratigraphic sections of the PLD and topographic mapping of prominent layers and layer sequences and investigation of intra- and interpolar stratigraphic and topographic variations in the PLD and residual ice caps, (2) detection and interpretation of structural deformation in the PLD, and (3) description and interpretation of the erosional history of the PLD.

Status: As a natural progression of our recent 1:5M-scale geologic mapping of the south polar region of Mars, in this project we are initially focusing on the $1: 1.5 \mathrm{M}$-scale geologic mapping of the PLD of Planum Australe. The stratigraphic mapping is largely being undertaken using the THEMIS datasets because of the high resolution, uniform solar illumination, and near complete surface coverage that these datasets provide. Currently, only a few southern summer THEMIS-VIS images of the SPLD have been released by the THEMIS science team. Therefore, our initial mapping has relied largely on MOLAderived topographic bases (114 m/pixel), and Viking (130 to $250 \mathrm{~m} /$ pixel) and MOC NA (4 to $16 \mathrm{~m} /$ pixel) images and image mosaics. As a result, the stratigraphic mapping (and primary task of this project) has been limited to a small number of localized regions of defrosted SPLD exposures.

Results: One of the most extensive exposures of SPLD occurs within a broad trough east of Chasma Australe. Within the trough, we have identified six distinct, successive, mappable sequences of SPLD $[1,2]$. SPLD subdivision is based on the topographic expression (e.g., cliff vs. terrace forming) of the layer sequences. The sequences are bounded by marker beds that are laterally continuous throughout the study area and beyond, extending $>150 \mathrm{~km}$ along the trough, within both enclosing trough walls, as well as within a trough system east of the north-trending radial trough. The trough's cliff and terrace-forming SPLD morphology indicates that the SPLD is composed of beds alternating in competency. This variable competency may be related to degree of induration, ice composition and structure, and/or concentration of dust particles within an icy matrix. Etching and deflation features within the trough's floor and enclosing walls (a densely spaced series of north-trending ridges and grooves and streamlined landforms) supports an eolian scouring history for formation of the trough.

Ancient impact craters that are emplaced within Promethei basin and along the margins of Planum Australe show thick, lobate tongues of SPLD material resting on several of the impact crater floors. This morphology has previously been cited $[3,4]$ as evidence supporting a flow-deformation SPLD history such that SPLD material at the margins of Planum Australe has in-filled subjacent impact craters by glacial-like flow processes similar to piedmont glacier formation. Mapping of these regions has not identified glacial process features within the crater-infilling SPLD sequences such as folded SPLD, crevasses, ogives, or proglacial thrust moraines typical of either warm- or cold-based glacial conditions. Instead, PLD structures appear to be related to simple draping over and minor adjustments to buried topography.

Future Work: The next THEMIS data release (July, 2004) will contain earlysummer images of the SPLD. Moreover, we will soon acquire from the THEMIS team a THEMIS-VIS mosaic of Planum Australe. 
Following these data releases, we will begin planum-wide stratigraphic mapping of Planum Australe.

References: [1] Kolb E. J. and Tanaka K. L. (2003) $3^{\text {rd }}$ Intl. Mars Polar. Sci. Conf. \#8116 [2] Kolb E. J. and Tanaka K. L. (2004) Lunar Planet. Sci. Conf. 35 ${ }^{\text {th }}$ \#2105. [3] Head, J. W. (2000). Sec. Intl. Conf. Mars Polar Sci. Explor., p. 66-67. [4] Hartmann, W. K. (2000). Sec. Intl. Conf. Mars Polar Sci. Explor., p. 64-65. 
GEOLOGIC MAPPING OF THE MEDUSAE FOSSAE FORMATION ON MARS. K. M. Shockey ${ }^{1}$, J. R. Zimbelman $^{1}$, S. J. Friedmann ${ }^{2}$, and R. P. Irwin ${ }^{1}$; ${ }^{1}$ Center for Earth and Planetary Studies, National Air and Space Museum, Smithsonian Institution, MRC 315, $6^{\text {th }}$ St. and Independence Ave. SW, Washington, DC 20560-0315, shockeyk@nasm.si.edu, jrz@nasm.si.edu, Irwinr@nasm.si.edu, ${ }^{2}$ University of Maryland Department of Geology, College Park, MD 20742, juliof@geol.umd.edu.

Introduction: To better understand the origins of the Medusae Fossae Formation (MFF), we are mapping the eastern part of MFF between 210 and $225 \mathrm{E}$ longitude, and from the equator to $15^{\circ} \mathrm{N}$. The MFF is a friable, extensive Amazonian deposit that overlies the crustal dichotomy boundary and adjacent lowlands between approximately 130 and $240 \mathrm{E}$ longitude [1], between the Tharsis and Elysium volcanic provinces. Yardangs and pedestal craters attest to considerable aeolian deflation of the MFF in recent geologic time $[1,2]$. Although diverse explanations for the MFF have been proposed (summarized by [1]), recent work has focused on deposition of loess or ignimbrite by aeolian processes $\left[\begin{array}{ll}1,3 & 6\end{array}\right]$. The new geologic mapping will be critical for evaluating the many proposed hypotheses of origin for the MFF materials.

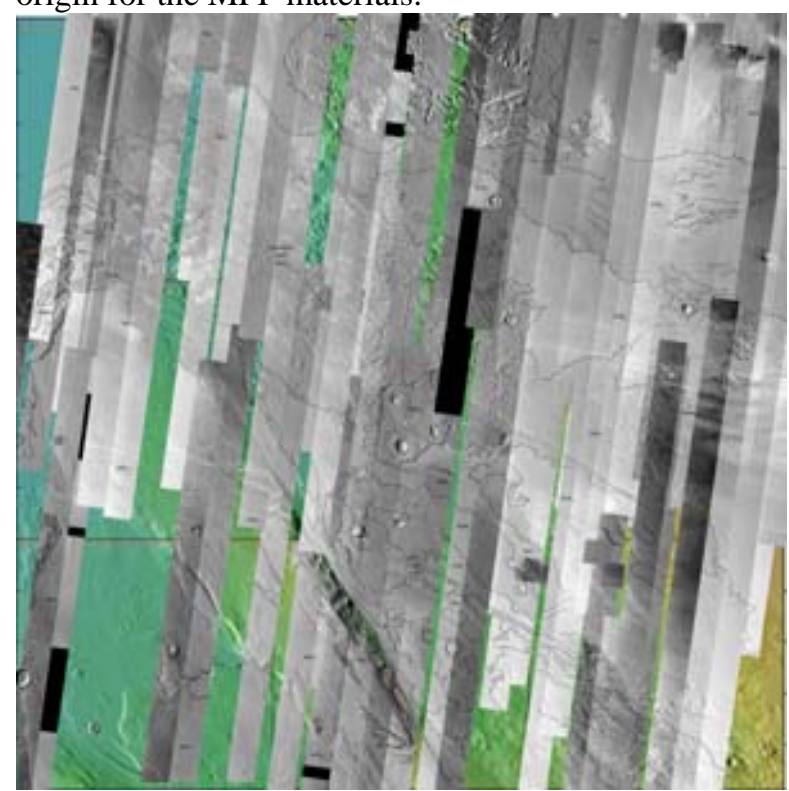

Figure 1: THEMIS daytime infrared (IR) data (as of June 2004) co-registered with MOLA data. THEMIS images are referenced to the same coordinate system used for the precise topographic measurements made by the Mars Orbiter Laser Altimeter (MOLA) instrument [11] on the Mars Global Surveyor (MGS) spacecraft, so that both the images and topography can be precisely registered in a fixed global reference system. The Gordii Dorsum escarpment is near the bottom center of this view.

Description: Recent planetary missions have provided several data sets that are of great use to mapping projects. The Mars Odyssey Thermal Emission Imaging System (THEMIS) [7, 8] operates at both visible and thermal infrared wavelengths. Each IR image covers an area on Mars that is $\sim 32 \mathrm{~km}$ wide, in strips of variable length as determined by the data rate available for downloads to Earth at the time the image was taken. Owing to the uniformly low thermal inertia of the dust-mantled study area encompassing MFF, the $100 \mathrm{~m} /$ pixel daytime THEMIS IR images reveal fantastic sensitivity to topography, showing subtle slopes as measurable temperature differences, along with other properties [4, 7]. The daytime IR is the image base for this mapping project, as the nighttime IR imaging predominantly shows the effects of homogeneous thermophysical properties of the dust cover [7]. Gaps in the THEMIS coverage are filled by MOLA [9] topography at $430 \mathrm{~m} /$ pixel (Fig. 1). Mars Orbiter Camera (MOC) Geodesy Campaign Mosaic (www.msss.com), at $231 \mathrm{~m} /$ pixel, was used for comparison as an additional data set as it highlights variations in albedo across the study area. Earlier mapping used Viking Orbiter data with only visible wavelengths and a comparatively low spatial resolution.

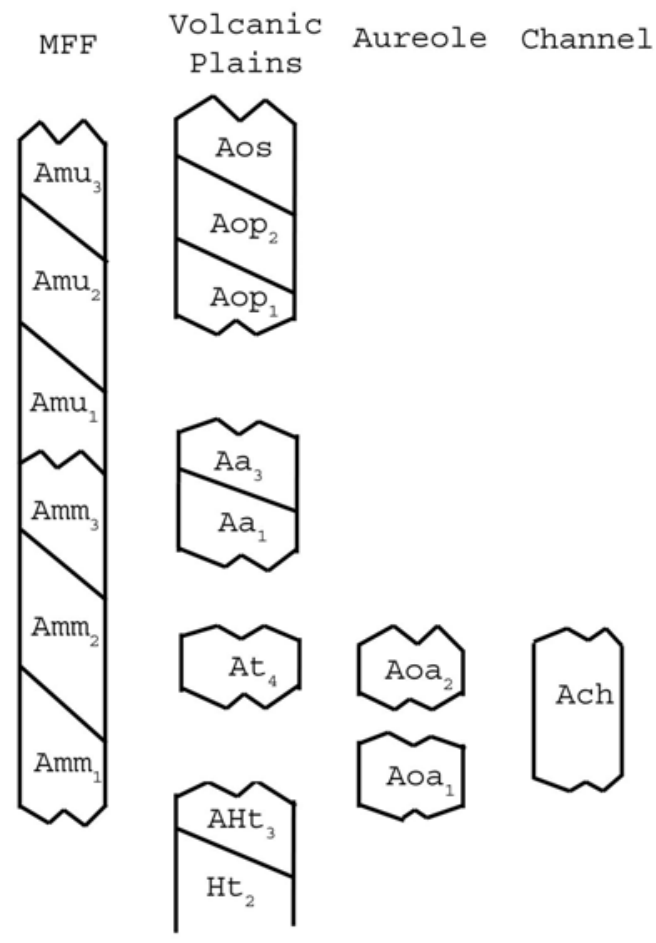

Figure 2: The stratigraphy for the map area in Fig. 1. 
Discussion: The origins of the MFF are still controversial, but the three primary hypotheses are [1]: ash flow, ash fall, and aeolianite (i.e., loess). Detailed mapping should provide constraints for evaluating the various alternatives. Ash fall and aeolianite origins may be difficult to distinguish from one another, unless diagnostic volcanic characteristics can be identified within MFF [4]. However, topographic relief should provide strength constraints that reduce the range of likely MFF materials.

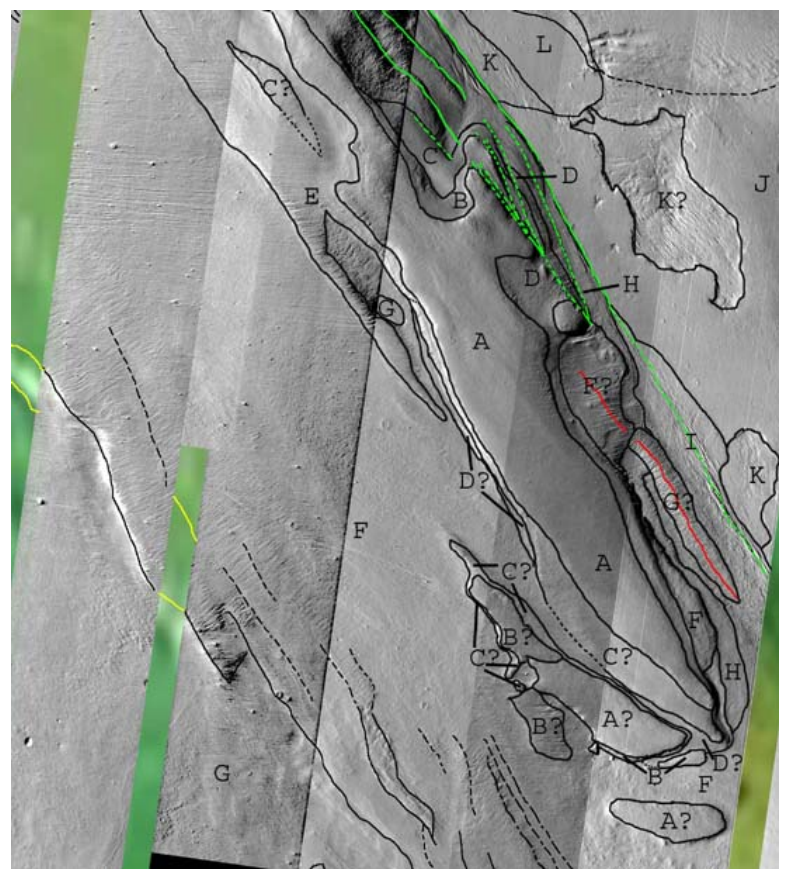

Figure 3: The details seen in the THEMIS images show many layers in the Gordii Dorsum escarpment not seen in previous data sets. The letters show the interpreted stratigraphy, A being the youngest.

During detailed mapping at Gordii Dorsum (Fig. 3), we discovered possible evidence for young deformation in the form of faults and folds that deform MFF strata. A fold within Gordii Dorsum (indicated by the red line in Fig. 3) is revealed in the THEMIS daytime IR data. The fold appears to plunge to the south. This indicates a late stage compression in the Tharsis region of Mars. A range of structural styles, including normal faulting, fault-propagation folding, and structural relays are proposed to be present. Of special interest, it appears that some faulting and folding was synchronous with deposition of MFF components, providing constraints on the magnitude and relative timing of deformation. Such evidence includes potential relative age relationships like onlapping and cross-cutting structures and depositional units. This could be prima facie evidence of very young faulting and folding at the Martian surface. Another possible explanation for the stepped topography along the NE margin of Gordii Dorsum is the development of erosional benches due to differential resistance of layered materials. If this is the reason for the appearance then there are likely to be more layers to the formation than we have already mapped.

Conclusions: The area currently being mapped at MFF is far from finished. Future releases of THEMIS will allow us to fill in the gaps for which MOLA is currently being used. Contact lines are constantly being examined and re-examined. Crater counts will be used as a tool to help determine a more precise stratigraphy and/or erosional history. The area mapped by Zimbelman [10] from $15^{\circ} \mathrm{N}$ to $15^{\circ} \mathrm{S}$ latitude and from $202.5^{\circ}$ to $225^{\circ}$ E longitude using Viking data is going to be used for a comparison between the two maps in order to reformulate previous conclusions drawn on the origins of MFF. One major goal is to remap the entire area previously mapped by Zimbelman using THEMIS daytime IR data.

References: [1] Bradley, B.A. et al. (2002) JGR107(E8), 10.1029/2001JE001537. [2] Ward A. W. (1979) JGR, 84, 8147 8166. [3] Scott D. H. and Tanaka K. L. (1982) JGR, 87, 1179 1190. [4] Zimbelman J. R. (2003) GSA Abs. Prog. 35(6) 107-7, 128. [5] Hynek B. M. et al. (2003) JGR, 108(E9), doi: 10.1029/2003JE002062. [6] Head J. W. and Kreslavsky M. A. (2001) Conf. Geophys. Det. Water on Mars, LPI. abst. 7083. [7] Christensen, P.R. et al. (2003) Science, 300. [8] http://themis.asu.edu [9] http://ltpwww.gsfc.nasa.gov/tharsis/mola.html [10] Zimbelman, J. R. et al. (2003) Mappers meeting. [11] Smith, D.E. et al. (1999) Science, 284, 1495-1503. 
TESTING PLANETARY PHOTOGEOLOGIC MAPPING METHODS USING TERRESTRIAL MARSLIKE DATA SETS AND GEOLOGIC SETTINGS. K. L. Tanaka ${ }^{1}$, J. A. Skinner, Jr. ${ }^{1}$, J. M. Dohm ${ }^{2}$, L. S. Crumpler $^{3}$, and T. M. Hare ${ }^{1}$, ${ }^{1}$ U.S. Geological Survey, 2255 N. Gemini Dr., Flagstaff AZ, 86001; ktanaka@usgs.gov, jskinner@usgs.gov, thare@usgs.gov; ${ }^{2}$ Dept. Hydrology and Water Resources, University of Arizona, Tucson, AZ, 85721; jmd@hwr.arizona.edu; ${ }^{3} \mathrm{New}$ Mexico Museum of Natural History and Science, 1801 Mountain Road NW, Albuquerque, NM 87104; larry_crumpler@mac.com.

Introduction: Photogeologic mapping of the planets has documented the geologic histories of planetary surfaces, going back to geologic mapping efforts of the Moon some 40 years ago. However, the accuracy of these approaches remains substantially untested. Indeed, planetary geologic maps have not been subject to field checking. Thus, this may result in the production of geologic maps that contain significant uncertainties and errors that generally go underappreciated. These errors can include improper unit assignments to outcrops, misplaced contacts, incorrect relative-age determinations of stratigraphic units and structures, and mapping of units that include secondary features formed substantially later. In some cases, new spacecraft and lander mission data sets have revealed such errors, particularly in geologic maps of Mars.

We have undertaken a study to assess this problem with grant support from the Mars Fundamental Research Program. We are using publicly available, Mars-like terrestrial data sets (topography and visible and thermal infrared images at appropriate resolutions) to simulate Viking, Mars Global Surveyor, and Mars Odyssey data sets useful for mapping and to perform blind tests of photogeologic mapping methods. Our team includes geologists experienced in both Mars photogeologic and terrestrial field mapping.

Approach: We are first selecting areas on Earth that have similarities with terrains on Mars that are sites of geologic significance and have potential for future exploration. We are selecting volcanic regions modified by tectonic deformation and fluvial erosion in Arizona and New Mexico, where we individually have field and research experience. Volcanic rocks provide the best radiometric ages and thus would likely be a prime target on Mars for sample return to pin down the cratering history of the planet [1]. Also, the ages of such materials can be used to constrain ages of tectonic and fluvial features, which has been done extensively on Mars [e.g., 2-4]. On Earth, such features may have complex, long-lived histories that include diverse styles of activity. For example, fault reactivation caused by differing stress orientation, intensity, and build-up rates has resulted in multiple offsets and styles of deformation associated with a single fault or fault system. In the desert Southwest, present-day fluvial activity is commonly governed by flash floods and spring runoff, whereas more sustained precipitation would have been characteristic of the same region during the Pleistocene. In addition, we plan to test map playa regions pertinent to mapping of sedimentary depositional sites on Mars, including the northern lowlands and inter- and intracrater basins.

We have also been discussing the merits and application of allostratigraphic (or unconformitybounded) units to Mars geologic mapping in comparison with traditional, rock-stratigraphic mapping $[5,6]$. For example, Martian stratigraphic units commonly consist of multiple and/or uncertain lithologies, yet unconformities that define periods of geologic activity can be mapped. We will also evaluate the circumstances where particular mapping approaches provide better results.

Each site expert provides the coordinates of his chosen site for which a GIS database of images and topography is produced (by Hare). We are using Shuttle Imaging Radar topography to simulate Mars Orbiter Laser Altimetry data, and aerial photos and Landsat data to simulate Viking, Mars Orbiter Camera, and Thermal Emission Imaging System images. The data are being re-sampled to match available resolutions on Mars. The data are then sent to the other team members to perform the geologic mapping, which is then returned to the site expert for evaluation.

Initial results: We have each mapped part of the San Francisco Volcanic Field $\left(\sim 340 \mathrm{~km}^{2}\right.$, or $\sim 7 \%$ of the entire field; Figs. 1 and 2), where Tanaka as site expert has extensive field experience and for which USGS geologic maps have been published at 1:50,000 scale. The area includes dissected and faulted material overlain by a number of cinder cones and lava flows. The geologic maps include a variety of laboratory compositional data, radiometric ages, magnetostratigraphic ages, field-based age relations, and field-based petrographic information for the volcanic rocks. The mappers are not allowed to consult the published geologic maps until the test mapping is completed.

Mappers are permitted to show three levels of uncertainty in (a) outcrop unit identification, (b) contact reliability, and (c) relative-age designations. This approach provides us with ways to recognize and acknowledge limitations in the data and in interpretive techniques. We have finished the first stage of geologic 
mapping, in which mappers are furnished data sets without any radiometric age data. Next, mappers will be given radiometric ages to see how these might influence age and unit assignments.

We found that the terrestrial data sets emulate the Mars data sets surprisingly well. Topography and Landsat image data were generally the most useful data for identifying units and drawing contacts, as are MOLA data and thermal infrared and visible images for Mars. High-resolution aerial photography data show that pristine flow textures are preserved only on the volcanic units, whereas soils and aeolian drift commonly obscure contacts and fault scarps and older volcanic surfaces, similar to what MOC narrow angle images display for Martian surfaces.

Comparing the geologic mapping results of each mapper shows general consistency, though there are notable disagreements in details among the maps. This is encouraging in that we will be able to assess who's approach was more successful and why, on a case-bycase basis. We can also check to see if uncertainty levels correspond with the proportion of correct unit and age assignments.

Each mapper identified and consistently mapped dissected light-colored material as the oldest rock unit. Crumpler (C), Skinner (S), and Tanaka (T) all identified terraces inferred to be layers in this unit. For the volcanic units, C and Dohm (D) each mapped 5 flow and 3 vent units; S, 6 flow and 5 vent units; and T, 8 flow and 4 vent units. These discrepancies illustrate the classic problem of lumping vs. splitting, as each mapper came up with different groupings of outcrops, some of which have potential relative age implications. $\mathrm{S}$ and $\mathrm{T}$ made much more detailed use of uncertainty levels for contacts, unit identifications, and relative-age determinations than did C and D. Finally, S mapped the most area of alluvium, whereas $\mathrm{T}$ mapped a moderate amount and divided it into dark and light-colored units; D mapped just a few outcrops of alluvium; and C mapped no alluvium. Some darker valley fill in the eastern part of the light-colored basal material was mapped variably as alluvium, lava, and light-colored rocks; also, a relatively smooth surface in the southwest part of the map is also mapped variably in terms of unit identifications and contacts. Similar levels of consistency in identification and age determination of structures occur among the mappers.

Future work: Mars provides us with an additional clue for determining relative ages-crater densities. We can simulate having crater densities for given units by converting their radiometric age information in a systematic fashion. After the maps are fine tuned with this additional data and finalized, each mapper will be given copies of the USGS geologic maps for comparison. We will then compile in detail the accuracy of our photogeologic maps and determine the best methodologies and observations to apply for Mars mapping studies. We also plan to visit key field locations where remaining conflicts and unanswered questions require further study.

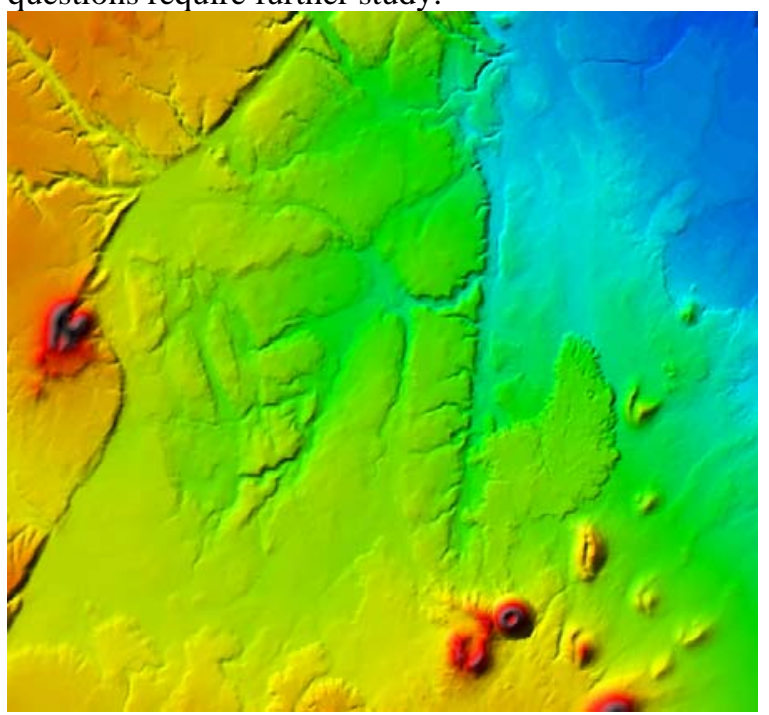

Figure 1. Color shaded-relief image of mapping test area, San Francisco Volcanic Field, Arizona; 18.4 km wide; north at top.

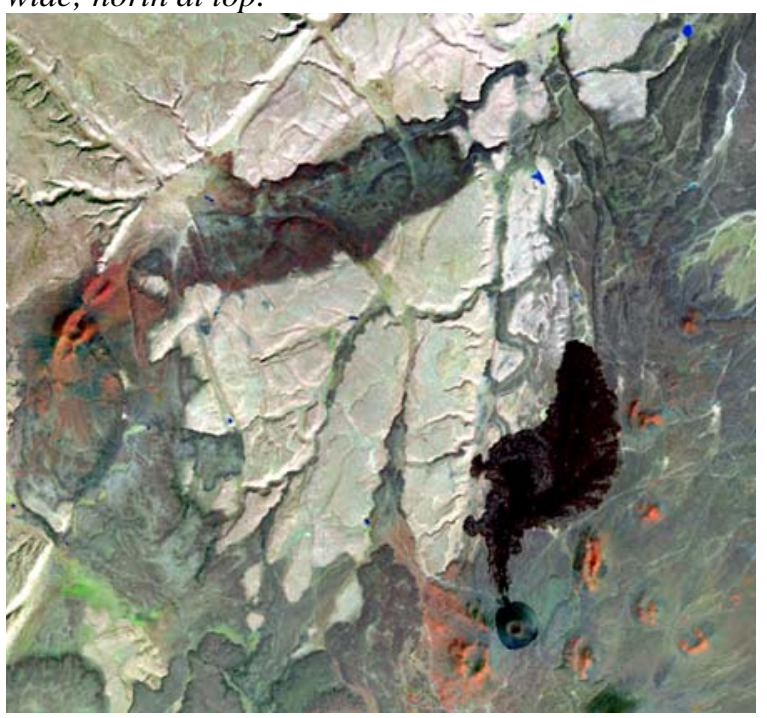

Figure 2. Landsat TM false-color image of mapping test area.

References: [1] McCleese D.R. et al. (2001) Science Planning for Exploring Mars, JPL Pub. 01-7, Pasadena, CA, 47 p. [2] Tanaka K.L. and Davis P.A. (1988) JGR, 93, 14,893-14,917. [3] Dohm J.M. et al. (2001) USGS Map I-2650. [4] Anderson R.C. et al. (2001) JGR, 106, 20,563-20,585. [5] Skinner J.A. Jr. and Tanaka K.L. (2003) Abstracts, LPSC XXXIV, \#2100. [6] Tanaka K.L. and Skinner J.A. Jr. (2003) Abstracts, Sixth Intl. Conf. Mars, \#3129. 


\section{ASPECTS OF CLARITAS FOSSAE REGION, MARS, IDENTIFIED DURING 1:1,000,000 GEOLOGIC MAPPING: James R. Underwood, Jr., Department of Geology, Kansas State University,}

Manhattan, KS 66506-3201, USA, jrujr@flash.net

Introduction: Claritas Fossae is a linear, intensely fractured zone in the western hemisphere of Mars lying on the southeast flank of the Tharsis rise. From its northern termination at Noctis Labyrinthus, Claritas Fosse extends south southeast some $2000 \mathrm{~km}$. The purpose of this 1:1,000,000-scale geologic mapping project is to understand the role of Claritas Fossae in the evolution of the Tharsis complex, the dominant geologic feature on Mars, and to see if the highly fractured rocks of the fossae provided conduits to the surface for Tharsis magma. Earlier reports, including geologic or structural maps at smaller scales [1-15], cover part or all of the map area. MOLA data [16] provided depth and height determinations; relative age assignments of stratigraphic units were based on crater counts and on overlapping and crosscutting relationships $[14,15]$. In the current project, thirteen mapped rock units, not including crater materials, were distinguished on the basis of surface texture, morphology, geometric pattern, and relative albedo.

This map area, $22.5-32.5 \mathrm{~S}$ and $100-110 \mathrm{~W}$, includes: (1) rocks representing Noachian, Hesperian, and Amazonian stratigraphic systems on Mars, (2) a 600km typical segment of Claritas Fossae, (3) high-standing Syria Planum and low-lying Daedalia Planum lava plains, and (4) chaotic terrain and massifs of the basement complex. The Claritas Fossae ridge has been interpreted as a horst formed by more than $8 \mathrm{~km}$ of vertical displacement, “...the largest tectonic feature on the planet” [3].

Physiographic and Geologic Setting: The map area is part of the Thaumasia highlands that border the Thaumasia plateau on the west and regionally is flanked by Noctis Labyrinthus to the north, by Syria and Solis Plana to the northeast and east, by the volcanoes of Tharsis Montes to the northwest, and by the plains of Daedalia Planum to the west and southwest. The large Argyre basin lies $1200 \mathrm{~km}$ east southeast of the center of the map area, and the southernmost of the Tharsis Montes, Arsia Mons, is $500 \mathrm{~km}$ northwest [2-4, 9, 13].

A series of overlapping normal faults in the almost north-south Claritas Fossae system has created a prominent west-facing escarpment, Claritas Rupes, which bisects the map area into approximately equal halves. MOLA data indicate that the scarp decreases in summit elevation from north to south.

Moving clockwise from the northeast map quadrant, the relatively young, smooth lava plains of Hesperian age extend southward from Syria Planum to onlap the highly disrupted, chaotic Noachian basement rocks that extend over much of the southeast quadrant and constitute several high-standing massifs. The less chaotic hummocky, cratered, and fractured Noachian rocks grade westward and northward into the widespread less uneven but heavily fractured and cratered Noachian rocks that extend over most of the area west of Claritas Rupes. Along the western margin of the study area, these rocks are overlapped by the younger, smoother plains of Daedalia Planum, which include lava flow rock from Arsia Mons. The multiple fracture patterns of these younger Noachian rocks are extremely complex, reflecting numerous reorientations of the stress field.

A system of linear grooves interpreted as channels is well developed over a restricted area of the southwest quadrant. The channels conducted running water and entrained sediments into a regional topographic depression to create a playa-like smooth-surfaced basin. Also along the western margin of the map area is the largest volcanic edifice in the study area with a maximum diameter of about $80 \mathrm{~km}$ and a relief of some $2000 \mathrm{~m}$. The summit has three overlapping craters or calderas, and the flanks have been severely eroded by running water or lava, or both.

The rocks of the northwest quadrant appear to be more intensely fractured than those in the other quadrants, but the apparent greater density of fractures there may be largely the result of higher-resolution images covering that area. The south half of the northsouth Thaumasia graben [10] lies in the study area; Claritas Rupes forms its eastern margin.

Distinctive Features: Geologic mapping has identified significant topographic, stratigraphic, structural, impact, volcanic, and drainage aspects of the map area.

Topography: 1) The highest elevations occur in the southeast quadrant and mark the summits of Noachian massifs. 2) The north-south, west-facing fault scarp, Claritas Rupes, reaches heights of $2.3-3.7 \mathrm{~km}$ above the lowlands to the west. 3) A north-facing massif of Noachian basement rocks overlooks the graben-laced Syria volcanic plain to the north. 4) Three poorly defined linear highs extend northwest from Claritas Rupes. 5) A well-defined linear basin created by the Thaumasia graben extends southward into the map area and lies just west of Claritas Rupes.

Stratigraphy: 1) High-standing chaotic basement rocks are surrounded by relatively smooth lava plains, both of which were broken by episodes of grabenforming normal faults. 2) North and west of the extensive occurrence of these ancient rocks in the southeast quadrant, younger lava plains surround a number of isolated massifs of old rocks. 3) Highly variegated material of uncertain origin, with irregular digitate margins, occurs in the south-central part of the 
study area where, in places, it extends westward across Claritas Rupes.

Structure: 1) Normal faults created grabens and scarps that trend east-west, north-south, north-northeast, northeast, east-northeast, north-northwest, northwest, and west-northwest. Collectively, they constitute one of the most complex fracture systems on Mars. 2) Throughout the long history of their existence, from the Noachian to the present, it is likely that faults of the Claritas Fossae complex have been reactivated one or more times, perhaps with a different sense of slip [17]. 3) In the northwest part of the map area, the pattern of intersecting faults bears a striking resemblance to conjugate shear fractures. 4) West-dipping cuestas occur along the southwest margin of the map area. 5) In the southeast quadrant, an enigmatic 110-km, gently curvilinear depression trending northeast varies in width from $15 \mathrm{~km}$ to $22 \mathrm{~km}$ and in depth from $400 \mathrm{~m}$ to $700 \mathrm{~m}$; the depression includes two relatively small basins. The nearly parallel curvilinear margins seen in map view suggest that the depression may be a graben and could have provided a major channel for surface runoff.

Volcanoes: 1) In addition to the relatively large construct cited earlier, dozens of isolated, scattered, conical hills 1-2 km in diameter may be volcanoes; almost certainly those with summit depressions are. 2) Two constructs, one $18 \mathrm{~km}$ in diameter and the other 22 $\mathrm{km}$ in diameter, lie near the southwest termination of the large curvilinear depression. One or both of them might be the source of the variegated unit that extends south and west from the area of those vents, if in fact the variegated unit is volcanic. 3) Only one example of a lava flow that emerged from a fracture was identified.

Impact Craters: 1) The largest of the 122 impact craters larger than $5 \mathrm{~km}$ in diameter in the study area is $53 \mathrm{~km}$ in diameter [18]. 2) Craters are more numerous in the south half of the map area owing to resurfacing of much of the north half. 3) In map view, numerous craters cut by northward trending grabens represent strain ellipsoids, the long axes of the ellipse oriented east-west parallel to the greatest principal tensional stress that created the grabens. 4) Angular craters are common, two or more of their sides paralleling the regional fracture orientations. 5) Dark-floored craters are rare; several relatively small craters have faint dark wind plumes trending west southwest. 6) The youngest craters with diameters greater than $6 \mathrm{~km}$ and with continuous ejecta blankets are concentrated in the northeast part of the map area and penetrated Hesperian lava flows of Syria Planum. 7) Several "crater clusters" occur in the south half of the map area and may be indicative of the breakup of an incoming bolide or the impact of a cluster of objects $[19,20]$. 8) Numerous craters in the 10-30km-diameter range have central peaks or central pits. 9) Several 10-15-km-diameter craters show ring furrows [21] but with only a subdued or absent central flat-topped mesa or plateau.
Fluvial Systems: 1) Although no certain evidence has been identified, it is probable that the numerous grabens in the Claritas Fosse region have served as channels for surface runoff from precipitation or from groundwater seepage. 2) In the southwest quadrant a well-developed dendritic system drains Noachian fractured and cratered plains into a basin about $170 \mathrm{~km}$ by $50 \mathrm{~km}$. 3) Leading south from the volcanic construct in the west-central part of the study area, parallel to subparallel channels lead to a basin, $135 \mathrm{~km}$ by $50 \mathrm{~km}$ that is bordered on the southwest by a cuesta complex that preserves the western half of an eroded 35-km-diameter impact crater. 4) Numerous short, relatively straight channels lead northward onto the Syria Planum lava plain from the north-facing escarpment of basement rocks in the northeast quadrant of the study area.

Outline of Geologic History: The following is a general outline of geologic history for the Thaumasia highlands, including Claritas Fossae [14, 15].

1) Emplacement and alteration of old crustal rocks.

2) Formation of Early to Middle Noachian, Tharsiscentered faults and grabens.

3) Diminished faulting in Late Noachian and throughout Hesperian and Amazonian.

4) Reduction in Tharsis-centered faulting accompanied by increased Syria- and Tharsis-related volcanism.

5) Tectonism and volcanism decreased significantly during early Amazonian.

6) Present-day processes include: eolian erosion and deposition, downslope movement of material, meteorite impact and related processes, possible seepage of groundwater or even brief outflow resulting from subsurface thermal conditions.

References: [1] Masson, P. (1977) Icarus, 30, 49-62. [2] Scott and Carr (1978) USGS I Map-1083. [3] Masursky et al. (1978) USGS I Map-896. [4] McGill, G.E. (1978) USGS I Map-1077. [5] Masson, P. (1980) Moon \& Planets, 22, 211-219. [6] Plescia, J.B. et al. (1980) NASA Tech. Memo. 81776, 68-70. [7] Roth, L.E. et al. (1980) Icarus, 42, 287-316. [8] Scott, D.H. and Tanaka, K.L. (1981) USGS I Map-1274. [9] Scott, D.H. (1981) USGS I Map-1274. [10] Plescia, J.B. and Saunders, R.S. (1982) JGR, 87, 9775-9791. [11] Scott, D.H. and Tanaka, K.L. (1986) USGS I Map1802-A. [12] Tanaka, K.L. and Davis, P.A. (1987) LPS XVIII, 994-995. [13] Tanaka, K.L. and Davis, P.A. (1988) JGR, 93 B-12, 14,893-14,917. [14] Dohm, J.M. and Tanaka, K.L. (1999) Planet. \& Space Sci., 47, 411-431. [15] Dohm et al., (2001) USGS I Map-2650. [16] Mars Orbital Laser Altimeter (MOLA) data provided by Jim Roark, GSFC, and Jeff Plescia, USGS, Flagstaff. [17] Muehlberger, W.R. (1986) $6^{\text {th }}$ Basement Tectonics Conference Proceedings, 7681. [18] Barlow, N.G. LPS XXXI, Abs. \#1465. [19] Oberbeck, V.R. and Aoyagi, Michio (1972) JGR, 97, 24192432. [20] Moore, H.J. (2001) USGS I Map-2727. [21] DeHon, R.A. (1987) Icarus, 71, 287-297. 
1:500,000 GEOMORPHIC MAPPING OF SOUTHEASTERN MARGARITIFER SINUS, MARS I: GEOLOGIC EVOLUTION IN MTMs -10022 AND -15022. K. K. Williams ${ }^{1}$ and J. A. Grant ${ }^{1},{ }^{1}$ Center for Earth and Planetary Studies, National Air and Space Museum, Smithsonian Institution, Washington, DC 20013-7012; williamsk@nasm.si.edu.

Introduction: Margaritifer Sinus, located between $0^{\circ}$ and $30^{\circ}$ south and $0^{\circ}$ to $45^{\circ}$ west (Figure 1 ), has been of particular interest in studying the history of water on Mars because well integrated valleys are numerous in this area [1-5]. Geomorphic structures within Margaritifer Sinus record a complex geologic history of water collection, transport, and discharge spanning the late Noachian to the mid Hesperian $[1,4,5]$. The west flank of Chryse trough is drained by the Uzboi-Ladon-Margaritifer (ULM) mesoscale outflow system that incises ridges and fills sinks as it travels northward from Argyre impact basin to Ares Vallis [5-7].

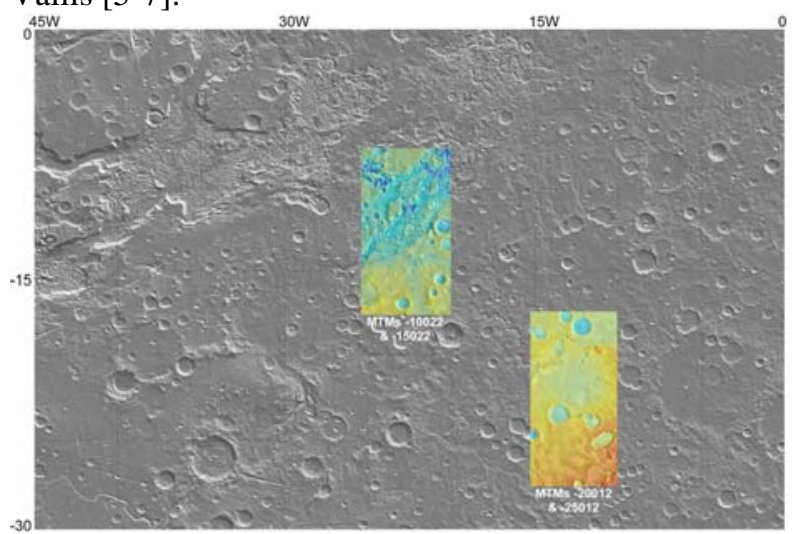

Figure 1. Mapped locations in Margaritifer Sinus.

By contrast, valleys comprising the Paraná-Loire and Samara-Himera network drain the eastern flank of the trough and form distinctly digitate and parallel networks of valleys [5]. The Paraná-Loire network drains $\sim 85 \%$ of the area drained by the Colorado River [5] and is one of the most laterally extensive, well integrated valley networks on the planet [4]. Paraná Valles is a network of multi-digitate, mostly east-west trending valleys that flowed into an ancient crater that is also fed by valleys to the north and south. Loire Valles has a deeply incised channel that heads at the west-northwest edge of the Paraná collection area and has recently been compared with the Grand Canyon in length and morphology [8]. The Paraná-Loire system converges with the Samara-Himera system then flows into Margaritifer valles and the ULM system.

Geologic Mapping in Margaritifer Sinus: Mapping and drainage system studies at a variety of scales [e.g., 1,4-6,9] defined the general geologic evolution and the complex history of water transport, storage, and release within Margaritifer Sinus. Geologic mapping delineated four preserved resurfacing periods [1,4,5,9] with the first episode occurring before, during and after the major period of fluvial activity. The second resurfacing event, interpreted to be volcanic, is widespread, and the third event surrounds the chaotic terrain within Paraná basin and embays all channels flowing into that basin. The final extensive resurfacing event occurs in southern Margaritifer Sinus and embays all channels in that area. More recent erosional and depositional features include mass wasting of craters and valleys and aeolian deposits within some valley floors.

Drainage mapping showed that valley systems within MC-19 converge and flow into Margaritifer basin, which has been greatly modified by erosion and deposition related to multiple episodes of discharge from the ULM system [1,4,5]. Valley incision initiated during the second resurfacing event, during which Paraná Valles breached the eastern rim of a degraded crater (Paraná basin). Loire Valles heads at the western edge of chaotic terrain on the floor of this crater and drains to the northwest within a well-integrated valley. Loire Valles intersects Samara Valles and both systems drained into Margaritifer basin. Within Margaritifer basin, water likely ponded, infiltrated into the subsurface, and was stored until its release, which formed Margaritifer and Iani Chaos [5].

Details in MTMs -10022 and -15022: 1:500,000scale geomorphic mapping has revealed details about the geologic history of the region covering Margaritifer basin (Figure 2). Mapping employed several data sets including the USGS Viking MDIM 2.1 base map and individual Viking images, Mars Global Surveyor MOC images and MOLA topography, and Mars Odyssey THEMIS visible and infrared (IR) images. The THEMIS data have greatly improved the ability to delineate unit boundaries and to interpret smaller features, especially in MTM 15022 where Viking image resolution is relatively poor ( $250 \mathrm{~m} /$ pixel).

Within MTM -15022, Samara Valles and Loire Valles join, then intersect the ULM system to the west where they empty into Margaritifer basin. This area is covered by THEMIS IR and color visible images as well as several MOC narrow angle images. Imagery together with MOLA gridded topography has led to a better understanding of the history of those valley systems, revealing that the confluence of Loire and Samara Valles is obscured by deposits from a proposed volcano (Figure 3). The course of the valley below the confluence cannot be discerned because 
volcanic materials post-date most fluvial activity in the Loire-

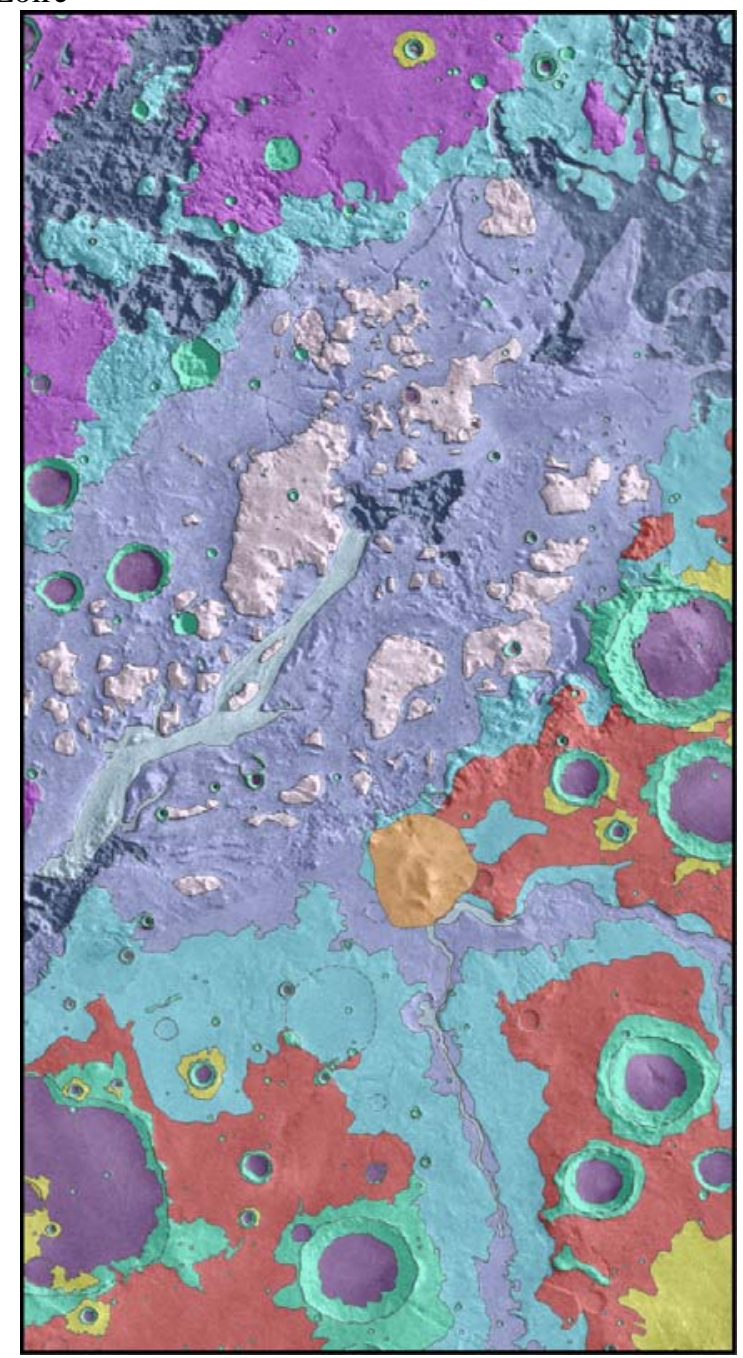

Figure 2a. Preliminary map of MTMs -10022 and -15022. Draft Correlation of Map Units

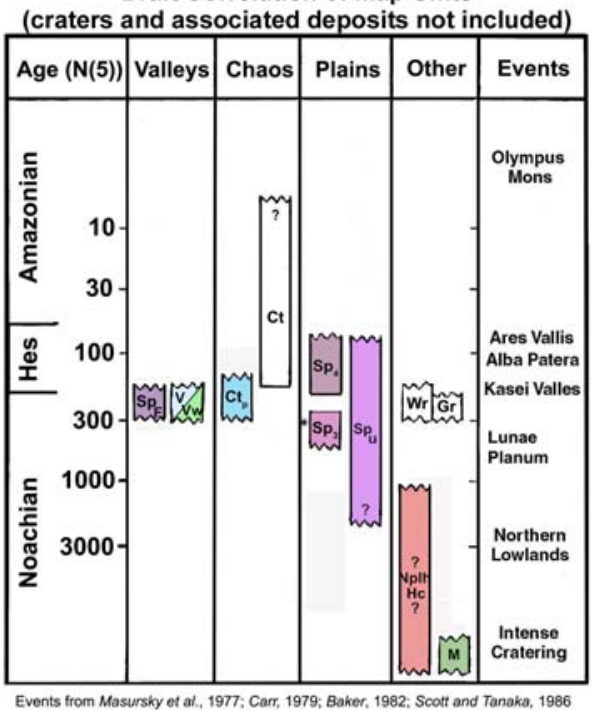

Figure 2b. Draft correlation of map units for map in fig. 2a.
Samara system. However, several collapse and outflow features on the northern flank of the volcanic edifice suggest that some fluvial flow was active following emplacement of volcanic materials, taking advantage of subsurface fractures or conduits.

Within Margaritifer basin, several large and many small remnants are elevated above the lower, etched surface. A late stage fluvial event within the basin is defined by the youngest (and lowest) channel in the basin, which is interrupted by a local collapse feature. Larger areas of chaos terrain from collapse dominate the northwest and northeast portions of MTM -10022. The collapse is likely due to release of subsurface water in outflow events to the north. Nearby grabenlike depressions are also likely related to subsidence of the surface. THEMIS images have helped delineate boundaries between these slight, moderate, and extreme chaotic terrains and the adjacent plans units [9]. The completed 1:500,000-scale map of these two quadrangles will be submitted to the USGS for review by the end of July, 2004.

References: [1] Saunders, S.R. (1979) USGS I-1144, USGS. [2] Baker V. R. (1982) The Channels of Mars., Univ. TX Press, Austin. [3] Mars Channel Working Group (1983), Geol. Soc. Am. Bull.., 94, 1035-1054. [4] Grant, J. A. (2000) Geology, 28, 223-226. [5] Grant, J. A. and T. J. Parker (2002) JGR, 107(E9), 5066. [6] Parker, T.J. (1985) Masters Thesis, California State Univ., LA. [7] Parker, T.J. (1994) Ph.D. Thesis, USC, LA. [8] Strom, R. et al. (2000) LPSC XXXI, \#1090, LPI. [9] Grant, J.A. (1987) NASA Tech Memo 89871.

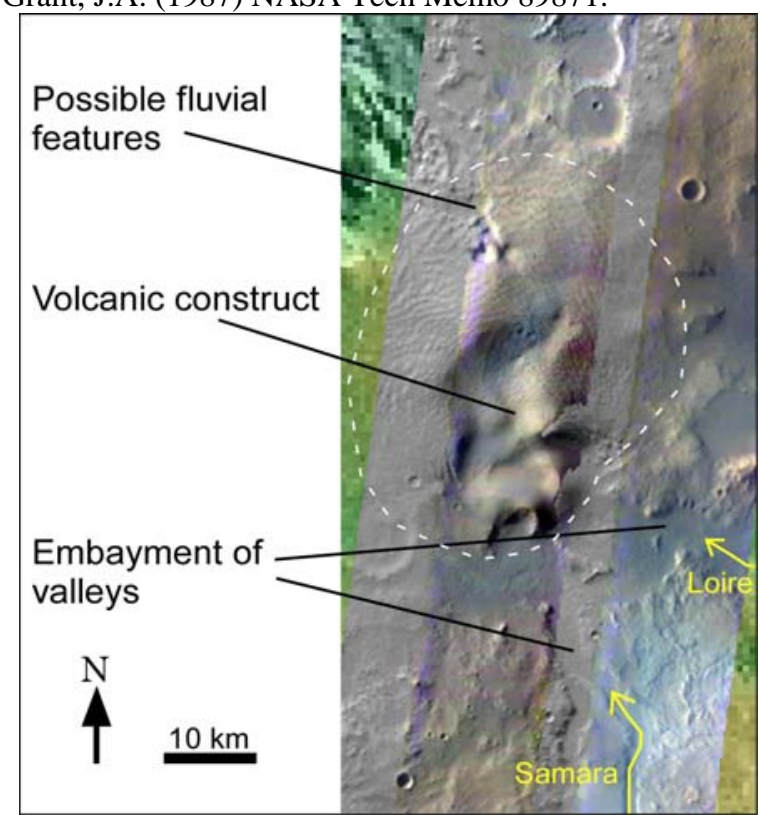

Figure 3. THEMIS color visible image mosaic over MOLA topography showing volcano at the confluence of Samara and Loire valles. 